


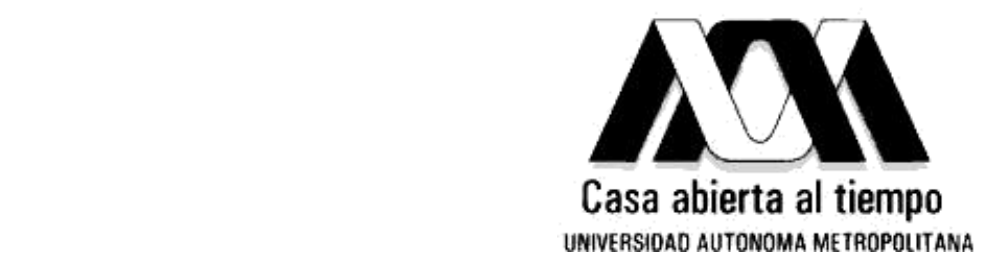

UNIVERSIDAD AUTÓNOMA METROPOLITANA

Unidad Iztapalapa

TESIS PARA OBTENER EL GRADO DE DOCTOR EN BIOTECNOLOGÍA

ESTUDIO DE LOS MECANISMOS DE TRANSFERENCIA DE MASA, CINÉTICO Y DE DESACTIVACIÓN DE UN BIORREACTOR DE PARTICIÓN DE TRES FASES

EMPLEANDO CÉLULAS COMPLETAS

STUDY OF MASS TRANSFER, KINETIC AND DEACTIVATION OF A THREE PHASE PARTITIONING BIOREACTOR USING WHOLE CELLS

\section{PRESENTA}

RODRIGO MELGAREJO TORRES

DIRECTOR

DR. SERGIO HUERTA OCHOA

ASESOR

DR. CARLOS OMAR CASTILLO ARAIZA

DR. MARIANO GUTIÉRREZ ROJAS

México D.F. Julio del 2014. 
El Doctorado en Biotecnología de la Universidad Autónoma Metropolitana está incluido en el Padrón Nacional de Posgrado (PNP) del Consejo Nacional de Ciencia y Tecnología (CONACyT). Y se agradece al CONACyT por la beca otorgada para la realización de este trabajo.

Este trabajo forma parte del proyecto "Estrategias de escalamiento descendente (scale down) para biorreactores de partición" financiado por el CONACYT con número de registro SEP-CONACyT-2007-80847. 
México D.F., Julio del 2014

El jurado designado por la División de Ciencias Biológicas y de la Salud de la Unidad Iztapalapa aprobó la tesis:

\title{
ESTUDIO DE LOS MECANISMOS DE TRANSFERENCIA DE MASA, CINÉTICO Y DE DESACTIVACIÓN DE UN BIORREACTOR DE PARTICIÓN DE TRES FASES EMPLEANDO CÉLULAS COMPLETAS
}

\section{STUDY OF MASS TRANSFER, KINETIC AND IEACTIVATION OF A THREE PHASE PARTITIONING BIOREACTOR USING WHOLE CELIS}

\author{
Que presentó
}

Rodrigo Melgarejo Torres

Director de la tesis: Dr. Sergio Huerta Ochoa

Universidad Autónoma Metropolitana Unidad Iztapalapa

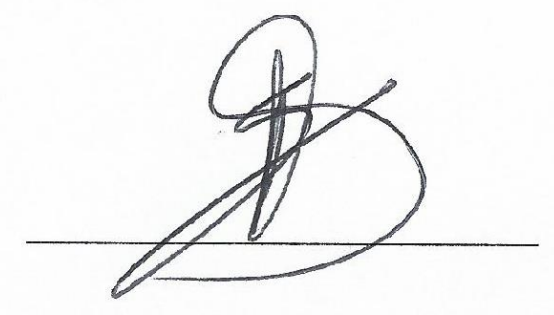

JURADO

Presidente: Dr. Frédéric Thalasso Siret

Centro de Investigación y Estudios Avanzados (CINVESTA

Secretario: Dr. Carlos Omar Castillo Araiza Universidad Autónoma Metropolitana Unidad Iztapalapa

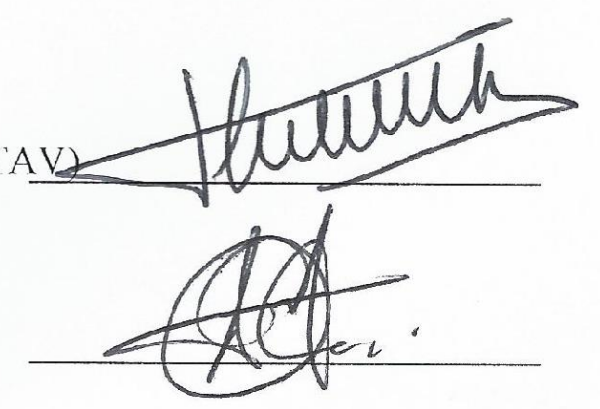

Vocal: Dr. Abhishek Dutta

Universidad Católica de Leuven

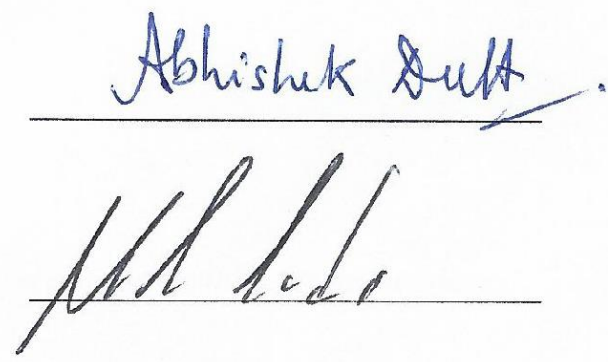

Vocal: Dr. Manuel Alejandro Lizardi Jiménez Universidad Politécnica de Pachuca 
To Vera, Ximena and Rodry

...For many hours and days that pass ever soon, The tides have caused the flame to dim. At last the arm is straight, the hand to the loom;

Is this to end or it just begin?....

...The cup is raised, the toast is made yet again.

One voice is clear above the din.

Proud Aryan, one word, my will to sustain.

For me, the cloth once more to spin...

...All of my love to you now...

All of my love to you and you and you and you.

Yes, all my love to you child...

...Sometime, sometime, sometime, sometime ...

I get a little bit lonely,

Just a little,

Just a little bit lonely

Yes now,

I get a little bit lonely

I think about it,

It's got to be

It's got to be

All of my love

All of my love

...All of my love to you now.

All of my love.

Taken from: In throught the out door .

Robert Plant \& John Paul Jones 1979 


\section{AGRADECIMIENTOS}

A Sergio y Omar, por la excelente mancuerna que hicimos, por haber sido guías y consejeros de este trabajo, pero sobre todo la gran amistad que nos une.

A Mariano por las acertadas y pertinentes correcciones que mejoraron esta tesis.

A Abhishek por recibirme al otro lado del mundo con la frescura de sus ideas y por la buena amistad que construimos.

A los Doctores Arely, Ernesto, y Gerardo por todas las facilidades otorgadas para la realización de este trabajo.

A Elizabeth, Celeste, Valeria y Alida por su valioso trabajo de servicio social, y también a Pedro. Sin ustedes, algunos capítulos de está tesis estarían incompletos. 


\section{DEDICATORIAS}

A Ximena, porque todos los días despierto y me pregunto ¿De verdad, cuánto me debía la vida, para haberme pagado contigo mi amor?

A Rodry, por enseñarme que después del luto, la oscuridad y el llanto; aun hay luz, vida y alegrías.

A Irene y Lucas, porque lo que sembraron ayer es lo que cosechan hoy. Este pequeño logro también es de ustedes.

Para Ame, Caro, Pie, Esther y Adri, compañeras ineludibles para acompañar el arduo, sinuoso y bello camino de la vida.

A Andrea que me saco del laberinto de las sombras, de los días de vicio y soledad. A esa muchacha que se quedo junto a mí, cuando yo la necesitaba; mi corazón no tiene lugar para nadie mas...

A Henrrous, Yury, Marco y Alfonso amigos y hermanos de hoy y siempre.

Para esos ingratos que ya evolucionaron: Vera, Mario, Rico y Jacob.

A mis queridos amigos íntimos: Palme, Candy, Blanquis, Dany, Mary Jo, Isa, Goyo, Alex, Edna, Flor, Pedro, Letty, Nancy, Mario, Juliana y Mauro, por todas las fechorías que cometimos y seguiremos cometiendo. Los quiero.

Sin excepción a todos mis queridos amigos y enemigos de la Planta Piloto 4 que de una u otra forma colaboraron en este trabajo.

Y a todos los que me faltaron, pero siempre están presentes. 
INDEX

1. GENERAL INTRODUCTION

2. CHAPTER I

PROBELM STATEMENT

3. CHAPTER II

PRODUCTION OF LACTONES WITH E. coli IN A THREE PHASE

PARTITIONING BIOREACTOR USING IONIC LIQUIDS AS DISPERSED PHASE

4. CHAPTER III

MASS TRANSFER COEFFICIENT DETERMINATION IN THREE BIPHASIC SYSTEMS (WATER-IONIC LIQUID) USING A MODIFIED LEWIS CELL

5. CHAPTER IV

KINETIC MATHEMATICAL MODEL FOR KETONE BIOCONVERSION USING Escherichia coli TOP10 pQR239

6. CHAPTER V

REGIME ANALYSIS OF A BAEYER-VILLIGER BIOCONVERSION IN A THREE-PHASE (AIR-WATER-IONIC LIQUID) STIRRED TANK BIOREACTOR

7. CHAPTER VI

MATHEMATICAL MODEL OF A THREE PHASE PARTITIONING BIOREACTOR FOR CONVERSION OF KETONES USING WHOLE CELLS

8. GENERAL CONCLUSIONS AND PERSPECTIVES

9. ANNEXES

PUBLISHING PAPERS 


\section{GENERAL INTRODUCTION}

Lactones have a wide aplication in flavors, anticancer precursors, hypertension medicine and fragancy in the pharmacy industry [1]. There are more than 500 lactones used as antibiotics, antitumors, insecticides, or even as treatment of the onchocerciasis

[2]. The ketone bioconversion to esters and lactones was discovered over a century ago by Adolf von Baeyer and Victor Villiger in 1899, [3]. In this reaction, the ketone is nucleophilic attacked by a hydrogen peroxide, this compound is instable and is re-arranged with the relase and migration of one carboxilate ion causing the carbon-carbon union. The Baeyer-Villiger (BV) reactions are attractive for the synthesis of lactones through esteres. Unfortunately the general use of peroxides and disolvents as reactive agents has several disadvantages, due to their explosive and irritant properties that at high levels lead to accidents requiring high safety standars. Besides, the bioprocess compared with the conventional chemical process represents an effective method for ensuring a high productivity of high-value lactones [4]. In the former, pure enzymes or whole cells are used as biocatalysts. Whole cells in comparation with the pure enzymes have more stability due to their celular matrix, which allows the re-generation of cofactors and enzyme active sites, reducing production costs [5].

In the $\mathrm{BV}$ oxidation reaction, cyclohexanone monooxygenase (CHMO) from Acinetobacter calcoaceticus NCIMB 9871 is one of the best-known enzymes [6]. In the last decade, an increase of the rate of oxidation of cyclic ketones has been obtained when the CHMO gene was cloned into an expression vector to give the biocatalyst strain E. coli TOP10 pQR239 [7]. Nevertheless, substrate/product inhibition was identified for this conversion with the whole cell-mediated conversion using bicyclo[3.2.0]hept-2-en-6-one [8]; particularly, the reaction is inhibited by ketone concentrations above $0.4 \mathrm{~g} / \mathrm{L}$ and by combined regioisomeric lactones with concentrations above $3.5 \mathrm{~g} / \mathrm{L}$. On the other hand Bennett [9] reported that the excess of disolved oxygen (DO) in the reaction medium may cause an oxidation of two peripheral serines to the active site and causing the sulphonic acid formation and a permanent change in the structure of the enzyme thus provoking an inactivation by DO.

A number of solutions have been recommended to decrease the substrate/product inhibition; for instance: the proposal of adsorbent resins [10]; in situ supply of the substrate 
and removal of lactone product, maintaining both substrate and product concentrations at subinhibitory levels in the environment of the biocatalyst [11]; and encapsulation of biocatalyst to prevent CHMO oxidation [12]. However, one of the main limitations of these strategies is the difficulty in controlling mass transfer of substrate, product and oxygen that directly impacts on the productivity and the cost-benefit ratio. As background this research group proposed the addition of a second liquid phase (ionic liquid) in a partitioning bioreactor, it can be a useful tool to reduce product inhibition due to the presence of a partition coefficient favourable to the second liquid phase [13]. Another work from the group identified the limiting step in this type of bioconversion through a regime analysis for a three phase partitioning bioreactor (TPPB) using as dispersed phase the ionic liquid [MeBuPyy][BTA] [14]. Nevertheless, it was not clear the role of different kinetic and transport phenomena on the performance of the TPPB.

The aim of this work was to evaluate, understand and predict the mass transfer, kinetic and deactivation mechanisms occurring in a TPPB at different operating conditions. Firstly the study was aimed at evaluating different dispersed phase in order to identify the adequate one. Secondly, a regime analysis was carried out to characterize those kinetic and mass transport mecahisms involved in the TPPB. Finally, a mathematical model for a TPPB was developed following chemical engineering criteria based on independent studies of mass transfer, kinetic, and cell deactivation.

This thesis contains six chapters and annexes. The first chapter concerns about the main aim, hypothesis, justification and the general strategy employed through this project. The second chapter called "Production of lactones with E. coli in a three phase partitioning bioreactor using ionic liquids as dispersed phase [15]" comprises a screening study of dispesed phases used for the production of lactones. Particularly, four ionic liquids (IL's) were tested and their role on the loss of cell viability is presented. The selection of the dispersed phase accounts for some criteria related to their toxic properties. The third chapter named "Mass transfer coefficient determination in three biphasic systems (water-ionic liquid) using a modified Lewis cell [16]" accounts for the study of mass transfer mechanisms involving the determination of the substrate and product mass transfer coefficients. The fourth chapter called "Kinetic mathematical model for ketone bioconversion using Escherichia coli TOP10 pQR239 [17]" deals with the study of kinetics. Specifically, an extrinsic kinetic model is developed for the production of lactones with E. coli. The fifth chapter named "Regime 
analysis of a three phase partitioning bioreactor" considers the analysis of characteristic times from the main mechanisms ocurring in a TPPB (mass transfer, kinetics and loss of cell viability). The regime analysis allows to determine those operating conditions leading to mass transfer constrains. The sixth chapter named "Mathematical model of a three phase partitioning bioreactor for bioconversion of ketones using whole cells [18]" accounts for all main results obtained from previous chapters. A mathematical model for the TPPB was developed, allowing to understand main transport, kinetic and deactivation mechanism during the bioconversion of ketones at operating conditions. Finally, annexes contain a description of some methodologies used but not explicitly mentioned during the thesis chapters.

\section{REFERENCES}

[1] M., J Fink, F. Rudroff, M.D. Mihovilovic. Baeyer-Villiger monooxygenases in aroma compound synthesis. Bioorganic \& Medicinal Chemistry Letters 21. (2011).6135-6138.

[2] J.A. Reyes Avila, N, Almaraz Abarca, N, J. Herrera Corral and N. Naranjo Jimenez. Efecto Letal y sub letal de lactonas sobre la garrapata del ganado Boophilus annulatus say. Veterinaria Mexico, (1999).Vol. 30(4): 281-284.

[3] A. Baeyer and V. Villiger. Einwirkung des Caro'schen Reagens auf Ketone. Berichte der deutschen chemischen Gesellschaft. 1899.Vol. 32(3). pages 3625-3633.

[4] K. Honda, T. Ishige, M. Kataoka, S. Shimizu. Microbial and enzymatic processes for the production of chiral compounds. Biocatalysis in the pharmaceutical andbiotechnology industries. New York: Taylor and Francis. (2006) p. 529-46.

[5] S. Bräutigam, S. Bringer-Meyer, D. Weuster-Botz. Asymmetric whole cell biotransformations in biphasic ionic liquid/water-systems by use of recombinant Escherichia coli with intracellular cofactor regeneration. Tetrahedron: Asymmetry. (2007) 18:1883-7.

[6] N.A. Donoghue, D.B. Norris, P.W. Trudgill. The purification and properties of cyclohexanone oxygenase from Nocardia globerula CL1 and Acinetobacter NCIB 9871. Eur J Biochem. (1976) 63(1):175-192.

[7] S. Doig, M. O’Sullivan, S. Patel and J. Ward. Large scale production of cyclohexanone monooxygenase from Escherichia coli TOP10 pQR239. Enzyme and Microbial Technology. (2001) Vol. 28: 265-274. 
[8] S. Doig, H. Simpson, V. Alphand, R. Furstoss, J. Woodley. Characterization of a recombinant Escherichia coli TOP10 [pQR239] whole-cell biocatalyst for stereoselective Baeyer-Villiger oxidations. Enzyme and Microbial Technology. (2003) 32 347-355.

[9] A. Bennett. Mechanism of Oxidative Inactivation of Acinetobacter sp. NCIMB 9871. Cyclohexanone Monooxygenase. Journal of Undergraduate Research. (2004) Volume 6, Issue 1.

[10] I. Hilker, C. Baldwin, V. Alphand, R. Furstoss, J. Woodley and R. Wohlgemuth. On the Influence of Oxygen and Cell Concentration in an SFPR Whole Cell Biocatalytic Baeyer- Villiger Oxidation Process. Biotechnology and Bioengineering. (2006). Vol. 93(6): 1138-1144.

[11] H.D. Simpson, V. Alphand, R. Furstoss. Microbiological biotransformations 49 Asymmetric biocatalysed Baeyer-Villiger oxidation: improvement using a recombinant E. coli whole cell biocatalyst in the presence of an adsorbent resin. J. Mol. Catal. B Enzym. (20011). 6, 101-108.

[12] M. Buĉko, A. Schenkmayerová, P. Gemeinera, A. Vikartovská, M. Mihovilovibĉ, B. Lacíkc. Continuous testing system for Baeyer-Villiger biooxidation using recombinant Escherichia coli expressing cyclohexanone monooxygenase encapsulated in polyelectrolyte complex capsules. Enzyme and Microbial Technology. (2011). 49 284- 288.

[13] D. Torres-Martínez, R. Melgarejo-Torres, M. Gutiérrez-Rojas, L. Aguilera-Vázquez, M. Micheletti, G.J. Lye, S. Huerta-Ochoa, Hydrodynamic and oxygen mass transfer studies in a three-phase (air-water-ionic liquid) stirred tank bioreactor, Biochem. Eng. J. 45 (3) (2009) 209-217.

[14] R. Melgarejo-Torres, D. Torres-Martínez, M. Gutiérrez-Rojas, A. Gómez de Jesús, G.J. Lye, S. Huerta-Ochoa. Regime analysis of a Baeyer-Villiger conversion in a three-phase (air-water -ionic liquid) stirred tank bioreactor, Biochem. Eng. J. (2011). 59:87-95.

[15] R. Melgarejo-Torres, P. López-Ordaz, N. V. Calleja-Castañeda, J.L. Cano-Lopéz, M. Gutiérrez-Rojas, C.O. Castillo-Araiza, R.M. Camacho-Ruíz, G. L. Lye G, S. HuertaOchoa. Production of lactones with E. coli in a three phase partitioning bioreactor using ionic liquids as dispersed phase (in writing).

[16] R. Melgarejo-Torres, D. Torres-Martínez, C.O. Castillo-Araiza, C. Arriaga-Juárez, M. Gutiérrez-Rojas, P. Esponda-Aguilar, G. Aroca, G.L. Lye, S. Huerta-Ochoa S. Mass 
transfer coefficient determination in three biphasic systems (water-ionic liquid) using a modified Lewis cell. Chemical Engineering Journal. (2012) 182:702-707.

[17] R. Melgarejo-Torres, C.O. Castillo-Araiza, P. López-Ordaz, D. Torres-Martínez, M. Gutiérrez-Rojas, G.J. Lye, S. Huerta-Ochoa. Kinetic mathematical model for ketone bioconversion using Escherichia coli TOP10 pQR239. (2014) Chemical Engineering Journal $2401-9$.

[18] R. Melgarejo-Torres, C.O. Castillo-Araiza, Abhishek-Dutta, Guido-Bény, D. TorresMartinez, G.J. Lye G, M. Gutiérrez-Rojas, S. Huerta-Ochoa. Mathematical model of a three phase partitioning bioreactor for conversion of ketones using whole cells. Chemical Engineering Journal . (submitted, 2014). 


\section{CHAPTER I}

\section{PROBLEM STATEMENT}




\section{HYPOTHESIS}

The independent studies of mass transfer, kinetic and loss of cell viability mechanisms occurring in a three phase partitioning bioreactor (TPPB) using whole cells biocatalyst would allow us to understand their effect on the performance of high value metabolite production. At the same time this information would be useful to develop a mathematical model of a TPPB which in a further study, could be used to describe and understand this technology for a commercial exploitation at different scales.

\section{JUSTIFICATION}

The use of TPPB with whole cells as biocatalyst allows an increment of the productivity in the bioprocess. Due to thermodynamic equilibrium, the dispersed phase maintains substrates, products or toxic secondary metabolites concentrations at sub-inhibitory levels. Since these systems present several mechanisms such as mass transfer, kinetics and deactivation of the biocatalyst, it is relevant to characterize them at different conditions with the aim to understand their effect on high value metabolite production and develop strategies for scale up or down of these biorectors.

\section{GENERAL AIM}

Evaluate, understand and predict mass transfer, kinetic and deactivation mechanisms occurring in a TPPB at different operating conditions through the use of a regime analysis and phenomenological mathematical modeling.

\section{SPECIFIC AIMS}

1. Characterize the biocatalyst deactivation mechanism and the selection of an adequate dispersed phase to diminish the loss of cell viability.

2. Characterize the mass transfer mechanisms through the determination of the substrate, oxygen and product mass transfer coefficients.

3. Characterize the bioconversion mechanismism through the development of an extrinsic kinetic mathematical model.

4. Identify the limiting step of the bioprocess in the TPPB by means of a regime analysis.

5. Develop a mathematical model for the TPPB technology at laboratory scale 


\section{GENERAL STRATEGY}

Figure 1 depicts the general strategy followed through this work: I) The first chapter contains the main aim, hypothesis, justification and specific objectives of the project. II) The second chapter deals with the evaluation and selection of an adequate ionic liquid as dispersed phase using as criteria the loss of cell viability and the bioconversion. III) Once selecting the most adequate dispersed phase, in the third chapter substrate, product and oxygen mass transfer mechanisms in the TPPB are studied through the determination of the corresponding mass transfer coefficients, ksA, kPA and kLa, respectively. IV) In the fourth chapter, an extrinsic kinetic model based on LangmuirHinshelwood-Hougen-Watson formalism is developed. V) The fifth chapter involves a regime analysis determining characteristic times of loss of cell viability, substrate, product and oxygen mass transfer and kinetics with the aim of identifying the limiting step in the bioconversion process. VI) Finally, in the sixth chapter a mathematical model of a TPPB is developed. This model involves all aforementioned mechanisms. At the end, the annexes section contains some details on methodologies that are not mentioned through chapters.

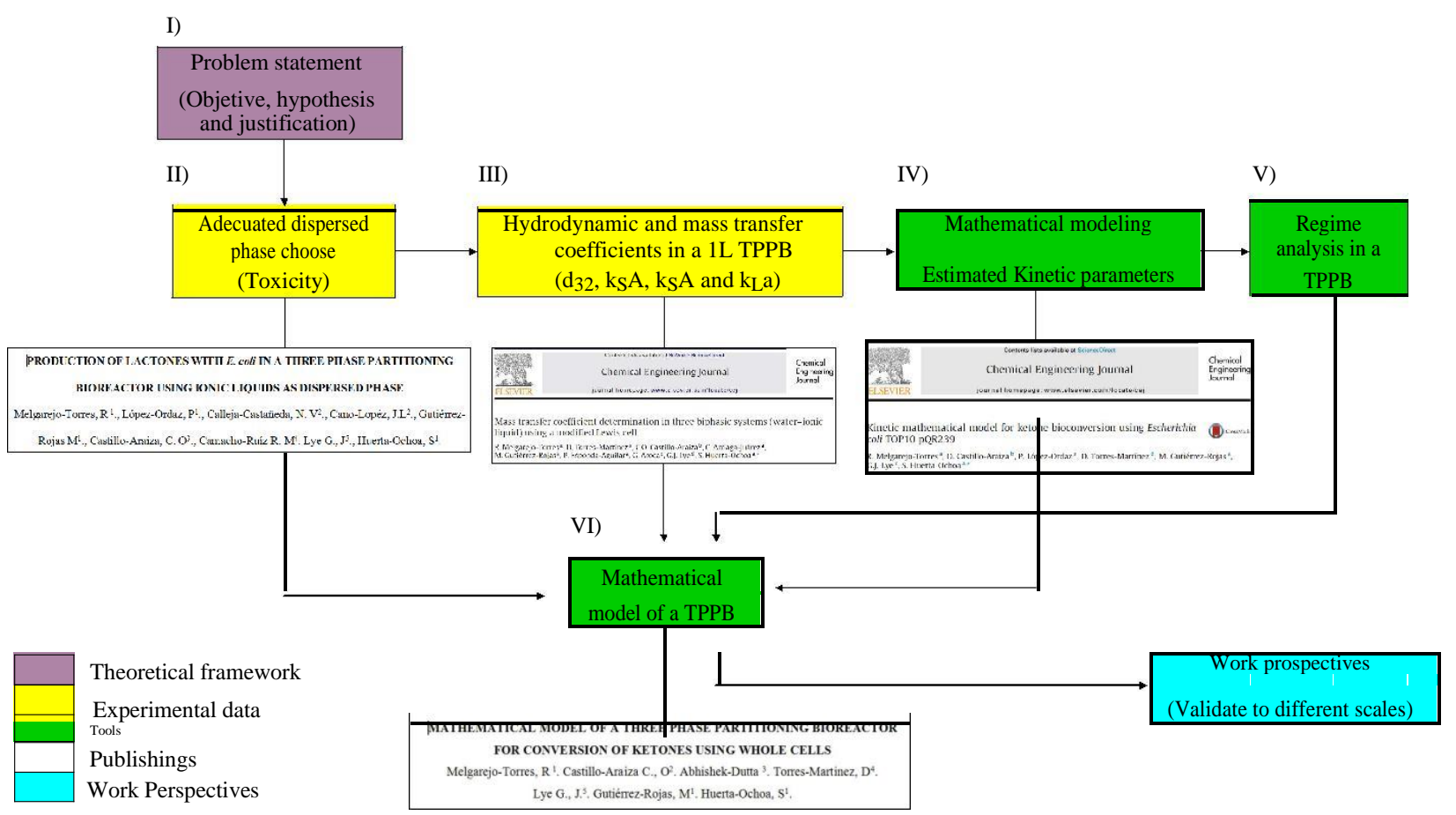

Figure 1. General strategy followed in this Thesis for the study of main different mechanisms that ocurring a three phase partitioning bioreactor for ketone bioconversion

NOTE: Each chapter has its self nomenclature, figures, tables and references. 


\section{CHAPTER II}

PRODUCTION OF LACTONES WITH E. coli IN A THREE PHASE

PARTITIONING BIOREACTOR USING IONIC LIQUIDS AS DISPERSED PHASE

TAKEN FROM: Chemical Engineering Journal. Chemical Engineering Journal 279, (2015) 379-386. 


\title{
PRODUCTION OF LACTONES WITH E. coli IN A THREE PHASE PARTITIONING BIOREACTOR USING IONIC LIQUIDS AS DISPERSED PHASE
}

\author{
Melgarejo-Torres, $\mathrm{R}^{1}$., Castillo-Araiza, C. $\mathrm{O}^{3}$, López-Ordaz, $\mathrm{P}^{1}$., Calleja-Castañeda, N. V ${ }^{2}$., Cano-Lopéz, J.L ${ }^{2}$., , \\ Camacho-Ruíz R. $\mathrm{M}^{4}$. Lye G., $\mathrm{J}^{5}$., Huerta-Ochoa, $\mathrm{S}^{1}$. \\ ${ }^{1}$ Departamento de Biotecnología, Universidad Autónoma Metropolitana-Iztapalapa, Av. San Rafael Atlixco \\ 186, Col. Vicentina, 09340, México D.F., México. \\ ${ }^{2}$ Departamento de Ingeniería Química. Universidad del Valle de México-Tlalpan. Calz de Tlalpan 122, Col. \\ Tlalpan 09979, México D.F., México. \\ ${ }^{3}$ Grupo de Procesos de Transporte y Reacción en Sistemas Multifásicos. Dpto. de IPH, Universidad \\ Autónoma Metropolitana- Iztapalapa, México D.F., México. \\ ${ }^{4}$ Centro de Investigación y Asistencia en Tecnología y Diseño del Estado de Jalisco, Normalistas 800, \\ Guadalajara, Jalisco, México. \\ ${ }^{5}$ Department of Biochemical Engineering, University College London, London WC1E 7JE, United Kingdom.
}

\author{
*Corresponding authors \\ E-mail address: rmt_melto2003@yahoo.com.mx (R. Melgarejo-Torres). \\ E-mail address: sho@xanum.uam.mx (S. Huerta-Ochoa). \\ E-mail address: coca@xanum.uam.mx (C. O. Castillo-Araiza).
}

\begin{abstract}
We studied the production of lactones in a three phase partitioning bioreactor (TPPB), air-water-ionic liquid, testing four ionic liquids (ILs) as dispersed phase $(5 \% \mathrm{v} / \mathrm{v})$. Particularly, this work was aimed to determining: the partition coefficients between aqueous and dispersed phase; interfacial mass transfer coefficients of substrate and product between aqueous and dispersed phase; interfacial mass transfer coefficient of oxygen between gas and aqueous phase; and, mainly, the deactivation parameters related to the loss of cell viability due to the presence of the dispersed phase. Dispersed phase increased the production of lactones in 60\% compared to an air-water system. All evaluated ILs are thermodynamically suitable for being used as disperse phase in the studied TPPB, however, all of them provoked a loss of cell viability, obtaining values from 58 to $77 \%$ corresponding to conversions from 70 to $20 \%$, respectively. The trioctylmethylammonium bis(trifluoromethylsulfonyl)imide [OMA][BTA] leaded to the highest conversions (70\% ) and the lowest the loss of cell viability (58\%) even though this IL presented the lowest oxygen, substrate and product mass transfer coefficients at studied operating conditions. These results indicate that TPPB using the [OMA][BTA] is a suitable technology for the production of lactones in a near future.
\end{abstract}

Key words: Production of lactones; partitioning biorreactors; ionic liquids, loss of cell viability, mass transfer. 


\section{INTRODUCTION}

Lactones are important compounds in food, medicine and cosmetic industries. Some of them are applied in medicine as anti-inflammatory because of their cytotoxic activity in vitro against human lung cancer and mouse melanoma cells $[1,2]$ Besides, a type of lactones is used in food industry as an essential flavour component in aged alcoholic beverages such as whisky, cognac and brandy, among others [3]. The BaeyerVilliger oxidation of cyclic or acyclic ketones allows their transformation to the corresponding lactone by oxidants such as peroxybenzoic acid and hydrogen peroxide. These oxidants are often intrinsically unstable, toxic presenting a lack of enantioselectivity (Renz and Meunier- $[4,5]$. There are chemical and biosynthetic routes used to carry out the Baeyer-Villiger oxidation, being the latter the most attractive because of their lower energy cost due to lower reaction temperatures, less or, even, no usage of organic solvents and higher chemo and enantioselectivity due to the use of enzymes $[6,7]$.

Baeyer-Villiger oxidation via a biosynthetic route is lately performed using enzymes as the cyclohexanone monooxygenase, CHMO, in whole cell systems [8]. The CHMO uses molecular oxygen to mediate the nucleophilic oxygenation of linear or cyclic ketones yielding the corresponding lactones. Nevertheless, there are some reaction constraints: a ketone concentration and/or a product concentration higher than ca. $0.4 \mathrm{~g} \mathrm{~L}^{-1}$ and ca. $5 \mathrm{~g} \mathrm{~L}^{-1}$, respectively, leads to bioconversion inhibition [9, 10]; and an excess of dissolved oxygen causes a permanent denaturation of CHMO due to oxidation of $-\mathrm{SH}$ groups in the corresponding active sites [11]. A number of strategies have been proposed to avoid this type of bioconversion limitations, such as: substrate feeding and in situ product removal using Lewatit resins [12]; biocatalyzer encapsulation to prevent CHMO oxidation [13], the use of a ionic liquid (IL) as an immiscible phase that works as substrate reservoir and in situ product removal, maintaining the biocatalyst (whole cells) in the aqueous phase [14]; the biocatalyzst is co-immobilized on a glutaraldehyde-activated support [15]; and among others as that where the CHMO molecular structure is changed to fold the serines susceptible to oxidation inside the enzyme [16].

Previous studies of our research group have shown the suitability, in terms of kinetic and mass transport analysis, of using a three phase stirred tank partitioning bioreactor (TPPB) using a IL as the dispersed phase to carry out the Baeyer-Villiger oxidation of ketones to lactones [17]. Nevertheless, there are no established criteria to select a proper IL to carry out the studied reaction. Thus, in this work, thermodynamic, mass transfer and deactivation 
parameters of four different IL were determined with the aim to obtain those criteria to select the most proper IL for the studied reaction. Particularly, those parameters to be estimated were: the partition coefficients between aqueous and dispersed phase; interfacial mass transfer coefficents of substrate and product between aqueous and dispersed phase; interfacial mass transfer coefficient of oxygen between gas and aqueous phase; and, the deactivation parameters related to the loss of cell viability due to the presence of the dispersed phase. From all these parameters, the deactivation parameter becomes an essential criterion to discard an IL as disperse phase since all ILs used as disperse phase contain high levels of toxic compounds that are dissolved due to the polarities and sizes of their cation and anions, and, hence, lead to both loss of cell viability and loss of the production of lactones.

\section{MATERIALS AND METHODS}

\subsection{Chemicals}

The four ionic liquids used were 1-butyl-3-metyl-imidazolium hexafluorophosphate [BMIM][PF6], 1-hexyl-3-methylimidazolium bis(trifluoromethylsulfonyl)imide [HMIM][BTA], butylmethylpyrrolidinium bis(trifluoromethylsulfonyl)imide [MBP][BTA] and the trioctylmethylammonium bis(trifluoromethylsulfonyl)imide [OMA][BTA]. All were purchased from Solvent Innovation $\mathrm{GmbH}$ (Köln, Germany). Bicyclic ketone bicycle[3.2.0]hept-2-to-6-one ( $\geq 98 \%)$ and bicyclic lactone (1S,5R)-(-)-2oxabiciclo[3.3.0]oct-6-en-3-ona ( $\geq 99.0 \%$ ) (Fluka, Switzerland) were used as the substrate and product standards, respectively. Tryptone, yeast extract, $\mathrm{NaCl}$ and glycerol were purchased from Sigma Aldrich (EUA).

\subsection{Microorganism}

The E. coli strain TOP10 pQR239 was kindly provided by Professor John M. Ward (University College London, London, United Kingdom) for research and academic purposes and is referred to hereafter simply as E. coli. To prepare inocula for bioconversion experiments, E. coli cells were cultured in Erlenmeyer flasks of $250 \mathrm{~mL}$ containing $70 \mathrm{~mL}$ of a complex media (in $\mathrm{g} \mathrm{L}^{-1}$ ): tryptone 10.0, yeast extract 10, $\mathrm{NaCl} 10.0$, in phosphate buffer $50 \mathrm{mM} \mathrm{pH} 7.0$, supplemented with $10 \mathrm{~g} \mathrm{~L}^{-1}$ glycerol. Culture media was sterilized in an autoclave at $120{ }^{\circ} \mathrm{C}$ for $15 \mathrm{~min}$ and supplemented with $100 \mathrm{mg} \mathrm{L}^{-1}$ ampicillin (previously filter sterilized using a $0.25 \mu \mathrm{m}$ filter). Erlenmeyer flasks were incubated at $150 \mathrm{rpm}$ for $16 \mathrm{~h}$ at $37{ }^{\circ} \mathrm{C}$. After this $16 \mathrm{~h}$ growth period, cyclohexanone monooxygenase expression was induced by adding the necessary amount of arabinose 
solution $\left(100 \mathrm{~g} \mathrm{~L}^{-1}\right)$ to reach a final concentration of $2 \mathrm{~g} \mathrm{~L}^{-1}$. After $3 \mathrm{~h}$ of induction, cells were harvested by centrifugation at $5,000 \mathrm{rpm}$ for $10 \mathrm{~min}$.

\subsection{Determination of Loss of cell viability}

Experiments of loss of E. coli viability due to IL for practical porpuses were carried out in Erlenmeyer flasks. E. coli was inoculated with $5 \%(\mathrm{v} / \mathrm{v})$ of ionic liquid in $20 \mathrm{~mL}$ of $50 \mathrm{mM}$ phosphate solution at $\mathrm{pH} 7$ and $3 \mathrm{~g} \mathrm{~L}^{-1}$ of biomass. Then, samples of $500 \mu \mathrm{L}$ were taken each hour ( 0 to 4 hours) before the incubation, and were serially diluted $\left(10^{-1}\right.$ to $\left.10^{-6}\right)$. After, $0.1 \mathrm{~mL}$ of each dilution was used to inoculate Petri dishes containing $10 \mathrm{~mL}$ of nutritive agar which was incubated for $16-20 \mathrm{~h}$ at $30{ }^{\circ} \mathrm{C}$. The E. coli viability was calculated on the basis of viable cell counts by counting colony-forming units $\left(\mathrm{CFU} \mathrm{mL}{ }^{-1}\right)$ (Coult-counter, Quebec, Canada). The experiment was carried out by triplicate.

\subsection{Determination of Substrate and product partitioning coefficients}

The partitioning coefficients were determinated using known concentrations of substrate and product with a total volume of $7 \mathrm{~mL}$ in a Corning tube of $15 \mathrm{~mL}$ capacity (with same volumes of the aqueous phase and ionic liquid). Every 6 hours the tubes were agitated for 5 min and $300 \mu \mathrm{L}$ samples of the aqueous phase were taken for a period of 24 hours. The samples were centifugated at $5000 \mathrm{rpm}$ for $10 \mathrm{~min}$ and the aqueous phase were analyzed by GC.

\subsection{Gas chromatography analysis}

Gas chromatography (GC) was used to quantify the concentrations of bicycle[3.2.0]hept-2en-6-one and its corresponding regioisomeric lactones. Samples $(1 \mu \mathrm{L})$ were injected into an XL gas chromatograph (Perkin Elmer, Norwalk, CT) fitted with a CYCLOSILB 1136632 capillary column $(30 \mathrm{~m} \times 530 \mu \mathrm{m})(\mathrm{J} \& \mathrm{~W}$ Scientific), and concentrations were determined using an external calibration curve. The GC injector temperature was set at $250^{\circ} \mathrm{C}$. The GC temperature program used was as follows: the initial oven temperature was $100{ }^{\circ} \mathrm{C}$, held for $1 \mathrm{~min}$ and followed by a temperature increase at $10{ }^{\circ} \mathrm{C} \mathrm{min}^{-1}$ up to $150{ }^{\circ} \mathrm{C}$, which was then held for $3 \mathrm{~min}$. Retention times were $3.7 \mathrm{~min}$ and $3.95 \mathrm{~min}$ for the substrate (mixture of ketone isomers) and 8.5 min for the product.

\subsection{Stirred tank bioreactor}

A module with two glass $100 \mathrm{~mL}$ stirred tank min-bioreactors (MMBR100, UAM-I, Mexico) was used for all conversion studies in air-aqueous phase-ionic liquid system. The jacketed mini-bioreactors had an internal diameter of $4.75 \mathrm{~cm}$ and an operating volume of $70 \mathrm{~mL}\left(\mathrm{HL}_{\mathrm{L}} \mathrm{D} \mathrm{T}=0.87\right)$. The bioreactors were fitted with a single, six flat blade Rushton turbine, $\mathrm{D}_{\mathrm{i}}=1.9 \mathrm{~cm}\left(\mathrm{Di}_{\mathrm{i}} / \mathrm{DT}_{\mathrm{T}}\right.$ 
$=0.40)$, located $1.9 \mathrm{~cm}$ from the flat base of the vessel. The bioreactor was equipped with four equidistant baffles, $0.5 \mathrm{~cm}$ in width, to enhance mixing.

\subsection{Overall oxygen mass transfer coefficient, kLa determination}

Optical fiber for Dissolved Oxygen (DO), mini sensors (PreSens, GmbH Germany) were used for kLa determination. The DO sensors were coupled to a 4-Channel Oxygen Meter OXY- 4 mini (PreSens, GmbH Germany). Overall oxygen mass transfer coefficients, kLa were calculated according to dynamic method and the correlation proposed by Fuchs and Dewey [18], which takes into account the electrode response time and the dimensionless DO concentration in the bioreactor:

$$
Y_{P}=\frac{K_{P} \cdot e^{-k_{L} a t}-k_{L} a \cdot e^{-K_{P} t}}{K_{P}-k_{L} a}
$$

where $\mathrm{Y}_{\mathrm{P}}$ is the dimensionless $\mathrm{DO}$ concentration in the bioreactor defined as:

$$
\mathrm{YP}=\frac{\left[\mathrm{O}_{2}^{*}\right]-\left[\mathrm{O}_{2}\right]}{\left[\mathrm{O}_{2} *\right]-\left[\mathrm{O}_{20}\right]}
$$

where $\left[\mathrm{O}_{2}^{*}\right]$ is the saturated oxygen concentration $\left(7.2 \mathrm{mg} \mathrm{L}^{-1}\right.$, which was determined with the OXY-4 module software using the atmospheric pressure of Mexico City, $1016.9 \mathrm{hPa}$ ), [O 2$]$ is the dissolved oxygen concentration, $\left[\mathrm{O}_{20}\right]$ is the initial dissolved oxygen concentration in the bioreactor. $\mathrm{KP}$ is the electrode constant defined as the inverse of the response time, kLa is the overall oxygen mass transfer coefficient, and $t$ is the time required for the sensor to reach the saturated oxygen concentration. Fitting was performed using a non-linear regression LevenbergMarquardt algorithm in Polymath ${ }^{\mathrm{TM}}$.

\subsection{Measurement of Sauter mean diameter $\left(\mathrm{d}_{32}\right)$}

Sauter mean droplet diameter $\left(\mathrm{d}_{32}\right)$ was measured using a 3D Optical Reflectance Measurement (ORM) particle size analyser (MTS, Messtechnik Schwartz) Lovick et al.

[19]. 2000 droplet diameter $\left(d_{1}\right)$ determinations were performed automatically for each measurement, enabling calculation of the Sauter mean diameter (d32) according to:

$$
\mathrm{d}_{32}=\frac{\sum \mathrm{d}_{1}{ }^{3} \mathrm{n}_{1}}{\sum^{\mathrm{d}^{2}{ }_{\mathrm{n} 1}}}
$$

Ionic liquid drop size diameters and distributions were obtained in situ and on-line during all the experiments. Because the ORM measures drop sizes using laser beam reflectance, and the fact that gas bubbles do not have reflective properties, it was assumed that gas bubbles do not interfere with liquid drop size measurements. No evidence of such interference was observed in any of the initial recorded size distributions and, therefore, 
ORM drop size measurements were recorded directly for the three-phase system. ORM techniques are able to show the change of the drop size for various power inputs, although they are not able to measure the exact size of the drops. Therefore, they are interesting for the control of processes [20]. Then, measurements were recorded at least 15 min after mixing was initiated in order to ensure that an equilibrium in drop size distribution was established. The interfacial area available for substrate and product mass transfer (A) in the one litre bioreactor is given by:

$$
A=\frac{6 \phi}{d_{32}}
$$

where $\varphi$ is the volume fraction of the dispersed phase. Overall mass transfer coefficients for substrate and product, $\mathrm{kSA}$ and $\mathrm{kPA}$, respectively, were determined using these areas according eq (4) and multiplied by the mass transfer coefficients for substrate and product, ks and kP obtained previously in a Lewis cell modified [21].

\subsection{Production of lactones in biphasic system (aqueous-air)}

For all bioconversions in biphasic and tri-phasic systems were used $3 \mathrm{~g}$ of biomass $\mathrm{L}^{-1}$. The aqueous phase was a buffer solution consisting of $50 \mathrm{mM}$ phosphate to $\mathrm{pH} 7.0$ supplemented with $5 \mathrm{~g}$ glycerol $\mathrm{L}^{-1}$. The initial concentration of substrate was $0.35 \mathrm{~g} \mathrm{~L}^{-1}$. The operation conditions of the MMBR100 were: agitation rate $1950 \mathrm{rpm}$, aeration rate 1 vvm at $30{ }^{\circ} \mathrm{C}$. During bioconversion experiments samples of $500 \mu \mathrm{L}$ were taken every 3 minutes during the first 15 minutes and then every hour for two hours. Samples were quickly frozen to stop the reaction. For substrate and product analysis, the samples were centrifuged at $5000 \mathrm{rpm}$ for 10 minutes to separate biomass and supernatant analyzed. Substrate and product concentrations were quantified by G-C.

\subsection{Production of lactones in a three phase system (air-water-ionic líquid)}

The initial substrate concentration in aqueous phase was $0.35 \mathrm{~g} \mathrm{~L}^{-1}$ and $5 \mathrm{~g} \mathrm{~L}^{-1}$ of glycerol due to the partition coefficients of the [OMA][BTA]. The operating conditions were at 30 ${ }^{\circ} \mathrm{C}, \mathrm{pH} \mathrm{7,} 1950 \mathrm{rpm}, 1 \mathrm{vvm}$ and $5 \%$ of ionic liquid fraction. The IL was equilibrated previously with oxygen, substrate and $50 \mathrm{~mL}$ aqueous phase and then as aforementioned 3 $\mathrm{g}$ of biomass $\mathrm{L}^{-1}$ were added and resuspended in $20 \mathrm{~mL}$ of $50 \mathrm{mM}$ phosphate buffer to start the bioconversion. During conversion experiments, samples of $500 \mu \mathrm{L}$ were taken every 3 minutes during the first 15 minutes and then every hour for 4 hours. Samples were quickly frozen to stop the reaction. The analysis of substrate and product was as that mentioned when thebiphasic system was studied, vide section 2.9. 


\section{RESULTS AND DISCUSION}

\subsection{Partitioning coefficients for substrate and product}

The determination of the partitioning coefficients for substrate $\left(\mathrm{K}_{\mathrm{ps}}\right)$ and product $\left(\mathrm{K}_{\mathrm{pp}}\right)$ allow to determine the the capability of each IL for supplying substrate to aqueous phase and for removing product from aqueous phase to IL in order to maintain non inhibition concentrations in aqueous phase where in biocatalyst is contained. Therefore, the values of the partition coefficients for substrate and product are important criteria for selecting a ionic liquid [22]. From this end, the partitioning coefficients for substrate $\left(\mathrm{K}_{\mathrm{ps}}\right)$ and product $\left(\mathrm{K}_{\mathrm{pp}}\right)$ using four ILs were determinated. Table 1 presents the $\mathrm{K}_{\mathrm{ps}}$ and $\mathrm{K}_{\mathrm{pp}}$ obtained for the ILs studied. The highest partitioning coefficients for susbtrate and product, 28.98 and 15.51, respectively, were obtained for [MBP][BTA]. As observed partitioning coefficients for susbtrate are larger than those for product. This difference is due to ketones possess of a stronger lipophilic character. All other ILs presented partitioning coefficients for substrate between ca. 9.77 to 15.66 and for product between ca. 4.07 to 4.14. Torres-Martínez et. al. [23] reported $\mathrm{K}_{\mathrm{ps}}$ values for ketones using the IL [OMA][BTA] of 25.8. Bräutigam et al., [24] mentioned that $\left[\mathrm{PF}_{6}\right]$ and $[\mathrm{BTA}]$ provided, considerably, higher distribution coefficients for the alcohol 4-Cl-PE and ketones. Abraham et al., [25] determined the partitioning coefficient of octanol, KOW in a water-ionic liquid system evaluating twelve ionic liquids at room temperature. They observed that $\mathrm{K}_{\mathrm{OW}}$ increases as the alkyl chain length of the cation increased as well.

Table 1 lists the partitioning coefficients for substrate and product in the pahses (buffer-IL) for the ILs studied.

\begin{tabular}{ccc}
\hline Ionic liquid & $\begin{array}{c}\mathrm{K}_{\mathrm{ps}} \text { for (bicycloketone } \\
{[3.2 .0] \text { hept-2-en-6-one) }}\end{array}$ & $\begin{array}{c}\mathrm{K}_{\mathrm{pp}} \text { for (bicyclolactone -2- } \\
\text { oxabicyclo[3.3.0]oct-6-en-3-one) }\end{array}$ \\
\hline [BMIN] [PF6] & $9.77 \pm 0.7$ & $4.07 \pm 0.5$ \\
[HMIM][BTA & $15.66 \pm 1.3$ & $4.09 \pm 0.3$ \\
] & $28.98 \pm 1.5$ & $15.51 \pm 1.6$ \\
[MBP][BTA] & $13.21 \pm 1.4$ & $4.14 \pm 0.7$ \\
\hline [OMA][BTA] & & \\
\hline
\end{tabular}

\subsection{Overall oxygen mass transfer coefficient, $\mathrm{k}_{\mathrm{La}}$}

Garcia and Gómez, [26] mention that many factors are known to affect the mass transfer coefficients, $\mathrm{k}_{\mathrm{L}} \mathrm{a}$, including parameters such as agitation, airflow rate, vessel geometry, fluid characteristics (density, viscosity, surface tension, etc.), the concentration and physical properties of the immobilizing materials (density, particle size, etc.). Thus, it is important know how is the $\mathrm{k}_{\mathrm{L}}$ a affected in a TPPB. In this work the influence of the IL fraction and agitation on the $\mathrm{k}_{\mathrm{L}}$ a were studied. The operating conditions were 1.4 vvm, $5 \%$ of ionic fraction and agitation of 750,1350 and $1950 \mathrm{rpm}$. The range of $\mathrm{k}_{\mathrm{L} a}$ values from airwater 
were 32 to $310 \mathrm{~h}^{-1}$ while for the air-water-ionic liquid system were between 20 to $280 \mathrm{~h}^{-1}$. Figure 2 shows the kLa values for the systems air-water and air-water-IL; the adition of 5\% of the dispersed fraction leads a slight decrease of the kLa for all ILs studied in comparation with the biphasic system without IL. Martín et al. [27] mention that these differences of kLa between the dispersed and the aqueous phase are due to the change in the viscosity in the bioreactor. These changes determine the liquid diffusivity value, the break-up and the coalescence behavior. They reported that the liquid viscosity has two effects that determine the mass transfer rates. Liquid viscosity affects bubble mean size. Bubbles are more stable in a viscous liquid and the contact area decreases. Furthemore, liquid diffusivity decreases due to the reduced mobility of the liquid layers surrounding the bubbles. As a result the volumetric mass transfer coefficient decreases because of these two physical phenomena, lower contact area and reduced diffusivity. The [OMA][BTA] had the lower kLa value. Torres-Martínez et al., [23] reported similar values of kLa between 20 to 220 $\mathrm{h}^{-1}$ for the same IL in a $1 \mathrm{~L}$ stirred tank biorreactor and mention that the [OMA][BTA] is more viscous than the others ILs.

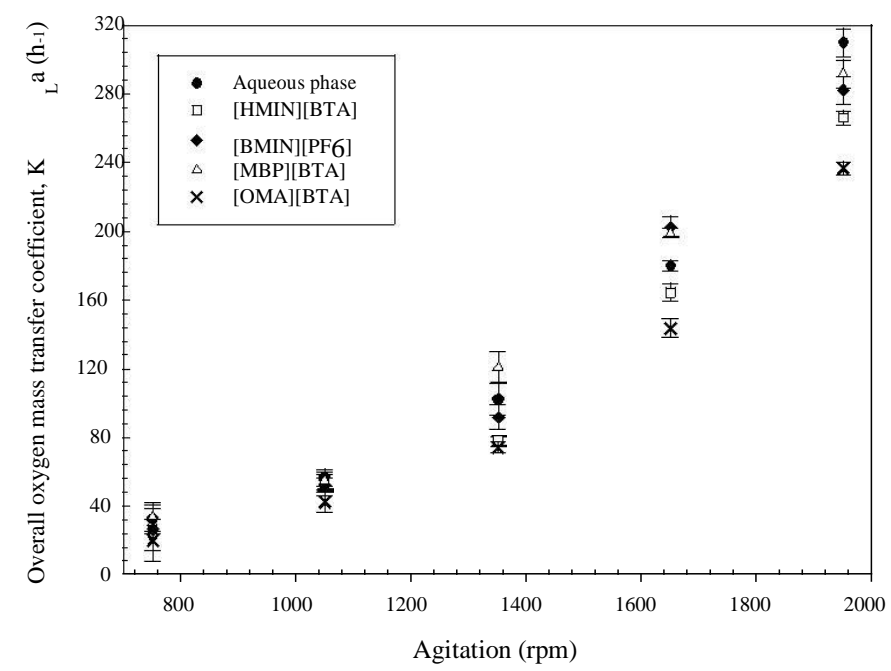

Figure 2. Overall mass transfer coefficient, $\mathrm{k}_{\mathrm{L}}$ for the four ILs studied at $5 \%$ and without IL to different agitation rates, the aeration was $1.4 \mathrm{vvm}$.

\subsection{Sauter mean drop diameter, $\mathrm{d}_{32}$}

In the TPPB, it is crucial the study of the substrate and product mass transfer to maintain an equilibrium between these mechanisms and the bioconversion. For this work, the effect of agitation rate on the mean drop diameter of the dispersed phase $\mathrm{d}_{32}$ was studied. Figure 3 a shows the $\mathrm{d}_{32}$ of dispersed phase at 1.4 $\mathrm{vvm}$ and $5 \%$ of ionic fraction. For this system at low agitation rate $(750 \mathrm{rpm})$ high values of $\mathrm{d}_{32}(250$ $75 \mu \mathrm{m}$ ) were observed. It was also observed that the dispersed phase did not have an adecuate mixing and remained at the bottom of the 
bioreactor. At this agitation rate the system was in transitional regime and there were not adequate conditions for the bioconversion due to possible troubles with the mass transfer mechanisms. At high agitation rates $(1050-1950)$ the smaller $\mathrm{d}_{32}(70-40 \mu \mathrm{m})$ were obtained, from $1350 \mathrm{rpm}$ onward the $\mathrm{d}_{32}$ were constant and no changes were observed for all ILs studied. Torres-Martínez et al. [23] reported values of $\mathrm{d}_{32}$ among 70 to $15 \mu \mathrm{m}$ for three of the ILs used in this work in a $1.0 \mathrm{~L}$ bioreactor. Figure $3 \mathrm{~b}$ shows the mass transfer interfacial area A obtained acording to Eq. (4), the ILs [HMIN][BTA],

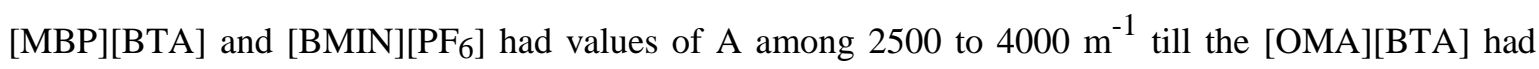
values between 2000 to $500 \mathrm{~m}^{-1}$. The differences of the A sizes between the ILs were because they had not the same viscosities and interfacial tensions leading to different breakage mechanisims and therefore different $d_{32}$ values. These results were coupled to a previous work [28], using estimated values of substrate and product mass transfer coefficients $\left(\mathrm{k}_{\mathrm{S}}\right.$ and $\left.\mathrm{k}_{\mathrm{P}}\right)$ respectively with a mathematical model of a TPPB to determine the global mass transfer coefficients for substrate and product $\mathrm{kS}_{\mathrm{S}} \mathrm{A}$ and $\mathrm{kPA}_{\mathrm{P}}$ respectively, the values obtained were among 690 to 5560 for $\mathrm{k}_{S} \mathrm{~A}$ and 65 to 520 for $\mathrm{kPA}_{\mathrm{PA}}$. Melgarejo et al., [21] mention that the determination of the mass transfer coefficients allow establishing the optimal conditions through a regime analysis using characteristic times for substrate and oxygen supply, in situ product recovery by the ionic liquid phase, and the cell metabolic demand.

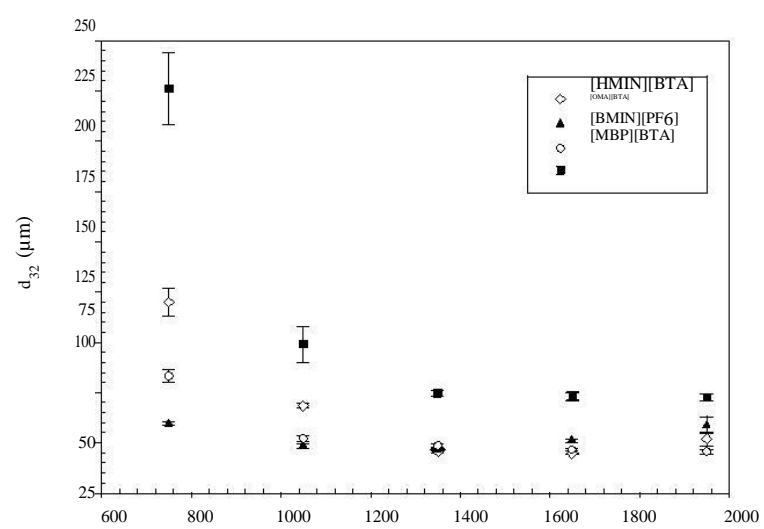

a)

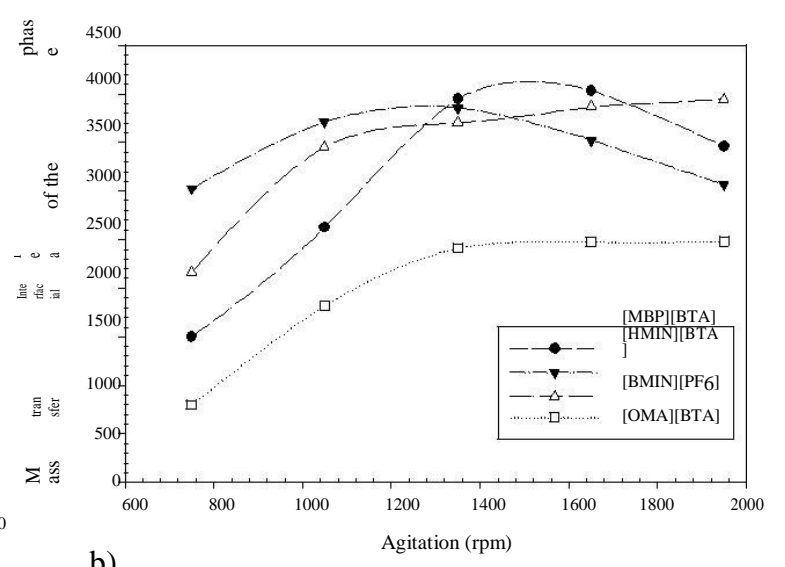

b)

Figure 3. a) Effect of agitation rate on Sauter mean drop diameter $\mathrm{d}_{32}$ for the ILs studied at 5\% v/v and $1.4 \mathrm{vvm}$.

b) Mass transfer interfacial area $A$ of the dispersed phase determined form the $\mathrm{d}_{32}$ values.

\subsection{Production of lactone in biphasic system (air-water)}

In a previous work, different operation conditions were studied for the production of lactone in aqueous phase, the best conditions were $1.4 \mathrm{vvm}, 1350 \mathrm{rpm}, 0.35 \mathrm{~g} \mathrm{~L}^{-1}$ of substrate and $3 \mathrm{~g}$ of biomass $\mathrm{L}^{-1}$ [29]. Figure 4a shows that at these conditions the 
biocatalyst consumed all substrate and the lactones production was of $100 \%$ in $90 \mathrm{~min}$. At these conditions there was not substrate and product inhibition. Figure $4 \mathrm{~b}$ shows that the DO in the bioreactor is enough for the metabolic demand of the cells and there was not oxygen inactivation [30]. Doig et. al. [9] mention that the optimum oxygen transfer rate allowed minimized potential oxidative damage. For optimum performance the DO should be maintained near to zero and successful scale-up to 300 litres was carried out on this basis. Nevertheless the productivity of lactones at these conditions is very low due to it is not possible increase the substrate concentration.
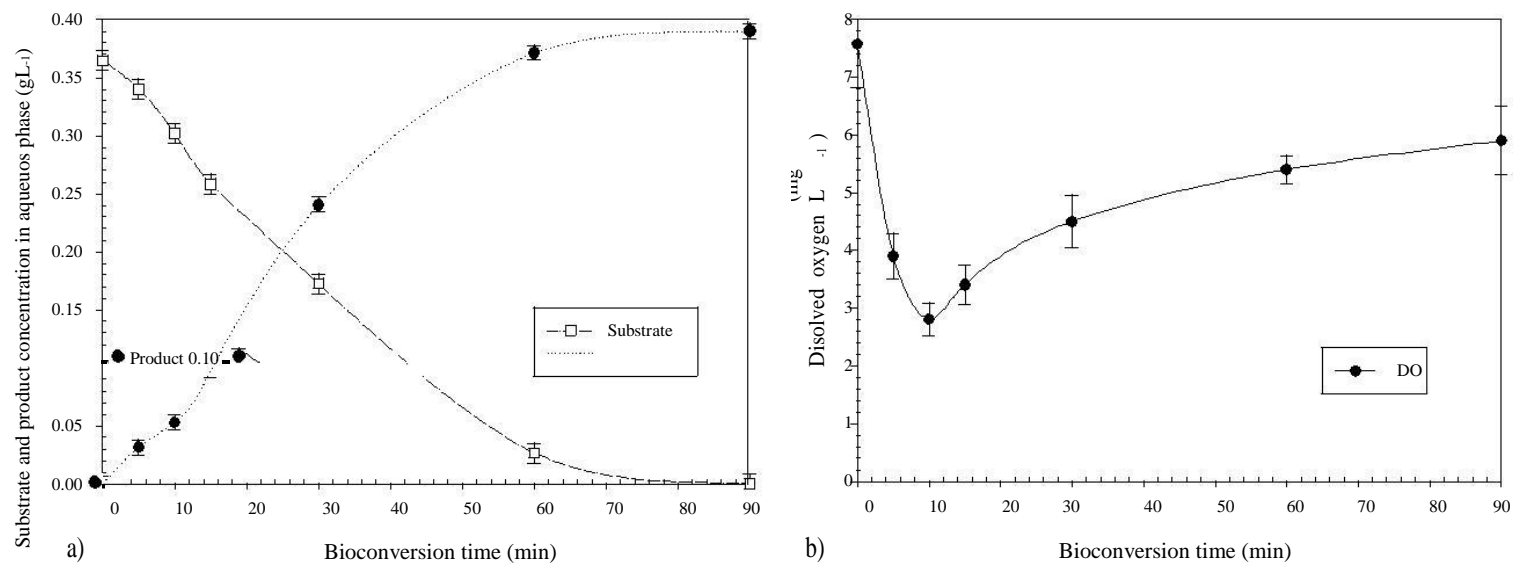

Figure 4. a) Lactone production due to the substrate uptake rate by the cells. b) DO in the bioreactor during the bioconversion in an air-water system.

\subsection{Production of lactones in three phase system (air-water-ionic liquid)}

To study the bioconversion of the lactones in a three phase system, the operation conditions for the four ILs studied were $1950 \mathrm{rpm}, 1.4 \mathrm{vvm}$ and 5\% of ionic fraction. It is relevant mention that all ILs, before of their use, were washed with distilled water to remove possible toxic traces synthetized during cell cultivation. Figure 5a shows the substrate concentration in aqueous phase, in the time interval from 0 to $180 \mathrm{~min}$. The substrate concentration decrease quickly due to substrate uptake rate (STR) by the cell and is higher than the substrate transfer rate from the ionic liquid to the aqueous phase. After this time (180 to 300) the STR decrease to stop and at this moment the mechanism that governed is the substrate mass transfer from the ionic liquid to the aqueous phase till come to equilibria between the phases. Figure $5 \mathrm{~b}$ shows the production of lactones as function of the time, the IL [OMA][BTA] had a high lactone production in ratio of the substrate concentration in the bioreactor (70 \%), the [HMIN][BTA] reached a conversion of $30 \%$ and for [BMIN][PF6] was of $16 \%$. 
Although $[\mathrm{MBP}][\mathrm{BTA}]$ was the IL that had the highest retention capacity of substrate and product due to its partition coefficients compared to another ILs, nevertheless it had the lowest lactone production $(11 \%)$. In this figure is possible to apreciate that the time of bioconversion for air-water-ionic liquid system was higher than the air-aqueous system (Figure 3a), this trend could be due to the adition of the dispersed phase that increase the viscosity in the system causing difficulty in mass transfer between the three phases. Dong-Xiang et. al. [31] mentioned that usually the high viscosity of IL's may result in the incomplete conversion due to the difficulty for whole of the IL being sufficiently contacted with aqueous phase. But the negative transfer effects caused by high viscosity seem very limited. Another explanation is according to Déziel et al. [32], they proposed three main mechanisms through which microorganisms utilize substrates in TPPB systems namely, uptake of dissolved substrate from the aqueous phase, aqueous-organic interfacial uptake and uptake of substrate by direct contact with the organic phase. But it is clear that for some reason the reaction was stoped between 240 and 300 minutes of bioconversion time in all cases. Dong-Xiang et al. [24] tested two IL's $[\mathrm{BMIN}][\mathrm{PF} 6]$ and $[\mathrm{BMIN}][\mathrm{BTA}]$ in the biotransformation of 16 $\alpha, 17$-epoxyprogesterone by $\mathrm{R}$. nigricans. Besides, they obtained in the biphasic system a total conversion of $87 \%$ at a phase ratio of 10 and $75 \%$ at a phase ratio of 5 , respectively. Since recycling of the $[\mathrm{BMIN}]\left[\mathrm{PF}_{6}\right]$ is quite easy, there is a great potential for the application of ILs in biotransformations to implement green production. Nevertheless for a suitable choice of IL it is neccesary to study the toxicity caused to the cell by the ILs.
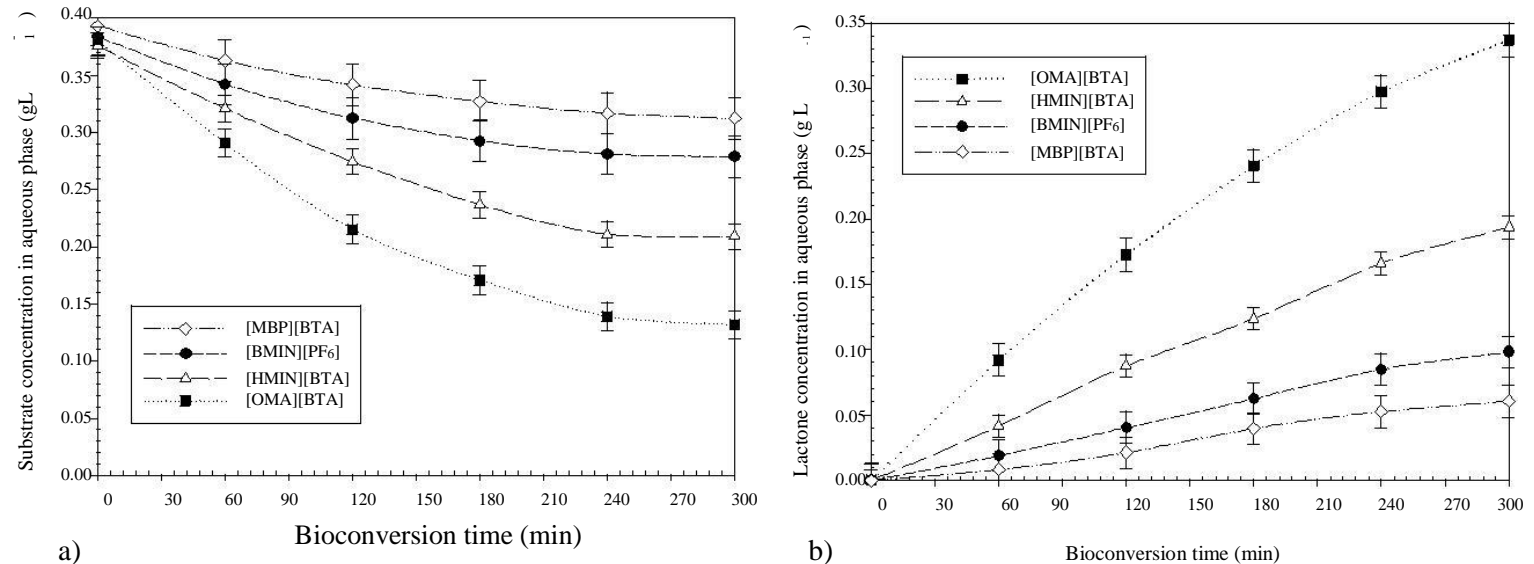

Figure 5. a) Susbtrate concentration and b) Lactone concentration in aqueus phase for the bioconversion of ketones in the TPPB for the four ILs studied at $5 \% \mathrm{v} / \mathrm{v}$ of dispersed phase. 


\subsection{Loss of cell viability determination}

For the best choice of an adecuate dispersed phase the loss of cell viablity due to the toxicity of the ionic liquid was studied. The ionic liquid fraction for all the studies was maintained at $5 \%(\mathrm{v} / \mathrm{v})$ [28]. The loss of cell viability was defined as CFU initial/CFU for each time. Figure 6 shows that the IL $[\mathrm{OMA}][\mathrm{BTA}]$ had the lowest loss of cell viability $(56 \%)$ than the other ILs $(\approx 77 \%)$. Currently, the ILs are regarded as promising "green" substitutes for organic solvents in manufacturing, processing, and cleaning technologies

[33]. However, recent studies are contradictory to the above assumption. Kumar and Malhotra [34] found therapeutic applications of ILs and for the first time demonstrated the anti-cancer activity and cytotoxicity of three different classes of ILs (imidazolium, phosphonium and ammonium) for 60 human tumor cell lines and they mentioned that the imidazolium and pyrrolidinium compounds confered more toxicity than amonium.

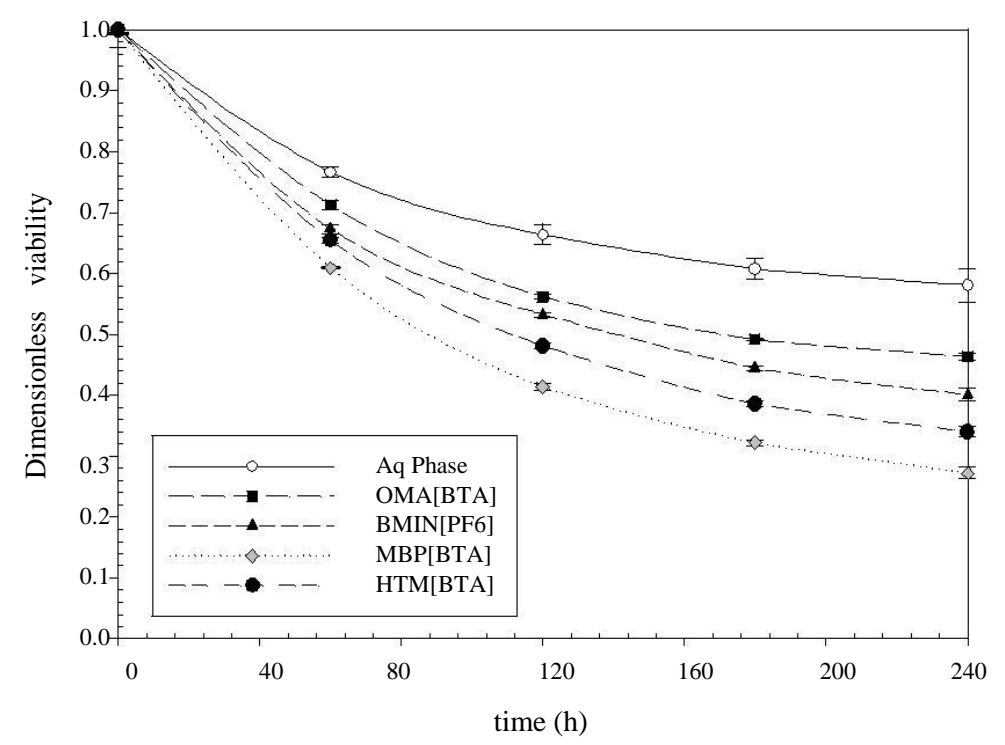

Figure 6a) Comparation of the dimensionless viability between aqueous phase with the four ILs studied with 5\% $\mathrm{v} / \mathrm{v}$, the [OMA][BTA] shown lower loss of cell viability.

For the ILs studied in this work, the cation of the [OMA][BTA] has ammonium (Figure 7a); while for the other ILs the cations have imidazolium and pyrrolidinium (Figure $7 \mathrm{~b}$ and $7 \mathrm{c}$ respectively). Probably in the case of the $\left[\mathrm{PF}_{6}\right]$ anion readily produced hydrofluoric acid in water and showed relatively high toxicity to the microbial cells (Figure 7e). Petkovic et al., [36]; Li et al., [37] mentioned that ILs may be released into water and cause damage to aquatic organisms during generation and application, including effluent discharges and accidental spills. Cull et al. [39] used the [BMIN][PF6] as second phase in the biotransformation of 1,3dicyanobenzene, 
however, the cells were not actively growing, and the viability of the cells was assessed over only $90 \mathrm{~min}$ of exposure to the IL, which does not confirm that the IL used in this case was entirely biocompatible with the Rhodococcus strain used. Gangu et al. [40] and Lou et al. [33] indicate that the biocompatibility of an IL should be considered as an essential evaluation criterion before and it can be fully exploited as a reaction medium for a whole-cell-based biotransformation. 

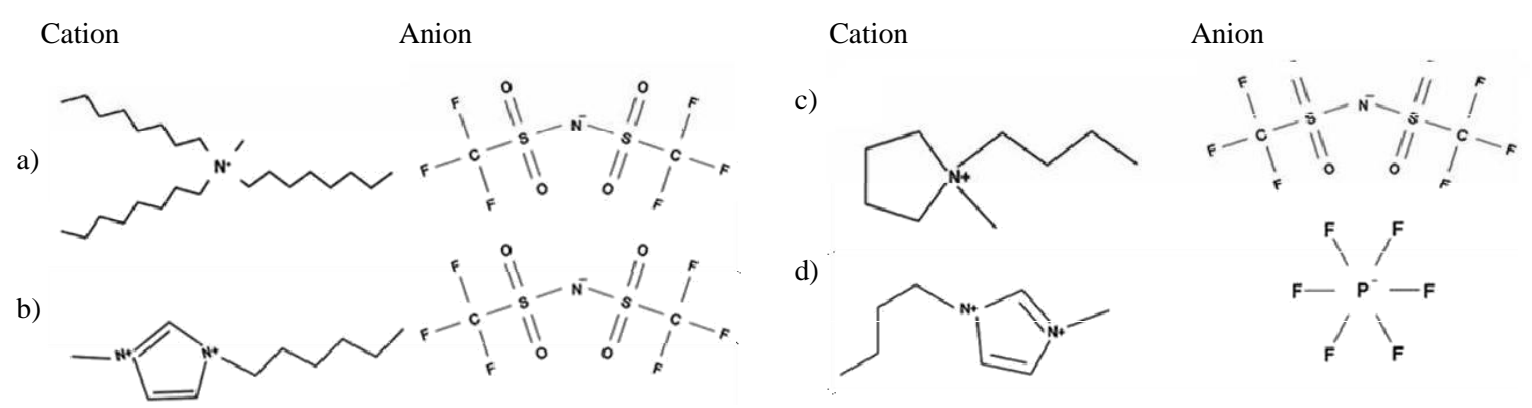

Figure 7. a) The IL[OMA][BTA] in its cation has an amonium; b) [HMIN] [BTA] the cation contained an imidazolium; c) [MBP][BTA] its cation contain a pyrrolidimium; and d) [BMIN][PF6] has in the cation an imidazolium and as anion hexaflurophosfate. The toxicity and the partitioning coefficients of the ILs are in function of the structures of their cations and anions.

\subsection{Modelling of Loss cell viability}

The loss of cell viability inhibition constants were determined for the IL's studied. The change rate of cell viability can be described as a second order equation (Eq. 5) and solved by Runge-Kutta Feldberg method.

$$
\frac{\mathrm{d}[\mathrm{CFU}]}{\mathrm{dt}}=\mathrm{k}_{\text {in }}\left(\left[\begin{array}{ll}
\mathrm{CFU} & 0
\end{array}\right]\right)^{2}
$$

Table 2 shows the percent of loss of cell viability during four hours and their respectives values of kin for the IL's studied at 5\% v/v. The IL [OMA][BTA] had the highest viability (55 $\%)$ and its kin was lower than the other IL's studied. For aqueous phase there is a loss of cell viability in lesser extent because the media reaction is compound only for phosphate buffer 50 $\mathrm{mM}$ and glycerol and does not contain nutrients for the growth of the cells. Peric et al. [35] analyzed the toxicty of two ILs groups: a new family of protic IL's, PILs (derived from aliphatic amines and organic acids) and some frequently used aprotic IL's, APIL's (substituted imidazolium and piridinium chlorides) in the aquatic toxicity (test organisms Vibrio fischeri, Pseudokirchneriella subcapitata and Lemna minor). The initial comparative hazard assessment showed that PILs are, in terms of toxicity, much favorable than the here tested AILs. This fact, together with their low production cost, simple synthesis and possible applications, suggests that they have a potential "greener" profile among other ionic liquids and a good prospect for a wider use. 
Table 2. Loss of cell viability and their inhibition constants due to the toxicity of the IL's studied at $5 \%$.

\begin{tabular}{ccc}
\hline Ionic liquid & $\begin{array}{c}\text { Loss of cell } \\
\text { viability }(\%)\end{array}$ & $\begin{array}{c}\text { Deactivation } \\
\text { constant }\left(\mathrm{k}_{\text {in }}\right) \mathrm{h}^{-1}\end{array}$ \\
\hline$[\mathrm{MBP}][\mathrm{BTA}]$ & 74 & 0.39 \\
{$[\mathrm{HTM}][\mathrm{BTA}]$} & 66 & 0.32 \\
{$[\mathrm{BMN}][\mathrm{PF} 6]$} & 60 & 0.28 \\
{$[\mathrm{OMA}][\mathrm{BTA}]$} & 55 & 0.24 \\
\hline Aq phase (only) & 43 & 0.16 \\
\hline
\end{tabular}

\section{CONCLUSIONS}

Although the IL [OMA][BTA] had the lower partition coefficients than the others IL's studied and a high viscocity that difficult to handle it. It was the IL that had a good performance in the bioconversion and a low loss of cell viability constant. The results obtained allowed to choose an adecuate dispersed phase in function of the performance of the bioconversion and the loss of cell viability. These facts suggest that the use of IL's as dispersed phase in a TPPB is an adequate strategy to increase the productivity of lactones compared to the ordinary processes (water-air). The ionic liquid phase allowed to increase the substrate concentration two fold $\left(0.7 \mathrm{~g} \mathrm{~L}^{-1}\right)$ than the water-air system $\left(0.35 \mathrm{~g} \mathrm{~L}^{-1}\right)$, thus increasing the productivity of lactones. This study shows that it is neccesary to consider a proper selection and a better designed ionic liquid in bioconversions with whole cells, with higher biocompatibility and favourable physicochemical and thermodynamic properties.

\section{NOMENCLATURE}

A Mass transfer interfacial area of dispersed phase $\left(\mathrm{m}^{2} \mathrm{~m}^{-3}\right)$

CFU Colonies Forming Units $\left(\mathrm{CFU} \mathrm{mL} \mathrm{m}^{-1}\right)$

TPPB Three Phase Partitioning Bioreactor

IL's Ionic liquids

\section{CHMO Cyclohexanone monooxygenase}

d32 Sauter mean diameter (micron)

DO Dissolved Oxygen $\left(\mathrm{mg} \mathrm{L}^{-1}\right)$

$\mathrm{O}_{2} *$ Saturated Oxygen in the bioreactor $\left(\mathrm{mg} \mathrm{L}^{-1}\right)$ 
$\mathrm{O}_{2}$ Oxygen in the bioreactor $\left(\mathrm{mg} \mathrm{L}^{-1}\right)$

Kp electrode constant $\left(\mathrm{h}^{-1}\right)$

kLa Oxygen mass transfer coefficient $\left(\mathrm{h}^{-1}\right)$

ks Substrate mass transfer coefficient $\left(\mathrm{h}^{-1}\right)$

kP Product mass transfer coefficient $\left(\mathrm{h}^{-1}\right)$

ksA Overall substrate mass transfer coefficient $\left(\mathrm{h}^{-1}\right)$

kPA Overall product mass transfer coefficient $\left(\mathrm{h}^{-1}\right)$

$\mathrm{K}_{\mathrm{ps}}$ Partition coefficient of substrate

$\mathrm{K}_{\mathrm{pp}}$ Partition coefficient of product

$\mathrm{k}_{\text {in }}$ Loss of cell viability inhibition constant $\left(\mathrm{h}^{-1}\right)$

\section{REFERENCES}

[1] N. S.Arakawa, L.Gobbo-Neto, S. R.Ambrosio, G. A. Antonucci, S. V. Sampaio, M. P. Tallarico, S. Said, T. J. Schmidt, F, Batista Da Costa. (2013). Phytochemistry 96:92-100.

[2] P. G. Taylor, O. A. D Loo, J. A, Bonilla, R. Murillo. Anticancer activities of two sesquiterpene lactones, millerenolide and thieleanin isolated from Viguiera sylvatica and Decachaeta thieleana. (2008). Fitoterapia 79, 428-432.

[3] F. Boratyński, M. Smuga, C. Wawrzenczyk. Stereoselective enzymatic/microbial synthesis of optically active isomers of whisky lactone. (2013). Lactones 42.

[4] M. Renz, and B. Meunier. 100 Years of Baeyer-Villiger oxidation of ketones. Eur. J. Org. Chem. (1999). 1, 737-750.

[5] G. Strukul. Transition metal catalysis in the Baeyer-Villiger oxidation of ketones. Angew. Chem. (1998). 37, 1198-1209.

[6] M. Persson, U. T. Bornscheuer. Increased stability of an esterase from Bacillus stearo thermophilus in ionic liquids as compared to organic solvents. Journal of Molecular Catalysis B: Enzymatic. (2003); 22 21-27.

[7] C. M. Clouthier, J. N. Pelletier. Expanding the organic toolbox: a guide to integrating biocatalysis in synthesis. Chemical Society Reviews; (2012). 41:1585-605.

[8] W-H. Lee, J-B. Park, K. Park, M-D. Kim, J-H Seo. Enhanced production of _-caprolactone by overexpression of NADPH-regenerating glucose 6-phosphate dehydrogenase in 
recombinant Escherichia coli harboring cyclohexanone monooxygenase gene. Applied Microbiology and Biotechnology; (2007). 76:329-38.

[9] S.D. Doig, L.M. O’Sullivan, S. Patel, J.M. Ward, J.M. Woodley. Large scale production of cyclohexanone monooxygenase from Escherichia coli TOP10 pQR239, Enzyme Microb. Technol. (2001). 28:265-274.

[10] S. D. Doig, H. Simpson, V. Alphand. Characterization of a recombinant Escherichia coli TOP10 [pQR239] whole-cell biocatalyst for stereoselective Baeyer-Villiger oxidations. Enzyme and Microbial Technology. (2003). 32:347-355.

[11] C. T. Walsh, J. Latham. Mechanism based inactivation of the flavoprotein cyclohexanone monooxygenase by S-oxygenation. J Protein Chem; (1986). 5:79-87.

[12] K. Geitner, A. Kirschner, J. Rehdorf, M. Schmidt, M. D. Mihovilovic, U. T . Bornscheuer. Enantioselective kinetic resolution of 3-phenyl-2-ketones using BaeyerVilliger monooxygenases. Tetrahedron: Asymmetry; (2007). 18:892-5.

[13] M. Buĉko, A. Schenkmayerová, P. Gemeinera, A. Vikartovská, M. Mihovilovibĉ, I. Lacíkc. Continuous testing system for Baeyer-Villiger biooxidation using recombinant Escherichia coli expressing cyclohexanone monooxygenase encapsulated in polyelectrolyte complex capsules, Enzyme Microb. Technol. (2011). 49:284- 288.

[14] H. Pfruender, R. Jones, V. Weuster-Botz. Water immiscible ionic liquids as solvents for whole cell biocatalysis, J. Biotechnol. (2006). 124:182-190.

[15] H. Mallin, H. Wulf1 H. , Bornscheuer U.T. A self-sufficient Baeyer-Villiger biocatalysis system for the synthesis of $\varepsilon$-caprolactone from cyclohexanol . Enzyme and Microbial Technology; (2013). 53:283-287.

[16] D.J. Opperman and M. T. Reetz. Towards practical Baeyer-Villiger-monooxygenases: Design of cyclohexanone monooxygenase mutants with enhanced oxidative stability. Chem. Bio. Chem. (2010). 18: 2589-2596.

[17] R. Melgarejo-Torres, D. Torres-Martínez, M. Gutiérrez-Rojas, A. Gómez de Jesús, J. G. Lye, S. Huerta-Ochoa. Regime analysis of a Baeyer-Villiger conversion in a three-phase (air- water ionic liquid) stirred tank bioreactor, Biochem. Eng. J. (2011). 59:87-95.

[18] D. Y. Fuchs and R, Dewey. Effect of Surface Aeration on Scale-Up Procedures for Fermentation Processes. Ind. Eng. Chem. Process Des. Develop. (1971). Vol. 10, No. 2.

[19] A.A. Lovick, S.V. Mouza, T. Paras, G.J. Lye, P. Angeli. Drop size distribution in highly concentrated liquid-liquid systems in stirred tanks using a light back scattering method, J. Chem. Technol. Biotechnol. (1995). 80:545-552. 
[20] S.G. Cull, J.W. Lovick, G. J. Lye, P. Angeli. Scale-down studies on the hydrodynamic of two-liquid phase biocatalytic reactors, Bioproc. Biosyst. Eng. (2002). 14:3-153.

[21] R. Melgarejo-Torres, D. Torres-Martínez, C. O. Castillo-Araiza, C. Arriaga-Juárez, M. Gutiérrez-Rojas, P. Esponda-Aguilar, G. Aroca, G. J. Lye, S. Huerta-Ochoa. Mass transfer coefficient determination in three biphasic systems (water-ionic liquid) using a modified Lewis cell. Chem. Eng. J. (2012). 182:702-707.

[22] D. Weuster-Botz. Process intensification of whole-cell biocatalysis with ionic liquids. Chem. Rec. (2007). 6, 334-340.

[23] D. Torres-Martinez, R. Melgarejo-Torres, M. Gutierrez-Rojas, L. Aguilera-Vazquez, M. Micheletti, G. J. Lye, S. Huerta-Ochoa. Hydrodynamic and oxygen mass transfer studies in a three-phase (air-water-ionic liquid) stirred tank bioreactor. Biochemical Engineering Journal. (2009). 45:209-217.

[24] S. Bräutigam, S. Bringer-Meyer, D. Weuster-Botz. Asymmetric whole cell biotransformations in biphasic ionic liquid/water-systems by use of recombinant Escherichia coli with intracellular cofactor regeneration. Tetrahedron: Asymmetry; (2007). 18:1883-7.

[25] M. H. Abraham, A. M. Zissimos, J. G. Huddleston, H. D. Willauer, R. D. Rogers and W. Acree. Some Novel Liquid Partitioning Systems: Water-Ionic Liquids and Aqueous Biphasic Systems Ind. Eng. Chem. Res., (2003). 42 (3), pp 413-418.

[26] F. Garcia-Ochoa, E. Gomez. Bioreactor scale-up and oxygen transfer rate in microbial processes: an overview. Biotechnol. Adv. (2009)27, 153-176.

[27] M. Martín, F. J. Montes, M. A. Galán. Mass transfer rates from bubbles in stirred tanks operating with viscous fluids. Chemical Engineering Science. (2010). 65:3814-3824.

[28] Melgarejo-Torres, R., Castillo-Araiza C. O., Abhishek-Dutta, Guido-Bény ${ }^{3}$, TorresMartinez D., Lye G. J., Gutiérrez-Rojas M., Huerta-Ochoa S. Mathematical model of a three phase partitioning bioreactor for conversion of ketones using whole cells. Chemical Engineering Journal . (submitted, 2014).

[29] R. Melgarejo-Torres, C. O. Castillo-Araiza, P. López-Ordaz, D. Torres-Martínez, M. Gutiérrez-Rojas, G. J. Lye, S. Huerta-Ochoa. Kinetic mathematical model for ketone bioconversion using Escherichia coli TOP10 pQR239. Chemical Engineering Journal 240 (2014) 1-9.

[30] A. Bennet. Mechanism of oxidative inactivation of Acinetobacter sp. NCIMB 9871. cyclohexanone monooxygenase, J. Undergrad. Res., (2004). 6(1): 1-9. 


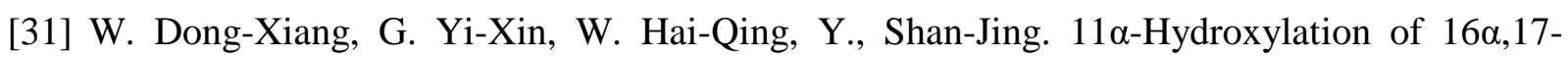
epoxyprogesterone by Rhizopus nigricans in a biphasic ionic liquid aqueous system. Bioresource Technology. (2011). Volume 102, Issue 20, Pages 9368-9373.

[32] E. Déziel, Y. Comeau, R. Villemur, Two-phase bioreactors for enhanced degradation of hydrophobic/toxic compounds. Biodegradation (10) (1999) 219-233

[33] W. Y. Lou, W. Wang, R. F. Li, M. H. Zong. Efficient enantioselective reduction of 40methoxyacetophenone with immobilized Rhodotorula sp. AS2.2241 cells in a hydrophilic ionic liquid-containing co-solvent system. J. Biotechnol. (2009a). 143, 190-197.

[34] V. Kumar and S. V. Malhotra. Antitumor Activity of Ionic Liquids on Human Tumor Cell Lines. Ionic Liquid Applications: Pharmaceuticals, Therapeutics, and Biotechnology. (2010). 91-102.

[35] B. Peric, J. Sierra, R. Cruañas, M. A. Garau, J. Arning, J. Bottin-Weber, S. Stolte. (Eco)toxicity and biodegradability of selected protic and aprotic ionic liquids. Journal of Hazardous Materials. (2013). 261. 99- 105.

[36] M. Petkovic, J. L. Ferguson, H. Q. Nimal Gunaratne, R. Ferreira, M.C. Leitao, K. R. Seddon, L. P. N. Rebelo, C. S. Pereira. Novel biocompatible cholinium-based ionic liquids toxicity and biodegradability. Green Chem. (2010). 12, 643-649.

[38] X. Y. Li,S. H. Zheng, X. Y. Dong, J. G. Ma, J. J. Wang. Acute toxicity and responses of antioxidant systems to 1-methyl-3-octylimidazolium bromide at different developmental stages of goldfish. Ecotoxicology. (2012). 21, 253-259.

[39] S. G. Cull, J. D. Holbrey,V. Vargas-Mora, K. R. Seddon, G. L. Lye. Room-temperature liquids as replacements for organic solvents in multiphase bioprocess operations. Biotechnnol Bioeng. (2000). 69:227-233.

[40] S. A. Gangu, L. R. Weatherley, A. M. Scurto. Whole cell biocatalysis with ionic liquids. Curr. Org. Chem. (2009). 13, 1242-1254. 


\section{CHAPTER III}

MASS TRANSFER COEFFICIENT DETERMINATION IN THREE BIPHASIC SYSTEMS (WATER-IONIC LIQUID) USING A MODIFIED LEWIS CELL

CHEMICAL ENGINEERING JOURNAL. (2012), 181702 - 707 


\title{
MASS TRANSFER COEFFICIENT DETERMINATION IN THREE BIPHASIC SYSTEMS (WATER-IONIC LIQUID) USING A MODIFIED LEWIS CELL
}

\author{
R. Melgarejo-Torres ${ }^{1}$, D. Torres-Martínez ${ }^{1}$, C.O. Castillo-Araiza ${ }^{2}$, C. Arriaga-Juárez ${ }^{1}$, M. Gutiérrez- \\ Rojas $^{1}$, P. Esponda-Aguilar ${ }^{1}$, G. Aroca ${ }^{3}$, G.J. Lye ${ }^{4}$, S. Huerta-Ochoa ${ }^{1}$ \\ ${ }^{1}$ Departamento de Biotecnología, Universidad Autónoma Metropolitana. \\ P.A. 55-535, 09340 Iztapalapa, México D.F., MÉXICO, e-mail:sho@ xanum.uam.mx \\ ${ }^{2}$ Grupo de Procesos de Transporte y Reacción en Sistemas Multifásicos. Dpto. De IPH, Universidad \\ Autónoma Metropolitana, México D.F., México. coca@xanum.uam.mx \\ ${ }^{3}$ Escuela de Ingeniería Bioquímica, Pontificia Universidad Católica de Valparaíso, CHILE \\ ${ }^{4}$ Department of Biochemical Engineering, University College London, London, WC1E 7JE, UNITED KINGDOM
}

\begin{abstract}
Baeyer-Villiger bioconversion productivity of the cyclic ketone ( \pm )-cis-bicyclo [3.2.0] hept-2-en-6-ona by the biocatalyst Escherichia coli TOP10 pQR239 in a multiphase system can be limited by mass transport. Mass transfer rates through the liquid-liquid interface depend on the volumetric mass transfer coefficient $(\mathrm{kA})$, the substrate and the product partition coefficients. In situ experimental determination of the volumetric mass transfer coefficient in a partitioning bioreactor is complex. In this work, the substrate $\left(\mathrm{ks}_{\mathrm{S}}\right)$ and product $(\mathrm{kP})$ global mass transfer coefficients were determined in a modified Lewis cell in three water-ionic liquids systems. The ionic liquids used were butylmethylpyrrolidinium bis (trifluoromethylsulfonyl)imide [MeBuPyrr][BTA], trioctylmethylammonium bis (trifluoromethylsulfonyl)imide [OMA][BTA] and 1-butyl-3-metyl-imidazolium hexafluorophosphate [BMIM][PF6]. The maximum ks and kP values obtained were: $4.35 \times 10^{-5}$ and $1.21 \times 10^{-5} \mathrm{~m} \mathrm{~s}^{-1}$ for water-[MeBuPyrr][BTA] system; $1.53 \times 10^{-5}$ and $7.84 \times 10^{-6} \mathrm{~m} \mathrm{~s}^{-1}$ for water-[OMA][BTA] system, respectively; and $\mathrm{kS}$ values up to $1.01 \times 10^{-5} \mathrm{~m} \mathrm{~s}^{-1}$ were found for the water-[BMIM][PF6] system. The association among the mass transfer coefficients and the physicochemical properties (interfacial tension, viscosity and density) and the thermodynamic (partition coefficients) were analysed and discussed. Finally, the volumetric mass transfer coefficients (kSA and $\mathrm{kPA}$ ) were calculated using interfacial areas (A) of the dispersed ionic liquid phase estimated from the "Sauter" mean drop diameter $\left(\mathrm{d}_{32}\right)$ in a one litre stirred tank partitioning bioreactor.
\end{abstract}

Key Words: Partitioning bioreactors; mass transfer coefficients; ionic liquids; Lewis cell. 


\section{INTRODUCTION}

Recent advances and future challenges for Baeyer-Villiger monooxygenases (BVMOs) were pointed out by Torres-Pazmiño et al. [1]. This review provides an overview on the recently gained knowledge on BVMOs and sketches the outlook for future industrial applications of these unique oxidative biocatalysts. Baldwin and Woodley [2] reported a Baeyer-Villiger whole cell bioconversion process using Escherichia coli TOP10 pQR239, which presents substrate (0.2-0.4 g L-1) and product (4.5-5.0 g L-1) inhibition. Different alternatives have been reported to overcome substrate and product inhibition, and BVMO's oxidation [3-5]. Ionic liquids can be used as a substrate reservoir and in situ product extracting agent in a partitioning bioreactor, replacing organic solvents and thereby increasing process efficiency [6]. Oppermann et al. [7] reviewed the use of ionic liquids for two-phase systems and their application for purification, extraction and biocatalysis. Recently, different applications of ionic liquids in two-phase systems for bioconversion processes have been reported [8-9]. However, Baeyer-Villiger bioconversion productivity in a multiphase system could be limited by low mass transfer rates across the interphases (gas-liquid and/or liquid-liquid). Substrate and product mass transfer rates through the liquid-liquid interfacial area depend on volumetric mass transfer coefficients. In situ experimental determination of volumetric mass transfer coefficients in a partitioning bioreactor is complex. Nevertheless, they can be obtained by studying transfer mechanisms of solutes through the liquidliquid interface [10] and determining global mass transfer coefficients using a constant interfacial area. Al-Dahham and Wicks [11] summarised Lewis cell modifications by several authors to determine mass transfer coefficients of solutes through the interface in different two phase systems [12-15]. However, reports on mass transfer coefficients determination in water-ionic liquids systems are scarce.

The aims of this work were to determine substrate and product global mass transfer coefficients in a three biphasic water-ionic liquid system using a modified Lewis cell and, on the other hand, to observe the effect of ionic liquid physicochemical properties on the resulting experimental global mass transfer coefficients. 


\section{MATERIAL AND METHODS}

\subsection{Chemicals}

Bicyclo[3.2.0]hept-2-en-6-ona and (-) 1(R),5(S)3-oxabicyclo[3.3.0]oct-6-en-2-ona (Fluka, Switzerland) were used as the substrate and product to be extracted, respectively. Ionic liquid phases used for mass transfer studies were: butylmethylpyrrolidinium

bis(trifluoromethylsulfonyl)imide $\quad$ [MeBuPyrr][BTA], trioctylmethylammonium bis(trifluoromethylsulfonyl)imide [OMA][BTA], and 1-butyl-3-metyl-imidazolium hexafluorophosphate $[\mathrm{BMIM}]\left[\mathrm{PF}_{6}\right]$. All had a purity of $>98 \%$ and were purchased from Solvent Innovation GmbH (Köln, Germany). These ionic liquid were chosen based on their microorganism compatibility and different physicochemical properties (Table 1) previously reported [16]. The aqueous phase used in all experiments was previously saturated with the studied ionic liquid.

Table 1. Physicochemical properties of the ionic liquids used reported by Torres-Martínez et al. [16].

\begin{tabular}{|c|c|c|c|c|c|c|}
\hline \multirow[b]{2}{*}{ Ionic liquids } & \multirow[b]{2}{*}{$\begin{array}{l}\text { Interfacial } \\
\text { tension, } \sigma \\
\left(\mathrm{kg} \mathrm{s}^{-2}\right)\end{array}$} & \multirow[b]{2}{*}{$\begin{array}{c}\text { Dynamic } \\
\text { viscosity, } \mu \\
\left(\mathrm{kg} \mathrm{m}^{-1} \mathrm{~s}^{-1}\right)\end{array}$} & \multirow[b]{2}{*}{$\begin{array}{l}\text { Density, } \rho \\
\left(\mathrm{kg} \mathrm{m}^{-3}\right)\end{array}$} & \multirow[b]{2}{*}{$\begin{array}{l}\text { Maximum } \\
\text { solubility } \\
\left(\mathrm{g} \mathrm{L}^{-1}\right)\end{array}$} & \multicolumn{2}{|c|}{ Partition coefficients } \\
\hline & & & & & Substrate & Product \\
\hline$[\mathrm{BMIM}]\left[\mathrm{PF}_{6}\right]$ & 0.0075 & 0.03 & 1190 & 18.6 & 27.8 & 13.0 \\
\hline [MeBuPyrr][BTA] & 0.0114 & 0.04 & 1389 & 5.4 & 25.8 & 13.3 \\
\hline [OMA][BTA] & 0.0197 & 0.30 & 1101 & 0.02 & 25.5 & 6.5 \\
\hline
\end{tabular}

\subsection{Lewis cell}

A modified Lewis cell was used (Figure 1), consisting of a jacketed glass vessel $11.8 \mathrm{~cm}$ high and with an internal diameter of $6.7 \mathrm{~cm}$. Each phase had a volume of $182 \mathrm{~mL}$. Two independent marine propellers $\left(\mathrm{d}_{\mathrm{i}}=3.5 \mathrm{~cm}\right)$, each one located inside a suction glass tube (internal diameter $4 \mathrm{~cm}$ and height $3.5 \mathrm{~cm}$ ) supported by six baffles producing a radial and tangential flow motion to a constant interfacial area (aCell) of $18.5 \mathrm{~m}^{2} \mathrm{~m}^{-3}$. Temperature of both liquids inside the Lewis cell was kept at $30{ }^{\circ} \mathrm{C}$ by passing water through the cell's jacket from a water bath. Different agitation rates $(65-205 \mathrm{rpm})$ in each phase were settled, allowing different liquid velocities $\left(V_{S}\right)$ in each phase near the interface. To determine $\mathrm{V}_{\mathrm{S}}$, small bead particles were made from silicon and epoxy resin with the same fluid density. Time required for the small bead to go around the internal tube at different agitation rates in each phase was measured and an arithmetic average was obtained, and this value was used to calculated fluid velocity [17]. Then, global mass transfer coefficients could be estimated at liquid velocity values close to those obtained in a dispersion system. 


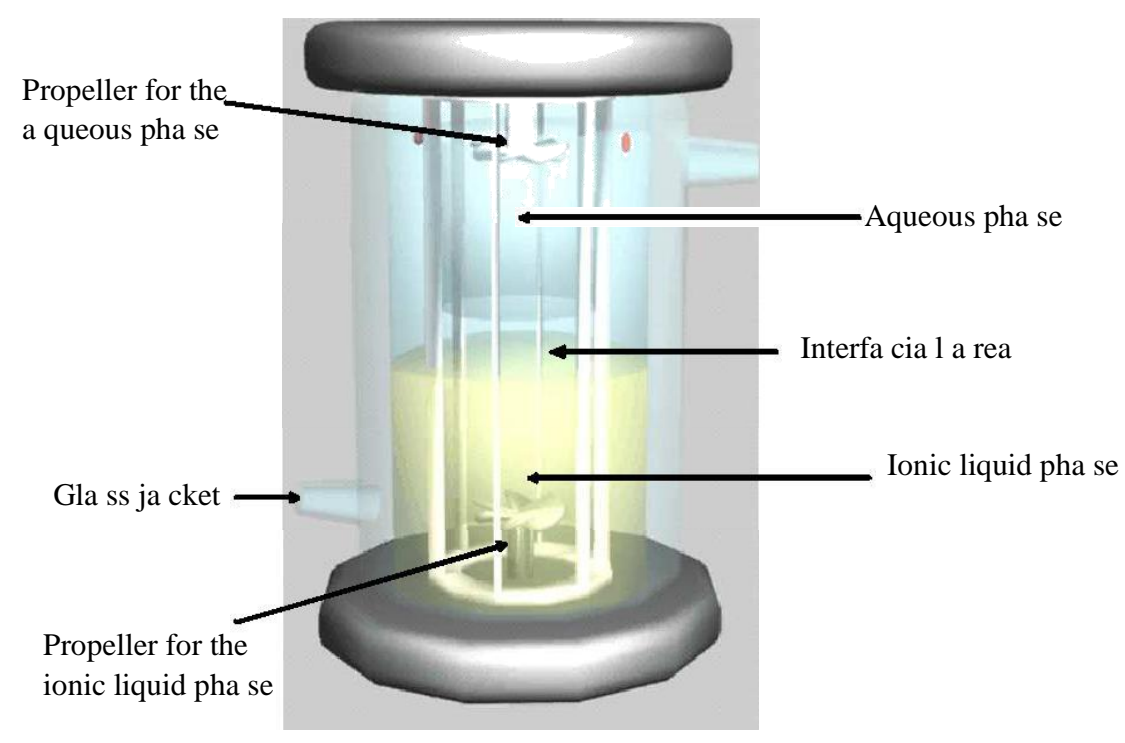

Figure 1. Modified Lewis cell used to estimate global mass transfer coefficients through the interface between two liquid phases.

\subsection{Experiments in the Lewis cell}

For experiments in the modified Lewis cell using [MeBuPyrr][BTA], agitation rates for aqueous and ionic liquid phases were established from a central composite experimental design with two independent factors (agitation in each phase), each one at three levels of operation (65, 100 and 205 $\mathrm{rpm}$ for the aqueous phase and 0,165 and $205 \mathrm{rpm}$ for the ionic liquid phase) requiring 11 experiments. For Response Surface Methodology (RSM) experiments, the "Fusion Pro" experiment design software (Version 6.7.0, USA) was used for regression and graphical analysis of the experimental results. In the experiments using [OMA][BTA] and [BMIM][PF6], only the aqueous phase was agitated. Aqueous phase agitation rates were 80,110, 140, 170 and $200 \mathrm{rpm}$ for the water-[OMA][BTA] system, and 115, 150 and $200 \mathrm{rpm}$ for the water-[BMIM][PF6] system. For each experiment, a pulse of $2.0 \mathrm{~mL}$ of solution containing substrate and product were added to the aqueous phase. Samples of $1.0 \mathrm{~mL}$ were taken from the aqueous phase at different time intervals from $t=0$ to 35 minutes; this time was necessary to reach equilibrium. The samples were analysed by gas chromatography (GC) and a standard curve was used to determine substrate and product concentration in the aqueous phase. Substrate and product concentrations in the ionic liquid phase were calculated from mass balance.

\subsection{Analysis}

Gas chromatography (GC) was used to quantify the concentrations of the substrate and the product in the aqueous phase. Samples of $1 \mu \mathrm{L}$ were injected into XL gas chromatograph (Perkin Elmer, Norwalk, CT) fitted with a CYCLOSILB 113-6632 capillary column (30 m x $530 \mu \mathrm{m})(\mathrm{J} \& \mathrm{~W}$ Scientific), and concentrations were determined using an external calibration curve 
(Figure 2). The GC injector temperature was set at $250^{\circ} \mathrm{C}$. The GC temperature program used was as follows: the initial oven temperature was $100^{\circ} \mathrm{C}$, held for $1 \mathrm{~min}$ and followed by a temperature increase at $10^{\circ} \mathrm{C} \mathrm{min}{ }^{-1}$ up to $150^{\circ} \mathrm{C}$, which was then held for 3 min. Retention times were $3.7 \mathrm{~min}$ and $3.95 \mathrm{~min}$ for the substrate (mixture of ketone isomers) and $8.5 \mathrm{~min}$ for the product.

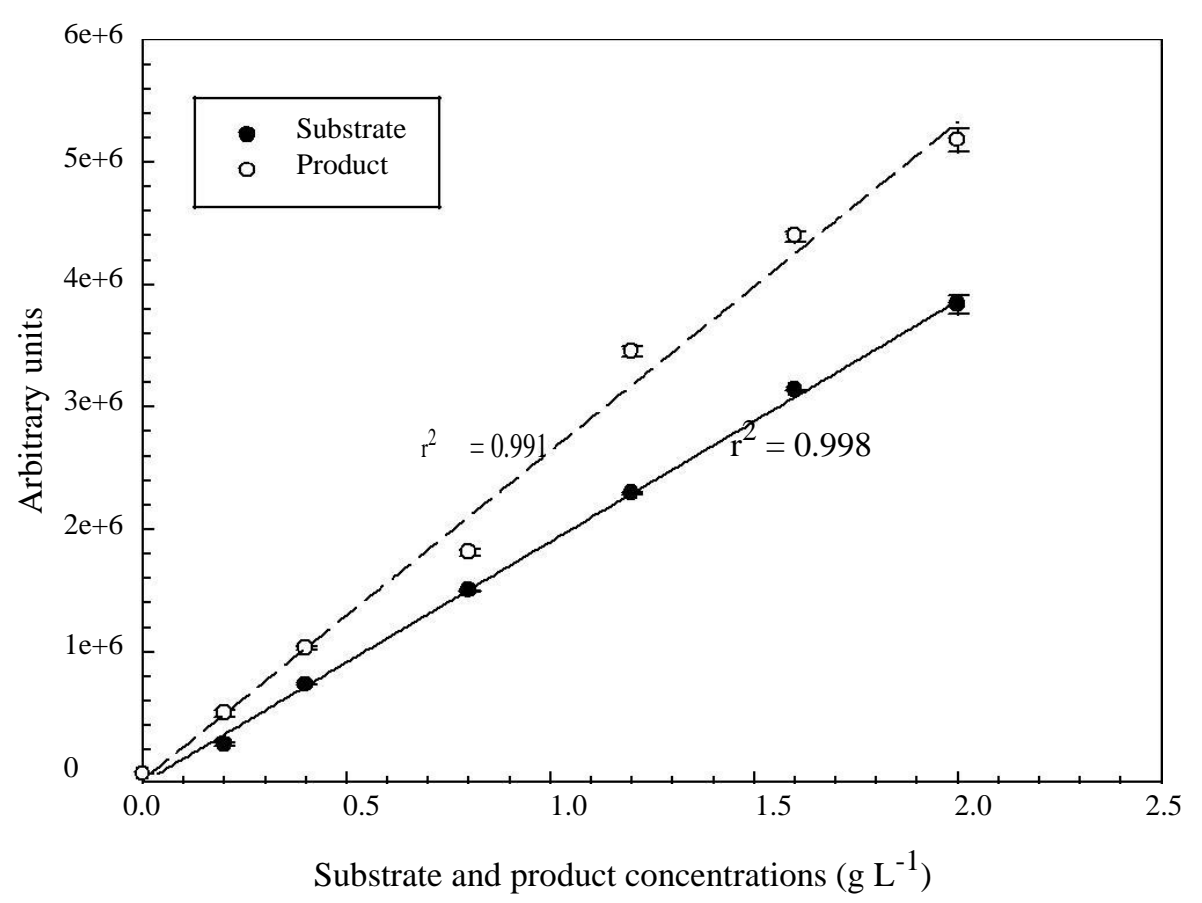

Figure 2. Standard curve for substrate $(\bullet)$ and product $(\circ)$ concentration measured by gas chromatography.

Lines for substrate (-) and product (---) are obtained by linear regression.

\subsection{Estimation of mass transfer coefficients}

Solute transfer rate through the interface water-ionic liquid can be expressed in a general form by the equation (1):

dS

$$
\frac{\mathrm{d}}{\mathrm{dt}}=-\mathrm{ka} \text { Cell }\left(\mathrm{S}-\mathrm{S}_{\mathrm{f}}\right)
$$

where: $\mathrm{dS} / \mathrm{dt}$ is the mass transfer rate in the interface, $\mathrm{k}$ is the global mass transfer coefficient, aCell is the interfacial area, $\mathrm{S}$ is the substrate or product concentration in the bulk aqueous phase, and $\mathrm{S}_{\mathrm{f}}$ is the solute equilibrium concentration in the aqueous phase. Solving equation (1) at $\mathrm{t}=0 \mathrm{~S}=\mathrm{S}_{0}$ and at $\mathrm{t}=\mathrm{t} \mathrm{S}=\mathrm{S}$ :

$$
\ln \frac{\left(S-S_{f}\right)}{\left(S_{0}-S_{f}\right)}=- \text { kacell } t
$$

The concentration $\mathrm{S}_{\mathrm{f}}$ can be expressed as a function of the initial solute concentration, $\mathrm{S}_{0}$, and its partition coefficient, $\mathrm{M}$ : 


$$
\mathrm{S}_{\mathrm{f}}=\frac{\mathrm{S}_{0}}{\mathrm{M}+1}
$$

Taking into account the design of the Lewis cell, near the interface both liquids flow parallel to the interfacial area, so we defined the characteristic length (L) as the cell diameter. Then the Reynolds number of liquids flowing near the interface can be expressed as:

$$
\mathrm{N}_{\mathrm{Re}}=\frac{\rho L V_{S}}{\mu}
$$

where: $\rho$ and $\mu$ are the density and dynamic viscosity of the liquid, respectively; $\mathrm{L}$ is the characteristic length, and $V_{S}$ is the fluid velocity near the interface.

\section{RESULTS AND DISCUSSION}

\subsection{Substrate and product global mass transfer coefficients obtained in the Lewis cell}

The substrate and product global mass transfer coefficients ( $\mathrm{kS}_{\mathrm{S}}$ and $\mathrm{kP}$, respectively) were estimated from the resulting slopes, early defined in (Eq. (2)), of the logarithmic profile of solute concentration against removal time divided by mass transfer area $\left(18.5 \mathrm{~m}^{2} \mathrm{~m}^{-3}\right)$ of the Lewis cell. The $\mathrm{kS}_{\mathrm{S}}$ and kP plotted against the Reynolds numbers $\left(\mathrm{N}_{\mathrm{Re}}\right)$ of each phase in the water-[MeBuPyrr][BTA] system are shown in Figure 3. Global mass transfer coefficients are influenced by hydrodynamics near the interface. It can be seen in Figure $3 \mathrm{~A}$ that the increase in the $\mathrm{N}_{\mathrm{Re}}$ of both phases increased the $\mathrm{ks}_{\mathrm{S}}$ value. The increment of the inertial forces decreased the thickness of the boundary layers of the liquids, probably diminishing resistance to the mass transport. A Pareto's analysis of the data showed that the agitation rate in the aqueous phase was the factor of greatest influence on the value of $\mathrm{kS}_{\mathrm{S}}(\mathrm{p}<0.05)$. It can also be seen in Figure 3B that the highest values of $\mathrm{kP}$ were obtained with the higher $\mathrm{N}_{\mathrm{Re}}$ in both phases. In this case, the Pareto's analysis showed that the two variables with most significant effect on the $\mathrm{kP}$ were the agitation rate in the ionic liquid phase and the simultaneous agitation rate of both phases $(\mathrm{p}$

$<0.05$ ). Maximum $\mathrm{kS}$ and $\mathrm{kP}$ values of $4.35 \times 10^{-5}$ and $1.20 \times 10^{-5} \mathrm{~m} \mathrm{~s}^{-1}$, respectively, were obtained. 

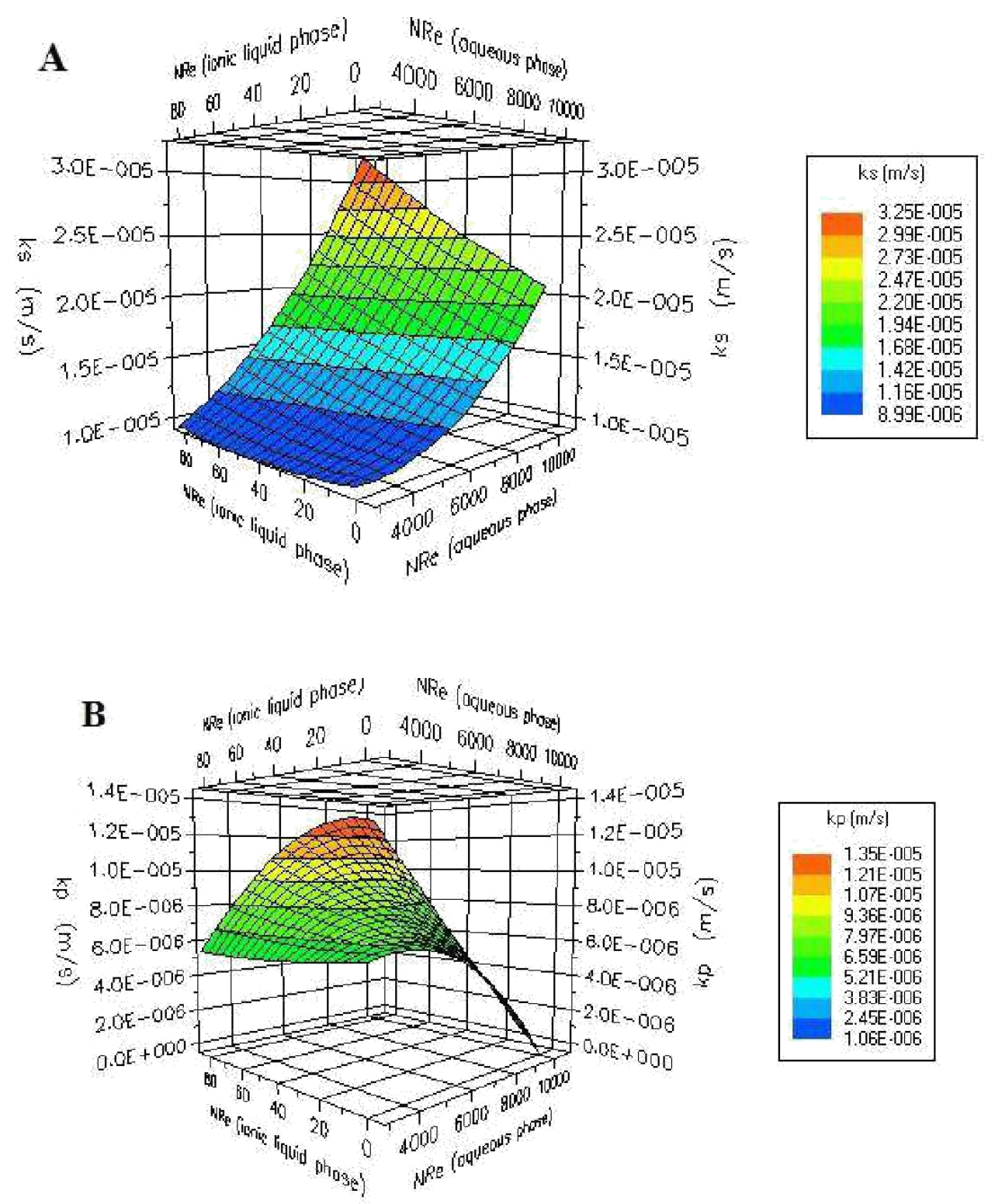

Figure 3. Global mass transfer coefficients versus Reynolds numbers $\left(\mathrm{N}_{\mathrm{Re}}\right)$ of both phases in the interface for water-[MeBuPyrr][BTA] system: A) substrate, ks; and B) product, kP.

In the water-[OMA] [BTA] system, it was not possible to stir the ionic liquid phase because of the disturbance of the interfacial area due to its high viscosity $\left(0.3 \mathrm{~kg} \mathrm{~m}^{-1} \mathrm{~s}^{-1}\right)$. In this case, $\mathrm{kS}$ and $\mathrm{kP}$ were reported as a function of the $\mathrm{N}_{\mathrm{Re}}$ of the aqueous phase (Figure 4). Variations in the $\mathrm{k}_{\mathrm{S}}$ values in the range tested did not let us to observe a tendency with respect to $\mathrm{N}_{\mathrm{Re}}$ of the aqueous phase where the maximum $\mathrm{kS}$ value $\left(1.53 \times 10^{-5} \mathrm{~m} \mathrm{~s}^{-1}\right)$ was obtained at $200 \mathrm{rpm}$. Different performance was observed for the water-[BMIM][PF 6$]$ system where $\mathrm{k}_{\mathrm{S}}$ values showed a direct linear relationship to $\mathrm{N}_{\mathrm{Re}}$ of the aqueous phase (Figure 5). ks values increased almost 10 fold up to $1.01 \times 10^{-5} \mathrm{~m} \mathrm{~s}^{-1}$ when the $\mathrm{N}_{\mathrm{Re}}$ increased from 4300 to 6800 . On the other hand, in the water-[OMA] [BTA] system the maximum $\mathrm{k}_{\mathrm{P}}$ 
value $\left(7.84 \times 10^{-6} \mathrm{~m} \mathrm{~s}^{-1}\right)$ was 1.95 times lower than that obtained for ks. Similar results were observed in the water-[MeBuPyrr][BTA] system (3.62 times lower).

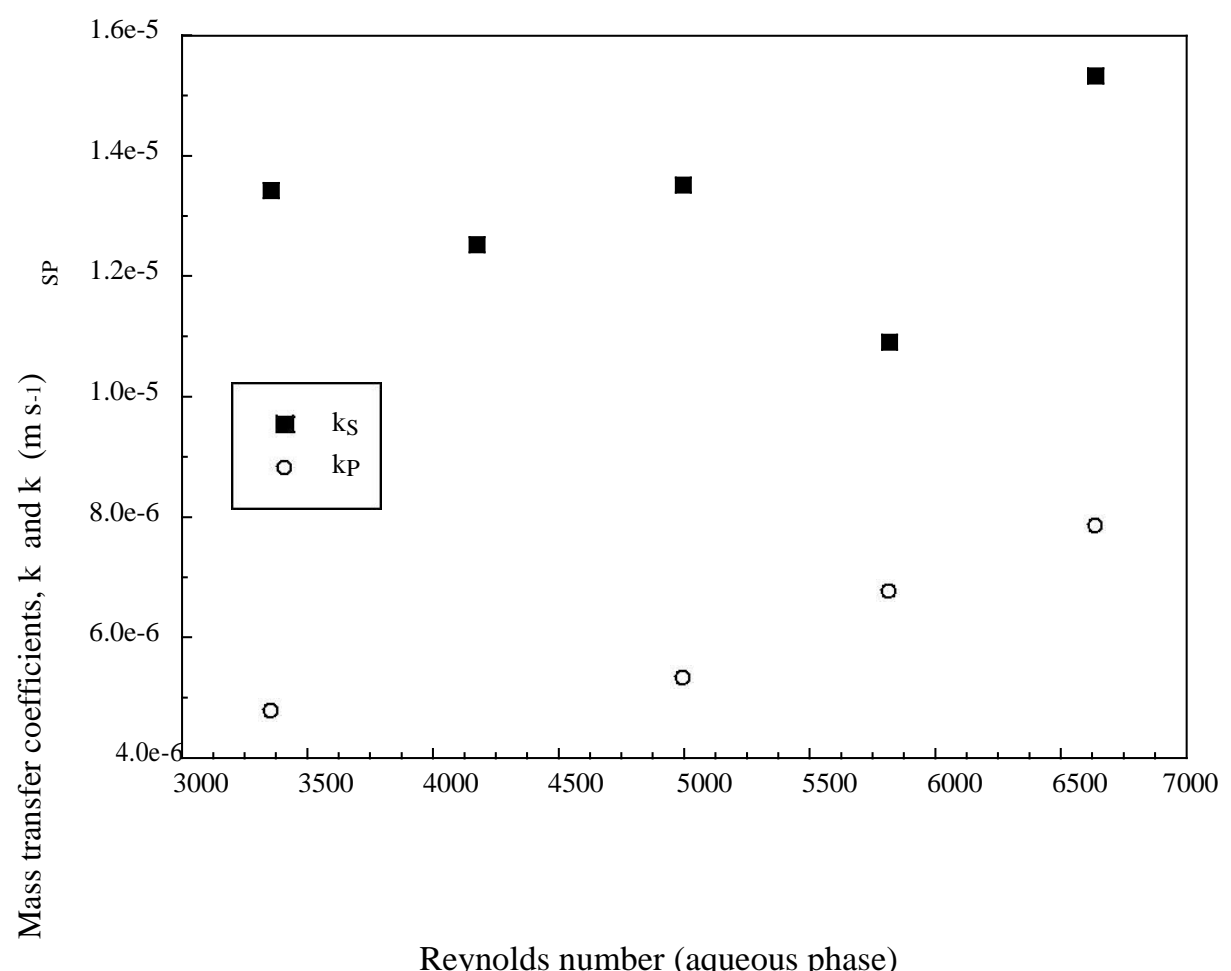

Figure 4. Global mass transfer coefficients versus Reynolds number $\left(\mathrm{N}_{\mathrm{Re}}\right)$ of the aqueous phase for the water[OMA][BTA] system: (ם) substrate, ks; and (o) product, kP.

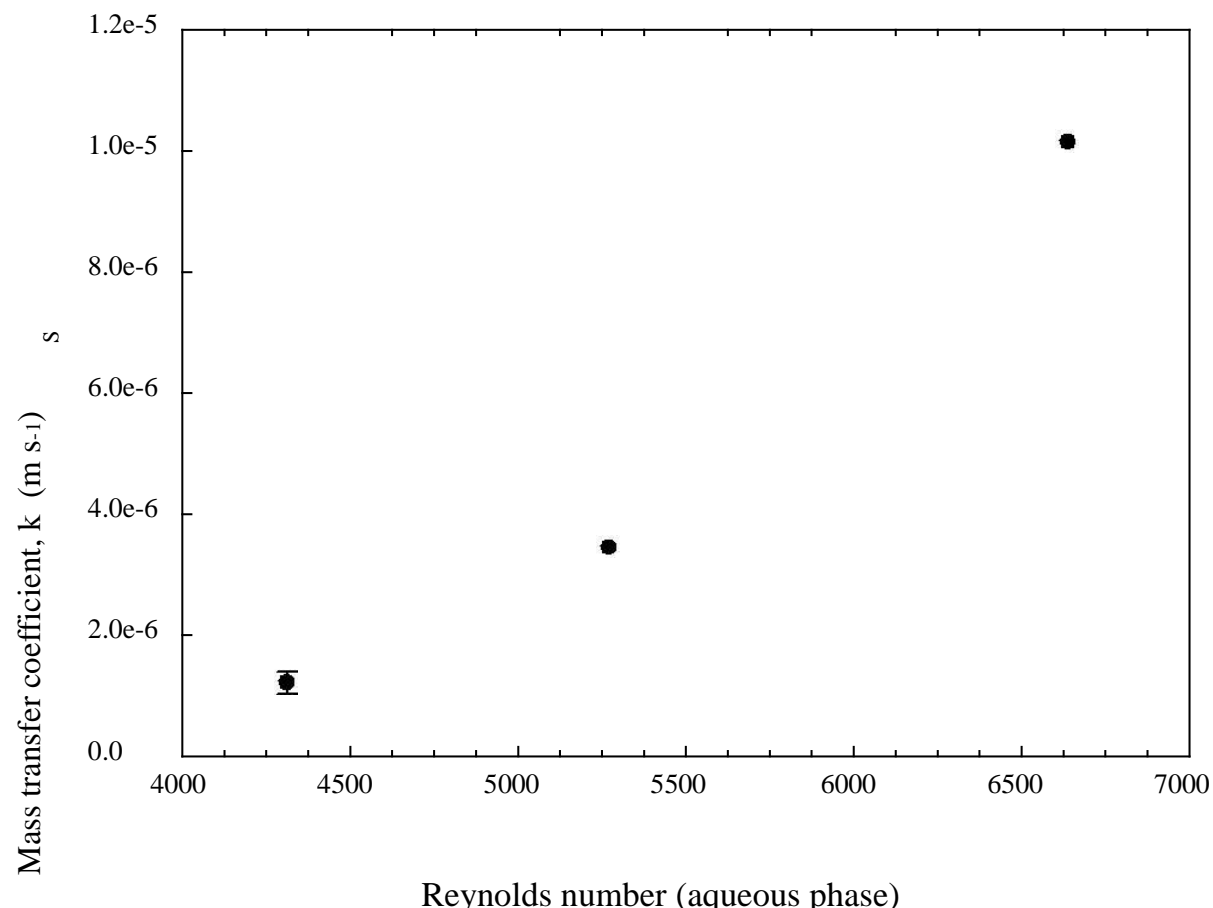

Figure 5. Substrate global mass transfer coefficients $\left(\mathrm{kS}_{\mathrm{S}}\right)$ versus Reynolds numbers $\left(\mathrm{N}_{\mathrm{Re}}\right)$ of the aqueous phase for water-[BMIM] $\left[\mathrm{PF}_{6}\right]$ system. 
In both the [MeBuPyrr][BTA] and [OMA][BTA] systems, kP values were less than those for ks, probably due to the different physicochemical properties of the substrate and the product, such as the partition and diffusivity coefficients. It was noted that the size of the solute molecules and liquid viscosity were inversely proportional to the diffusivity coefficient. Molecular diffusivities for the substrate and the product $\left(7.89 \times 10^{-6}\right.$ and $7.43 \times 10^{-6} \mathrm{~cm} \mathrm{~s}^{-1}$, respectively) in the aqueous phase were estimated using Wilke-Chang correlations [18]. On the other hand, analysing the variables that influence mass transfer during liquid-liquid extraction through dimensional analysis [19] showed the effect of density and viscosity of the ionic liquid phase on mass transfer coefficients. Mass transfer coefficients obtained in this work were on the same order of magnitude as those reported in similar Lewis cells. For example, Woodley et al. [12] obtained k values of $11.1 \times 10^{-6}$ $21.9 \times 10^{-6} \mathrm{~m} \mathrm{~s}^{-1}$ for benzyl acetate transferred from its own organic phase to an aqueous phase composed of phosphate buffer. The agitation rates in both phases were 260 to $604 \mathrm{rpm}$. Srivastava et al. [14] reported $\mathrm{k}$ values of $11 \times 10^{-6}$ and $12 \times 10^{-6} \mathrm{~m} \mathrm{~s}^{-1}$ for a limonene/water/heptanoic acid system, where heptanoic acid was the molecule transferred from the aqueous phase to the organic phase (limonene). Both studies noted that by increasing the agitation rate in both phases, the thickness of the boundary layer of the interface is reduced, leading to an increase of the mass transfer coefficient.

Global mass transfer coefficients are not only influenced by hydrodynamics near the interface, but also by the thermodynamics. Global mass transfer coefficients values in relation to the physicochemical properties of ionic liquids (interfacial tension, viscosity, density) and the partition coefficients of the compounds extracted (Table 1) were analysed. The ks values for the three water-ionic liquid systems at higher aqueous phase agitation (200-205 rpm) and non-agitation of the ionic liquid phase are presented in Table 2. It was observed that the viscosity of the ionic liquids showed a direct linear relationship to ks. The increment of mass transfer coefficients due to the increment in viscosity of the organic phase (tri-n-butyl phosphate) has also been reported by Bandyopadhyay et al. [20] for the extraction of tellurium (IV) using a biphasic system. Interfacial tension also showed a direct linear relationship to $\mathrm{k}_{\mathrm{S}}$. However, the influence of interfacial tension has mainly been related to droplet breakage and coalescence mechanisms [21] rather than mass transfer resistance. In contrast, the partition coefficients showed an inverse linear relationship to $\mathrm{kS}_{\mathrm{S}}$, probably due to the highest mass transfer resistance located in the phase with the lower equilibrium solute concentration (the aqueous phase in these systems) [15]. No relationship between the density of ionic liquids and $\mathrm{k}_{\mathrm{S}}$ values was observed. The 
maximum ks values were obtained with the water-[OMA][BTA] system, which has a higher viscosity and interfacial tension. On the other hand, ks values were lower for the water$[\mathrm{BMIM}]\left[\mathrm{PF}_{6}\right]$ system, which has a viscosity 10 times lower than that of [OMA][BTA], and the lowest interfacial tension value of the others two biphasic systems. Despite this, there was a significant difference in the product partition coefficient values between the water-[OMA][BTA] and $[\mathrm{MeBuPyrr}][\mathrm{BTA}]$ systems; it was also observed that the kP values were higher in the water[OMA][BTA] system than in the [MeBuPyrr][BTA] system. These results could also be influenced by the maximum solubility differences of the three ionic liquids tested (Table 1). More molecules of the ionic liquid dissolved in the aqueous phase probably influence molecular diffusivity through the aqueous phase boundary layer; therefore, mass transfer is reduced. Recently, it has been reported the study of a biphasic system using the ionic liquid [HMIM][Tf $2 \mathrm{~N}]$ and 1-Octene, which are partially soluble. The authors claimed that concentration influenced phase equilibrium, and interfacial physical properties [22,23]. Besides, interfacial tension values of the biphasic system are much lower than the surface tension of pure ionic liquids [24]. Therefore, these results show an important influence of the physicochemical properties of the ionic liquid phase on mass transfer.

Table 2. Higher global mass transfer coefficients of ionic liquids used (agitation in aqueous phase, 200-205 rpm, and non-agitation in the ionic liquid phase).

\begin{tabular}{lcc}
\hline \multirow{2}{*}{ Ionic liquids } & \multicolumn{2}{c}{ Global mass transfer coefficients } \\
\cline { 2 - 3 } & $\begin{array}{c}\text { Substrate } \\
\mathrm{ks} \mathrm{x} 10^{5}\left(\mathrm{~m} \mathrm{~s}^{-1}\right)\end{array}$ & $\begin{array}{c}\text { Product } \\
\mathrm{kP} \mathrm{x} 10^{6}\left(\mathrm{~m} \mathrm{~s}^{-1}\right)\end{array}$ \\
\hline$[\mathrm{BMIM}][\mathrm{PF} 6]$ & 1.01 & -- \\
{$[\mathrm{MeBuPyrr}][\mathrm{BTA}]$} & 1.25 & 5.32 \\
{$[\mathrm{OMA}][\mathrm{BTA}]$} & 1.53 & 7.84 \\
\hline
\end{tabular}

In order to highlight the methodology used to estimate the global mass transfer coefficients, liquid velocities near the interface can be compared to those obtained from computational fluid dynamic (CFD) simulations (unpublished results) in a baffled one litre bioreactor at $1000 \mathrm{rpm}$, using the [MeBuPyrr][BTA] ionic liquid as the dispersed phase. The highest experimental aqueous phase velocities (2.29-14.4 $\left.\mathrm{cm} \mathrm{s}^{-1}\right)$ and ionic liquid velocities (1.0-3.5 $\mathrm{cm} \mathrm{s}^{-1}$ ) were close to the velocity values of the continuous aqueous phase $\left(1.74 \mathrm{~cm} \mathrm{~s}^{-1}\right)$ and the dispersed ionic liquid phase $\left(2.28 \mathrm{~cm} \mathrm{~s}^{-1}\right)$ preliminary obtained in our laboratory using CFD simulations. 3.2 Volumetric mass transfer coefficients in a stirred tank partitioning bioreactor 
The lower values $\mathrm{k}_{\mathrm{S}}$ and $\mathrm{k}_{\mathrm{P}}$ measured in the modified Lewis cell in both biphasic systems were multiplied by the mass transfer volumetric areas (A) of the dispersed ionic liquid phases obtained under different operation conditions (ionic liquid fraction, agitation and aeration rates) in a stirred tank partitioning bioreactor, as reported by Torres-Martínez et al.

[16]. This allows for obtaining volumetric mass transfer coefficients for the substrate and the product ( $\mathrm{k}_{\mathrm{S}} \mathrm{A}$ and $\mathrm{kPA}_{\mathrm{P}}$ ), which could occur in this type of bioreactor. The obtained range values were: $\mathrm{k}_{\mathrm{S}} \mathrm{A}$ (162 to $2470 \mathrm{~h}^{-1}$ ) and $\mathrm{kPA}_{\mathrm{PA}}\left(80\right.$ to $\left.500 \mathrm{~h}^{-1}\right)$ in the water-[MeBuPyrr][BTA] system; $\mathrm{k}_{\mathrm{S}} \mathrm{A}\left(7.5\right.$ to $36 \mathrm{~h}^{-1}$ ) and $\mathrm{K}_{\mathrm{PA}}\left(2.8\right.$ to $\left.12 \mathrm{~h}^{-1}\right)$ for the water-[OMA][BTA] system; and $\mathrm{k}_{\mathrm{S}} \mathrm{A}\left(142.6 \mathrm{~h}^{-1}\right)$ in the water-[BMIM][PF 6$]$ system. Melgarejo-Torres et al. [25] reported a regime analysis of a Baeyer-Villiger bioconversion in a three-phase stirred tank partitioning bioreactor using [MeBuPyrr][BTA] as dispersed phase. The authors found that the characteristic time for substrate transfer $\left(1 / \mathrm{k}_{S} \mathrm{~A}\right)$ was between 2 and $22 \mathrm{~s}^{-1}$. Using global mass transfer coefficients for [OMA][BTA] obtained in this work the characteristic time

for substrate transfer increased up to 100 and $480 \mathrm{~s}^{-1}$, respectively. This association between the kS and kP with the drop area of the dispersed ionic liquid phase (A), in a three phase partitioning bioreactor, will make it possible to establish if the mass transfer rate is equal to or greater than the substrate consumption rate and product formation in a BaeyerVilliger bioconversion [25].

\section{CONCLUSIONS}

Experimental substrate and product global mass transfer coefficients values were affected by the hydrodynamics near the interface, as well as the physicochemical properties of the ionic liquid phase (interfacial tension and viscosity) and thermodynamics (partition coefficient). Determination of experimental mass transfer coefficients by approaching aqueous and ionic liquid velocities near the interface in the Lewis cell to those estimated in a stirred tank partitioning bioreactor seems suitable. The volumetric mass transfer coefficients ( $\mathrm{kSA}$ and $\mathrm{kPA}$ ) can be calculated with the coefficients (ks and kP) obtained using the Lewis cell and the interfacial areas (A) of the dispersed ionic liquid phase estimated from the Sauter mean drop diameter (d32) in a one litre stirred tank partitioning bioreactor. Such kSA and kPA experimental values will allow us to compare mass transfer rates and product formation or substrate consumption rates in bioconversion processes.

\section{NOMENCLATURE}

A Liquid-liquid interfacial area available for mass transfer in the bioreactor $\left(\mathrm{m}^{2} \mathrm{~m}^{-3}\right)$ 
Interfacial area of the Lewis Cell $\left(\mathrm{m}^{2} \mathrm{~m}^{-3}\right)$

acell $\quad \mathrm{k} \quad$ Substrate or product mass transfer coefficient $\left(\mathrm{m} \mathrm{s}^{-1}\right)$

Substrate or product volumetric mass transfer coefficient in the bioreactor $\left(\mathrm{h}^{-1}\right)$

Product mass transfer coefficient in the Lewis cell $\left(\mathrm{m} \mathrm{s}^{-1}\right)$

kA Product volumetric mass transfer coefficient in the bioreactor $\left(\mathrm{h}^{-1}\right)$

$\mathrm{kP} \quad$ Substrate mass transfer coefficient in the Lewis cell $\left(\mathrm{m} \mathrm{s}^{-1}\right)$

Substrate volumetric mass transfer coefficient in the bioreactor $\left(\mathrm{h}^{-1}\right)$

kPA L Characteristic length, diameter of the interfacial area $(m)$

ks MSubstrate or product partition coefficient (Dimensionless)

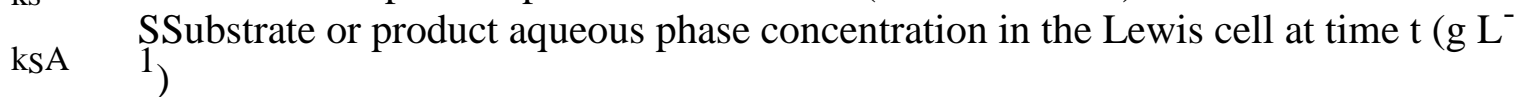

$\mathrm{S}_{0} \quad$ Substrate or product aqueous phase initial concentration in the Lewis cell $\left(\mathrm{g} \mathrm{L}^{-1}\right)$

Substrate or product aqueous phase equilibrium concentration in the Lewis cell

$\mathrm{S}_{\mathrm{f}} \quad\left(\mathrm{g} \mathrm{L}^{-1}\right)$

VS Fluid velocity near the interface $\left(\mathrm{m} \mathrm{s}^{-1}\right)$

Greek letters

$\varphi \quad$ Volume fraction of the dispersed phase $\left(\mathrm{L} \mathrm{L}^{-1}\right)$

$\rho \quad$ Density of the ionic liquid or aqueous phase $\left(\mathrm{kg} \mathrm{m}^{-3}\right)$

$\mu \quad$ Viscosity of the ionic liquid or aqueous phase $\left(\mathrm{kg} \mathrm{m}^{-1} \mathrm{~s}^{-1}\right)$

oInterfacial tension $\left(\mathrm{kg} \mathrm{s}^{-2}\right)$

\section{Acknowledgments}

We are grateful to the National Council of Science and Technology (Conacyt México) for financial support for project SEP-CONACyT-2007-80847.

\section{REFERENCES}

[1] D.E. Torres Pazmiño, H.M. Dudek, M.W. Fraaije, Baeyer-Villiger monooxygenases: recent advances and future challenges, Curr. Opin Chem. Biol. 14 (2010) 138-144.

[2] C. Baldwin, J. Woodley, On oxygen limitation in a whole cell biocatalytic BaeyerVilliger oxidation process, Biotechnol. Bioeng. 95 (2006) 362-369.

[3] H. Pfruender, R. Jones, V. Weuster-Botz, Water immiscible ionic liquids as solvents for whole cell biocatalysis, J. Biotechnol. 124 (2006) 182-190.

[4] K. Geitner, J. Rehdorf, Radka Snajdrova, Scale-up of Baeyer-Villiger monooxygenasecatalyzed synthesis of enantiopure compounds, Appl. Microbiol. Biotechnol. 88 (2010) 1087-1093. 
[5] M. Bǔcko, A. Schenkmayerova, P. Gemeiner, A. Vikartovská, M.D. Mihovilovič, I. Lacík, Continuous testing system for Baeyer-Villiger biooxidation using recombinant Escherichia coli expressing cyclohexanone monooxygenase encapsulated in polyelectrolyte complex capsules, Enzyme Microb. Tech. 49 (2011) 284-288.

[6] G. De Gonzalo G, C. Rodríguez, A. Rioz-Martínez, V. Gotor, Improvement of the biocatalytic properties of one phenylacetone monooxygenase mutant in hydrophilic

organic solvents, Enzyme Microb. Technol. doi:10.1016/j.enzmictec.2011.09.006

[7] S. Oppermann, F. Stein, U. Kragl, Ionic liquids for two-phase systems and their application for purification, extraction and biocatalysis, Appl. Microbiol. Biotechnol. 89 (2011) 493-499

[8] W. Dong-Xiang, G. Yi-Xin, W. Hai-Qing, Y. Shan-Jing, 11a-Hydroxylation of 16 $\alpha$,17epoxyprogesterone by Rhizopus nigricans in a biphasic ionic liquid aqueous system, Bioresource Technol. 102 (2011) 9368-9373.

[9] Y. Liu, D. Chen, Y. Yan, C. Peng, L. Xu, Biodiesel synthesis and conformation of lipase from Burkholderia cepacia in room temperature ionic liquids and organic solvents, Bioresource Technol. 102 (2011) 10414-10418.

[10] J. Lewis, The mechanism of mass transfer of solutes across liquid-/liquid interfaces, Chem. Eng. Sci. (1954) 248.

[11] M-H. Al-Dahan, C.E. Wicks, Modified contactor for experimental studies of mass transfer and chemical reaction across a liquid-liquid interface, Ind. Eng. Chem. Res. 35 (1996) 3812-3816.

[12] J.M. Woodley, A.J. Brazier, M.D. Lilly, Lewis cell studies to determine reactor design data for two-liquid-phase bacterial and enzymic reactions, Biotechnol. Bioeng. 37 (1991) 133-140.

[13] R.K. Biswas, M.A. Habib, M.R. Ali, M.Z. Haque, Kinetics of $\mathrm{Mn}^{2+}$ extraction in the acidic chloride D2EHPA-kerosene system using the constant Interfacial Area Stirred Cell Technique, Pak. J. Sci. Ind. Res. 41(3) (1998) 121-127.

[14] P. Srivastava, O. Hahr, R. Buchholz, M. Worden, Enhancement of mass transfer using colloidal liquid aphrons: measurement of mass transfer coefficients in liquid-liquid extraction, Biotechnol. Bioeng. 70(5) (2000) 525-532.

[15] G. Apreotesei, R. Tudose, H. Kadi, Mass transfer resistance in liquid-liquid extraction with individual phase mixing, Chem. Eng. Process. 42 (2003) 909-916. 
[16] D. Torres-Martínez, R. Melgarejo-Torres, M. Gutiérrez-Rojas, L. Aguilera-Vázquez, M. Micheletti, G.J. Lye, S. Huerta-Ochoa, Hydrodynamic and oxygen mass transfer studies in a three-phase (air-water-ionic liquid) stirred tank bioreactor, Biochem. Eng.

J. 45(3) (2009) 209-217.

[17] M.A. Lizardi-Jiménez, M. Gutiérrez-Rojas, Assessment of the local hydrodynamic zones in a three-phase airlift reactor: looking for the lowest liquid-phase Re, Rev. Mex. Ing. Quim. 10 (2011) 59-65.

[18] B. Bird, W. Stewart, E. Lightfoot, Fenómenos de transporte. $2^{\text {nd }}$ Ed. Limusa-Wiley. México (2010) 615-631.

[19] R.Z. Tudose, G. Lisa, The determination of individual mass transfer coefficients in liquid-liquid extraction, Chem. Ind., 57(9) (2003) 393-398.

[20] M. Bandyopadhyay, S. Datta, S.K. Sanya, Correlation of mass transfer coefficient for tellurium (IV) extraction with instantaneous reaction in modified Lewis cell, Hydrometallurgy, 42 (1996) 115-123.

[21] M. Jaradat, M. Attarakih, H.J. Bart, Effect of phase dispersion and mass transfer direction on steady state RDC performance using population balance modeling, Chem. Eng. J. 165 (2010) 379-387.

[22] A. Ahosseini, B. Sensenich, L.R. Weatherley, A.M. Scurto, Phase equilibrium, volumetric, and interfacial properties of the ionic liquid, 1-hexyl-3methylimidazolium bis(trifluoromethylsulfonyl)amide and 1-octene, J. Chem. Eng. Data. 55 (2010) 1611-1617.

[23] A. Ahosseini, L.R. Weatherley, A.M. Scurto, Viscosity and diffusivity for the ionic liquid 1hexyl-3-methylimidazolium Bis(trifluoromethylsulfonyl)amide with 1-octene,

J. Chem. Eng. Data. 56 (2011) 3715-3721.

[24] W. Jian-Ying, Z. Xiang-Jing, L. Yu-Min, H. Yong-Qi, Interfacial Tensions of imidazolium-based ionic liquids with $\mathrm{N}$-alkanes and cyclohexane, J. Chem. Eng. Data. 56 (2011) 3734-3737.

[25] R. Melgarejo-Torres, D. Torres-Martínez, M. Gutiérrez-Rojas, A. Gómez de Jesús, G.J. Lye, S. Huerta-Ochoa. 2011. Regime analysis of a Baeyer-Villiger bioconversion in a three-phase (air-water-ionic liquid) stirred tank bioreactor. Biochem. Eng. J. 5859 (2011) 87-95. 


\section{CHAPTER IV}

KINETIC MATHEMATICAL MODEL FOR KETONE BIOCONVERSION USING Escherichia coli TOP10 pQR239

CHEMICAL ENGINEERING JOURNAL 240 (2014) 1-9 


\title{
KINETIC MATHEMATICAL MODEL FOR KETONE BIOCONVERSION USING Escherichia coli TOP10 pQR239
}

Melgarejo-Torres, $\mathrm{R}^{1}$. Castillo-Araiza, $\mathrm{O}^{2}$. López-Ordaz, $\mathrm{P}^{1}$. Torres-Martínez, $\mathrm{D}^{4}$. Gutiérrez-Rojas, $\mathrm{M}^{1}$. G.J. Lye ${ }^{3}$, Huerta-Ochoa $\mathrm{S}^{1}$.

${ }^{1}$ Departamento de Biotecnología, Universidad Autónoma Metropolitana. P.A. 55-535, 09340 Iztapalapa,

México D.F., México. sho@xanum.uam.mx

${ }^{2}$ Grupo de Procesos de Transporte y Reacción en Sistemas Multifásicos. Dpto. De IPH, Universidad Autónoma Metropolitana, México D.F., México. coca@xanum.uam.mx

${ }^{3}$ Department of Biochemical Engineering, University College London, London WC1E 7JE, United Kingdom. g.lye@ucl.ac.uk

${ }^{4}$ Universidad Politécnica de Tlaxcala, San Pedro Xalcaltzinco Tepeyanco, Tlaxcala, México. danieltm99@hotmail.com

\begin{abstract}
The aim of the current work was to develop a pseudo intrinsic kinetic model based on elementary reactions for bicyclic ketone bioconversion to form lactone using cyclohexanone monooxygenase (CHMO) expressed in Escherichia coli TOP10 pQR239. In this model the reaction mechanism proposed followed the formalism of Langmuir-Hinshelwood and considered both substrate inhibition and oxygen inactivation by the formation of intermediary complexes. Therefore, approximations of the pseudo equilibrium of reaction rates or steady state intermediary species were not considered, which allowed for identifying the role of each reaction step involved in the bioconversion. This kinetic model adequately described the observations with and without substrate inhibition and/or oxygen inactivation. And the regression and the estimated parameters were statistically significant, making these analyses reliable regarding the kinetic behavior of CHMO. Then, substrate and oxygen affinity and inhibition constants were obtained from the kinetic parameters of the model. It was observed that oxygen and substrate presented similar affinity constant values. The substrate inhibition (KIS) and oxygen inactivation ( $\left.\mathrm{K}_{\mathrm{IO} 2}\right)$ constants were determined to be $9.98 \mu \mathrm{M}$ and $22.3 \mu \mathrm{M}$, respectively, showing that the CHMO enzyme was twice more sensitive to inhibition by an excess of substrate than oxygen. There are no reports of the oxygen inactivation constant in the literature. The proper studies of mass transport phenomena and kinetics are essential to describe, understand and find optimal conditions for the design and scale-up of this kind of bioconversion. Current work is evaluating a partitioning bioreactor to minimize the inhibitory effect of substrate.
\end{abstract}

Key words: Bioconversion; Cyclohexanone monooxygenase; Modelling; Kinetic parameters; Substrate inhibition; Escherichia coli 


\section{INTRODUCTION}

Lactones have wide applications in flavorings, as precursors of anticancer and antihypertension drugs and in the pharmaceutical industry [1]. Lactones have been obtained by whole cell Baeyer-Villiger bioconversions using cyclohexanone monooxygenase (CHMO) expressed in Escherichia coli TOP10 pQR239 [2]. The use of whole cells allows enzyme cofactor regeneration for the production of enantiomerically pure compounds [3]. However, it has been reported [4,5] that ketone bioconversion using CHMO is inhibited by the substrate and product at concentrations above 0.4 and $4 \mathrm{~g} \mathrm{~L}^{-1}$, respectively. Additionally, Bennet [6] reported that enzyme inactivation may occur due to residue oxidation of two serines close to the active site. A number of strategies have been proposed to avoid these types of inhibition, such as substrate feeding and in situ product removal using Lewatit resin [7], biocatalyzer encapsulation to prevent CHMO oxidation [8], the use of ionic liquids as an immiscible phase substrate reservoir and in situ product removal and maintaining the biocatalyzer (whole cells) in the aqueous phase [3], a stirred tank partitioning bioreactor using ionic liquids as the dispersed phase [9] and CHMO molecular structure changes to fold the serines susceptible to oxidation inside the enzyme [10].

Despite several experimental studies on the molecular structure of CHMO, its catalytic activity and reaction rates of the intermediate steps in the overall reaction in order to propose a basic bioconversion mechanism $[11,12,13]$, there have been few studies on kinetic modeling considering simultaneous substrate, product and oxygen inhibition phenomena. Some pseudo empirical kinetic models have been reported following Michaelis-Menten approach to describe product formation and substrate consumption in monooxygenase kinetics $[14,15,8]$. However, they do not take into account elementary reactions accounting for oxygen as a second substrate for bioconversion. The use of this kind of kinetic models reduces the number of required kinetic parameters; nevertheless, the estimated kinetic values depend on the catalyst concentration and become independent of the reactor size and its geometrical configuration, providing uncertainties for scaling-up ketone bioconversion. In this sense the development of a kinetic model based on an elementary reaction mechanism describing Baeyer-Villiger bioconversion will make it possible to describe, understand and find optimal conditions for carrying out this kind of bioconversion but mainly for design and scale-up. 
The objective of this work was to develop a pseudo-intrinsic kinetic model to describe the behavior of the bioconversion of ketones using whole cells. The mathematical model was based on an elementary reaction mechanism that followed the Langmuir-Hinshelwood formalism, considering inhibition and inactivation by the formation of substrate or oxygen enzyme complexes in the active site of the CHMO. The mathematical model was adjusted and kinetic parameters were estimated for three possible cases of the bioconversion of ketones: 1) without any inhibition, 2) inactivation by oxygen excess and 3) inhibition by substrate excess. The mathematical model was validated through the comparison of experimental data obtained for simultaneous substrate inhibition and oxygen inactivation versus calculated values using the estimated kinetic parameters. The kinetic parameters obtained yielded valuable information to determine which may be the limiting step in the bioconversion reaction.

\section{MATERIAL AND METHODS}

\subsection{Chemicals}

Bicyclic ketone bicycle[3.2.0]hept-2-to-6-one ( $\geq 98 \%)$ and bicyclic lactone (1S,5R)-(-)-2oxabiciclo[3.3.0]oct-6-en-3-ona ( $\geq 99$. 0\%)) (Fluka, Switzerland) were used as the substrate and product standards, respectively. Tryptone, yeast extract, $\mathrm{NaCl}$ and glycerol were purchased from Sigma Aldrich (EUA).

\subsection{Analysis}

Gas chromatography (GC) was used to quantify the concentrations of bicycle[3.2.0]hept-2-en6-one and its corresponding regioisomeric lactones. Samples $(5 \mu \mathrm{L})$ were injected into an XL gas chromatograph (Perkin Elmer, Norwalk, CT) fitted with a CYCLOSILB 113-6632 capillary column $(30 \mathrm{~m} \times 530 \mu \mathrm{m})(\mathrm{J} \& \mathrm{~W}$ Scientific), and concentrations were determined using an external calibration curve. The GC injector temperature was set at $250^{\circ} \mathrm{C}$. The GC temperature program used was as

\subsection{Microorganism}

The E. coli strain TOP10 pQR239 was kindly provided by Professor John M. Ward (University College London, London, United Kingdom) for research and academic purposes, and is referred to hereafter simply as E. coli. To prepare inocula for bioconversion experiments, E. coli cells were cultured in Erlenmeyer flasks of $250 \mathrm{~mL}$ containing $70 \mathrm{~mL}$ of a complex media

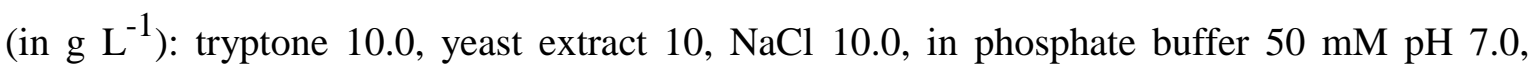
supplemented with $10 \mathrm{~g} \mathrm{~L}^{-1}$ glycerol. Culture 
media was sterilized in an autoclave at $120^{\circ} \mathrm{C}$ for $15 \mathrm{~min}$ and supplemented with $100 \mathrm{mg} \mathrm{L}-1$ ampicillin follows: the initial oven temperature was $100^{\circ} \mathrm{C}$, held for $1 \mathrm{~min}$ and followed by a temperature increase at $10^{\circ} \mathrm{C}$ min- 1 up to $150^{\circ} \mathrm{C}$, which was then held for $3 \mathrm{~min}$. Retention times were $3.7 \mathrm{~min}$ and $3.95 \mathrm{~min}$ for the substrate (mixture of ketone isomers) and $8.5 \mathrm{~min}$ for the product. (previously filter sterilized using a $0.25 \mu \mathrm{m}$ filter). Erlenmeyer flasks were incubated at $150 \mathrm{rpm}$ for $16 \mathrm{~h}$ at $37^{\circ} \mathrm{C}$. After this $16 \mathrm{~h}$ growth period, cyclohexanone monooxygenase expression was induced by adding the necessary amount of arabinose solution $\left(100 \mathrm{~g} \mathrm{~L}^{-1}\right)$ to reach a final concentration of $2 \mathrm{~g} \mathrm{~L}^{-1}$. After $3 \mathrm{~h}$ of induction, cells were harvested by centrifugation at $5,000 \mathrm{rpm}$ for $10 \mathrm{~min}$.

\subsection{Stirred tank bioreactor description}

A module with two glass $100 \mathrm{~mL}$ stirred tank bioreactors (MMBR100, UAM-I, Mexico) was used for all bioconversion studies. The jacketed bioreactors had an internal diameter of $4.75 \mathrm{~cm}$ and an operating volume of $70 \mathrm{~mL}\left(\mathrm{H}_{\mathrm{L}} / \mathrm{D}_{\mathrm{T}}=0.87\right)$. The bioreactors were fitted with a single, six flat blade Rushton turbine, $\mathrm{D}_{\mathrm{i}}=1.9 \mathrm{~cm}\left(\mathrm{D}_{\mathrm{i}} / \mathrm{D}_{\mathrm{T}}=0.40\right)$, located $1.9 \mathrm{~cm}$ from the flat base of the vessel. The bioreactor was equipped with four equidistant baffles, $0.5 \mathrm{~cm}$ in width, to enhance mixing.

\subsection{Oxygen mass transfer coefficient $\left(\mathrm{k}_{\mathrm{L}} \mathrm{a}\right)$ determination}

Optical fiber dissolved oxygen mini sensors (PreSens, GmbH Germany) were used for kLa determinations. The oxygen sensors were coupled to an OXY-4 mini four-channel oxygen meter (PreSens, GmbH Germany). Oxygen mass transfer coefficients (kLa) were calculated according to the dynamic method and mathematical model proposed by Fuchs et al. [17], which takes into account the electrode response time and the dimensionless dissolved oxygen concentrations in the bioreactor (Equation 1). The effect of operating conditions, including agitation $(750,1350$ and $1950 \mathrm{rpm})$ and aeration $(0.75,1.0$ and $1.4 \mathrm{vvm})$ rates on kLa was studied.

$$
Y_{P} \frac{K_{p} \cdot e^{-{ }^{k}{ }_{L} a t}-k_{L} a \cdot e^{-K_{p} t}}{K_{P}-k_{L} a}
$$

where $\mathrm{YP}_{\mathrm{P}}$ is the dimensionless dissolved oxygen concentrations in the bioreactor defined by Equation 2.

$$
\mathrm{Y}_{\mathrm{P}}=\frac{\mathrm{C}_{\mathrm{P}}^{*}-\mathrm{C}_{\mathrm{P}}}{\mathrm{C}_{\mathrm{P}}-\mathrm{C}_{\mathrm{P} 0}}
$$

where $\mathrm{CP}^{*}$ is the saturated oxygen concentration $\left(7.2 \mathrm{mg} \mathrm{L}^{-1}\right.$, which was determined with the OXY-4 module software using the atmospheric pressure of Mexico City, $1016.9 \mathrm{hPa}$ ), 
$\mathrm{CP}_{\mathrm{P}}$ is the dissolved oxygen concentration, $\mathrm{CP}_{\mathrm{P}}$ is the initial dissolved oxygen concentration the bioreactor. $\mathrm{KP}_{\mathrm{P}}$ is the electrode constant defined as the inverse of the response time, $\mathrm{kLa}_{\mathrm{L}}$ is the oxygen mass transfer coefficient, and $t$ is the time. Fitting was performed using a non-linear regression Levenberg-Marquardt algorithm in Polymath ${ }^{\mathrm{TM}}$.

\subsection{Aerated power consumption $\left(\mathrm{Pg}_{\mathrm{g}}\right)$ measurement}

Aerated power consumption $\left(\mathrm{Pg}_{\mathrm{g}}\right)$ was measured using the methodology recently discussed by Ascanio et al. [18]. Basically, the method is based on electrical measurements performed directly in the bioreactor stirrer shaft motor by watt meters and ammeters. To take into account losses occurring in the agitation system, a blank of the measurements was first performed with an empty bioreactor. All measurements were performed in triplicate.

\subsection{Bioconversion experiments}

Bioconversion experiments were carried out using $3.0 \mathrm{~g}$ of biomass $\mathrm{L}^{-1}$. A buffer solution consisting of $50 \mathrm{mM}$ phosphate $\mathrm{pH} 7.0$ supplemented with $10 \mathrm{~g}$ glycerol $\mathrm{L}^{-1}$ was used as the aqueous phase for the bioconversion media. A full face-centered central composite experimental design with three factors and eleven experiments was used. Three levels of each factor were studied: agitation rate $(750,1350$ and $1950 \mathrm{rpm})$, aeration rate $(0.75,1$ and $1.4 \mathrm{vvm})$ and substrate concentration $\left(0.35,0.80\right.$ and $\left.1.0 \mathrm{~g} \mathrm{~L}^{-1}\right)$. During bioconversion experiments, samples of $500 \mu \mathrm{L}$ were taken every 3 minutes during the first 15 minutes and then every hour for three hours. Samples were quickly frozen to stop the reaction. For substrate and product analysis, the samples were centrifuged at $5000 \mathrm{rpm}$ for 10 minutes to separate the biomass and the supernatant was analyzed. The substrate and product were quantified by gas chromatography.

\section{MATHEMATICAL MODEL}

\subsection{Kinetic model}

To develop a kinetic model for ketone bioconversion, the reaction mechanism suggested by Sheng et al. [11] was modified as follows: this reaction mechanism considers oxidation of the CHMO active site (E) to form the complex enzyme-oxygen $\left(\mathrm{EO}_{2}\right)$ which interacts with the substrate to form the complex enzyme-oxygen-substrate $\left(\mathrm{EO}_{2} \mathrm{~S}\right)$, which is the intermediate to form the product of interest $(\mathrm{P})$, and finally the regeneration of the active site (E) to start again the catalytic cycle. However, this mechanism does not consider any type of inactivation by oxygen excess or substrate inhibition, and only proposes the oxidation-reduction dynamic of the active site of the CHMO for product formation. The reaction mechanism proposed in this paper (Figure 1) takes into account the possible 
formation of two inactive complexes, one involving the over-oxidation of the active site $\left(\mathrm{O}_{2} \mathrm{EO}_{2}\right)$ and another that represents substrate inhibition $\left(\mathrm{EO}_{2} \mathrm{SS}\right)$. Product inhibition was not considered in the proposed reaction mechanism since the maximum product concentration, estimated from the specific rate of $0.11 \mathrm{~g}$ lactone $\mathrm{g}$ biomass ${ }^{-1} \mathrm{~h}^{-1}$ [9], and the substrate concentrations used in this study did not reach inhibition concentrations.

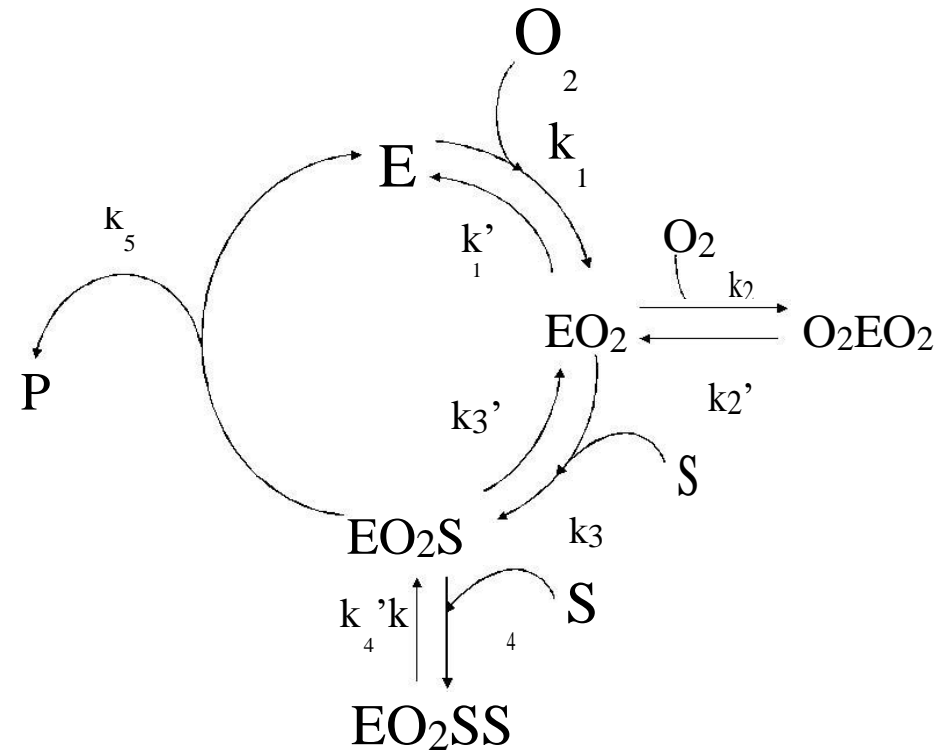

Figure 1. Reaction mechanism proposed for ketone bioconversion considering substrate inhibition and oxygen inactivation.

The reaction mechanism, the stoichiometric coefficient $(\Sigma)$ and the reaction rates for each elementary step in the catalytic cycle are presented in Table 1. The reaction mechanism follows the Langmuir-Hinshelwood-Hougen-Watson formalism [19], considering the following assumptions:

a) Glycerol enters in the pentose phosphate pathway and citric acid cycle, generating a sufficient concentration of $\mathrm{NADPH}^{2+}$ to regenerate and hold constant the active site of the CHMO in the reduced form, FADPH $^{2+}[20]$.

b) The substrate is not consumed as an energy and carbon source.

c) All the steps with the exception of product formation are considered reversible.

d) The amount of CHMO in $\mu \mathrm{g}$ per gram of biomass $\left(\mathrm{N}_{\mathrm{T}}\right)$ was approximated using the specific rate obtained previously [9] and a kcat value of $6 \mathrm{~s}^{-1}$. This $\mathrm{k}_{\mathrm{cat}}$ value was also used as an initial value during the kinetic parameter estimation. 
Table 1. Reaction mechanisms and reaction rates

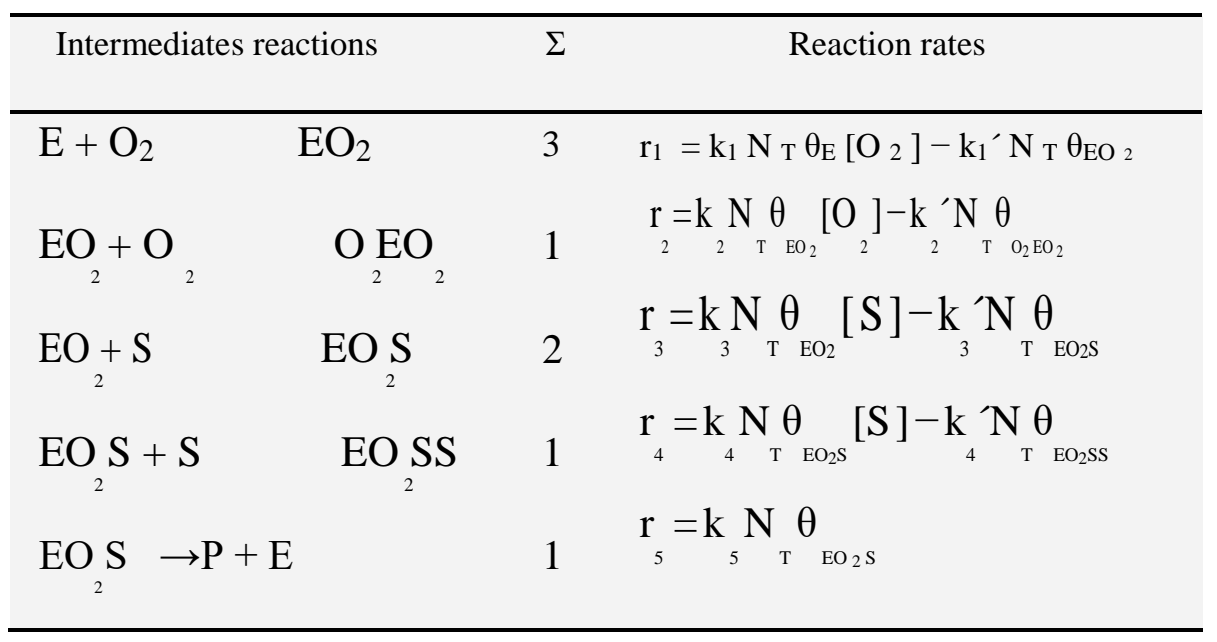

Fractions of the enzyme intermediary complex are described by the differential equations in Table 2.

Table 2. Kinetic model for ketone bioconversion

$\mathrm{N}_{\mathrm{T}} \frac{\mathrm{d} \theta_{\mathrm{E}}=\mathrm{r}_{5}-\mathrm{r}_{1} \mathrm{dt}}{\mathrm{dt} \theta_{\mathrm{EO}_{2}}=\mathrm{r}_{1}-\mathrm{r}_{2}-\mathrm{r}_{3}}$
$\mathrm{NT} \frac{\mathrm{d} \theta_{\mathrm{O}_{2} \mathrm{EO}_{2}}}{\mathrm{dt}}=\mathrm{r}_{2}$
$\mathrm{NT}_{\mathrm{T}} \frac{\mathrm{d} \theta_{\mathrm{EO}_{2} \mathrm{SS}}}{\mathrm{dt}}=\mathrm{r}_{4}$
$\theta_{\mathrm{E}}+\theta_{\mathrm{EO}_{2}}+\theta_{\mathrm{E}_{2} \mathrm{EO}_{2}}+\theta_{\mathrm{EO}_{2} \mathrm{SS}}+\theta_{\mathrm{EO}_{2} \mathrm{~S}}=1$

3.2. Mathematical model in the bioreactor

Mass transfer and the bioconversion mechanism were considered for the development of the mathematical model in the bioreactor. The following assumptions were made:

a) The reaction system is isothermic and perfectly mixed, and the agitated tank bioreactor was batch operated. 
b) Oxygen mass transfer ( $\mathrm{kLa}_{\mathrm{L}}$ ) from the gas phase to aqueous phase was considered. The effective kLa that characterizes this mechanism was determined with independent experiments in an abiotic system.

c) Intraparticle and interparticle mass transfer resistances were considered negligible because of the cell size $(\approx 6 \mu \mathrm{m})$ and insignificant shear stress between the cell and the aqueous phase, respectivelly.

d) Due to the aeration rates used, there was no loss of substrate by evaporation.

e) There was no cell shear damage due to stirring according to studies previously carried out on the same bioconversion system.

Table 3 shows the differential equations describing the mathematical model in the bioreactor. The model involves both oxygen mass transfer and the bioconversion mechanism. The proposed mathematical model was solved by integrating a set of differential equations (ODEs) with the Runge Kutta Felberg method.

Table 3. Mathematical model in the bioreactor for ketone bioconversion

$\frac{\mathrm{d}[\mathrm{S}]}{\mathrm{dt}}=-\mathrm{r}_{3}-\mathrm{r}_{4}$
$\frac{\mathrm{d}\left[\mathrm{O}_{2}\right]}{\mathrm{dt}}=\mathrm{kLa}\left(\left[\mathrm{O}_{2}{ }^{*}\right]-\left[\mathrm{O}_{2}\right]\right)-\mathrm{r}_{1}-\mathrm{r}_{2}$
$\frac{\mathrm{d}[\mathrm{P}]}{\mathrm{dt}}=\mathrm{r}_{5}$

The model contains nine kinetic parameters, $\mathrm{k}_{\mathrm{j}}$, which were estimated by the weighted least-squares of the residuals (RSS) between the calculated and experimental concentrations according to the following minimized weighted objective function (Equation 3):

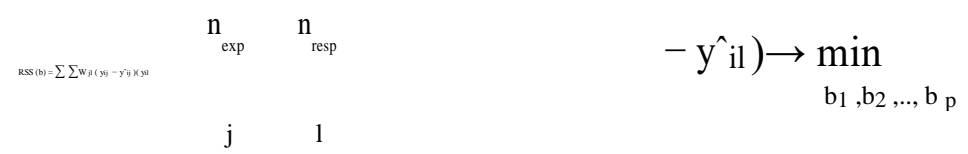

The responses used in the regression are the concentration of dissolved oxygen, lactone and ketone trough time. In Equation (3) yij denotes the calculated value and $\hat{y}_{i j}$ denotes the observed concentration in experiment $\mathrm{j}, \mathrm{b}_{\mathrm{j}}$ is the kinetic parameter vector $\left(\mathrm{k}_{\mathrm{i}}\right)$ to be estimated, $\mathrm{n}_{\exp }$ is the number of independent experiments, $\mathrm{n}_{\text {resp }}$ is the number of the model response variables and $\mathrm{W}_{\mathrm{jl}}$ is the weighting factor that can be used to give greater 
importance to some portion of the response variables. The kinetic parameters were estimated by a software program (ODRPACK 2.01) using multi-response non-linear regression and the Levenberg-Marquardt method with a 95\% confidence interval. To determine the statistical significance of the parameters, the t-test was used, while the F test was used to obtain the regression significance. In this sense, statistical confidence in the development of the kinetic model will allow us to relate the kinetic parameters to the rate of formation of different intermediaries that induce inhibition and product formation in the catalytic cycle of the cell.

\section{RESULTS AND DISCUSSION}

In Section 4.1, the experimental results of oxygen mass transfer in the absence of bioconversion are presented. The mass transfer coefficients were determined at different agitation and aeration rates in the MMBR 100 bioreactor. The experimental results of ketone bioconversion are presented in section 4.2, and various case studies are discussed with and without substrate and oxygen inhibition. Finally, in section 4.3, the model of the bioreactor (described in Table 4), which considers oxygen mass transfer and the reactions that take place in the cell, was used to fit the experimental data estimating the corresponding kinetic parameter from the model presented in Tables 1-3. The estimation strategy of kinetic parameters is particularly discussed with the aim of obtaining phenomenological and statistical confidence in the kinetic model that will be used in a future study using a partitioning bioreactor technology.

\subsection{Oxygen mass transfer studies in the absence of bioconversion}

Mass transfer was studied in an abiotic system through the determination of oxygen mass transfer coefficients by the dynamic method under various operation conditions. The agitation rate had a greater effect than aeration rate on kLa. The kLa values achieved at high aeration and agitation rates (1950 rpm and $1.4 \mathrm{vvm}$ ) were between 220 to $290 \mathrm{~h}^{-1}$, while at low aeration and

agitation rates ( $750 \mathrm{rpm}$ and $0.71 \mathrm{vvm}$ ), the kLa values were between 20 to $32 \mathrm{~h}^{-1}$. These mass transfer coefficients were used for MMBR-100 bioreactor modeling under various reaction conditions. 


\subsection{Bioconversion of ketones in an aqueous-gas system}

The bioconversion experimental results obtained through the experimental design under various operation conditions in terms of agitation rates $(750,1350$ and $1950 \mathrm{rpm})$, aeration rates $(0.75,1.0$ and $1.4 \mathrm{vvm})$ and substrate concentrations $\left(0.35,0.7\right.$ and $\left.1 \mathrm{~g} \mathrm{~L}^{-1}\right)$ are shown in Figure 2. One hundred percent ketone bioconversion was observed at $1 \mathrm{vvm}$ and $1350 \mathrm{rpm}\left(\mathrm{k}_{\mathrm{La}}=180 \mathrm{~h}^{-1}\right)$, with substrate concentrations less than $0.4 \mathrm{~g} \mathrm{~L}^{-1}$ (Figure 2a). However, when the aeration and agitation rates were increased to $1.4 \mathrm{vvm}$ and $1950 \mathrm{rpm}\left(\mathrm{k}_{\mathrm{La}}=290 \mathrm{~h}^{-1}\right)$ at substrate concentrations less than $0.4 \mathrm{~g} \mathrm{~L}^{-1}$, the bioconversion decreased to $42 \%$. Figure $2 \mathrm{~b}$ shows that at substrate concentrations greater than $0.4 \mathrm{~g} \mathrm{~L}^{-1}$, and at $1 \mathrm{vvm}$ and $1350 \mathrm{rpm}\left(\mathrm{k}_{\mathrm{L}} \mathrm{a}=180 \mathrm{~h}^{-1}\right)$, only $20 \%$ bioconversion was obtained. Once again, when the aeration and agitation rates were increased to $1.4 \mathrm{vvm}$ and $1950 \mathrm{rpm}\left(\mathrm{k}_{\mathrm{L}} \mathrm{a}\right.$

$=290 \mathrm{~h}^{-1}$ ) at substrate concentrations over $0.4 \mathrm{~g} \mathrm{~L}^{-1}$, the bioconversion decreased to $17 \%$. Statistical analysis using the Pareto box indicated that the substrate had the greatest effect on the ketone bioconversion. The second most important factor was the interaction between agitation and aeration rates, which relate the oxygen mass transfer from the gas phase to the aqueous phase. The decrease in the percentage of bioconversion when the substrate concentration was increased from 0.4 to $1 \mathrm{~g} \mathrm{~L}^{-1}$ was mainly due to substrate inhibition. For the same biocatalyzer, Doig et al. [21], working under various substrate concentrations ( 0.2 to $6 \mathrm{~g}$ $\mathrm{L}^{-1}$ ), observed that greater ketone bioconversion was achieved in the range of 0.2 to $0.4 \mathrm{~g} \mathrm{~L}^{-1}$ in a $1.0 \mathrm{~L}$ flask with a volume of $20 \mathrm{~mL}$ at $250 \mathrm{rpm}$. Modification and control of the kLa value (180 to $290 \mathrm{~h}^{-1}$ ) could increase oxygen transfer from the gas phase to the aqueous phase by maintaining a constant concentration of dissolved oxygen; however, this mechanism causes oxidation in the biocatalyzer and a decrease in bioconversion. Bennet [6] reported that oxygen excess in the reaction medium caused oxidation of two peripheral serine residues to form sulfonic acid, causing a change and permanent inactivation of CHMO. These results were also observed by Opperman and Reetz [10] who designed a CHMO by identifying the surface amino acids susceptible to oxidation and folding back them inside the enzyme. The mutated enzyme retained $40 \%$ activity in $\mathrm{H}_{2} \mathrm{O}_{2}(0.2 \mathrm{M})$, while the wild-type enzyme lost all activity in 5

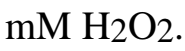



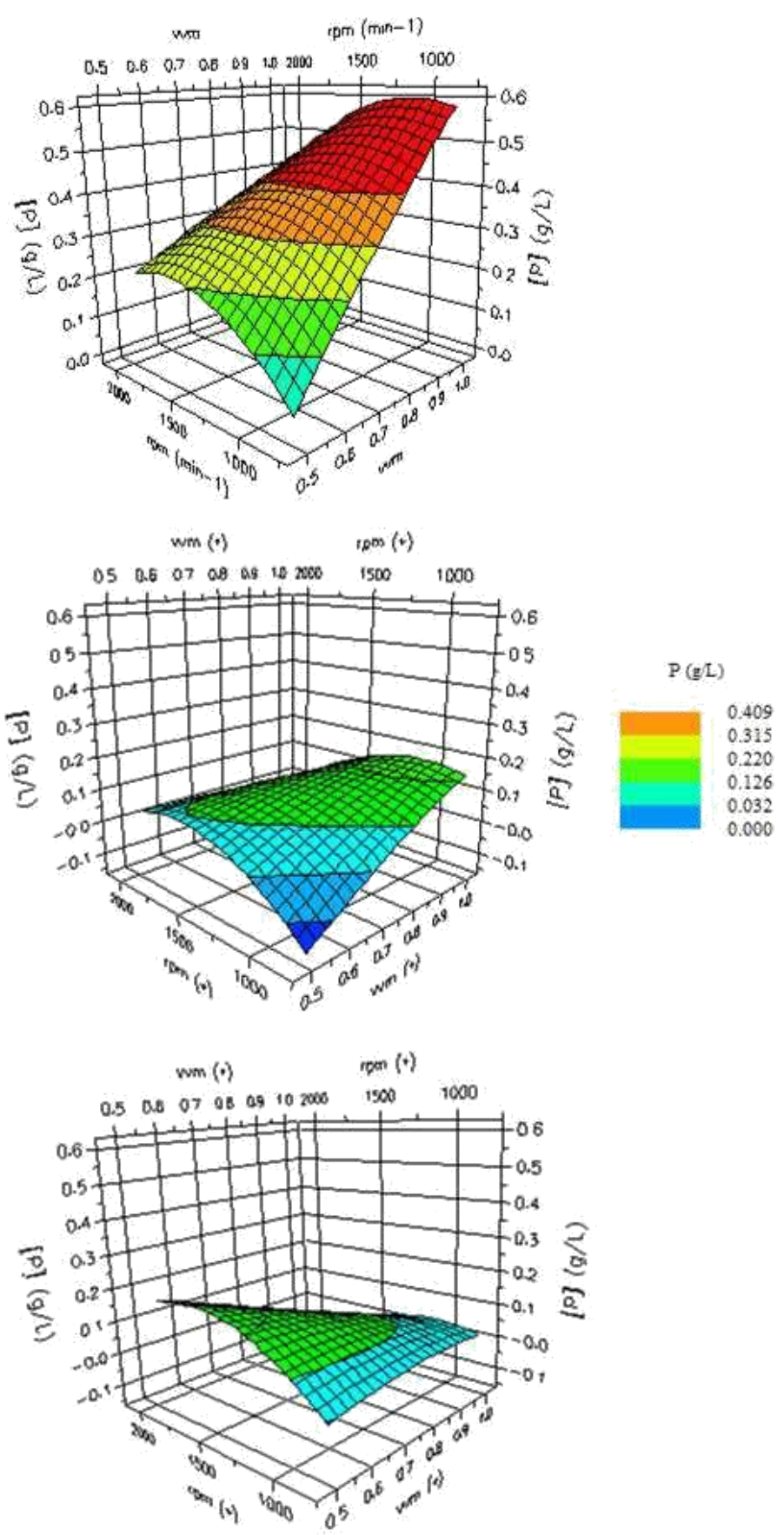

Figure 2. Ketone bioconversion under various operating conditions of agitation and aeration rates, and substrate concentrations: $2 \mathrm{a} 0.4 \mathrm{~g} \mathrm{~L}^{-1}$; 2 b. $0.7 \mathrm{~g} \mathrm{~L}^{-1} ; 2$ c. $1.0 \mathrm{~g} \mathrm{~L}^{-1}$.

\subsection{Mathematical model for ketone bioconversion}

The proposed kinetic model based on elementary reactions including substrate inhibition and oxygen inactivation was coupled to the bioreactor model that accounts for an oxygen transfer mechanism from the gas to the aqueous phase. The resulting model was fed with bioconversion experimental data and oxygen mass transfer coefficients obtained from abiotic experiments in order to estimate the kinetic parameters. 
In order to obtain a global minimum, to reduce the statistical correlation between kinetic parameters to be estimated and, hence, to describe the intrinsic enzymatic behavior inside the cell under various reaction conditions, the estimation of kinetic parameters considered the following strategy: (a) kinetic parameter estimation for bioconversion without either substrate inhibition or oxygen inactivation were carried out. This allowed for obtaining reliable values of the parameters $\mathrm{k}_{1}, \mathrm{k}_{1}$ ', $\mathrm{k}_{3}, \mathrm{k}_{3}$ ' and $\mathrm{k}_{5}$ related to the reaction steps where there is no substrate inhibition or oxygen inactivation; (b) the kinetic parameters $\mathrm{k}_{2}$ and $\mathrm{k}_{2}$ ' were estimated from the experimental data when oxygen inactivation was present, relating to the reaction step that considers oxygen inactivation; c) the kinetic parameters $\mathrm{k} 4$ and $\mathrm{k} 4$ ' were estimated from the experimental data when substrate inhibition was present, relating to the reaction step that causes substrate inhibition; (d) finally, the proposed kinetic model was validated by predicting observations under reaction conditions in the presence of substrate inhibition and oxygen inactivation simultaneously. According to t-tests and Ftests, the regression and parameters showed statistical significance within the $95 \%$ confidence interval. There was no statistical correlation between the parameters estimated according to the variance-covariance matrix. The kinetic parameters estimated by the model are shown in Table 4.

Table 4. Estimated kinetic parameters

\begin{tabular}{|c|c|}
\hline Kinetic parameters & Estimated value \\
\hline $\mathrm{k}_{1}$ & $1653.33\left(\mathrm{Lg}^{1} \mathrm{~s}^{-1}\right)$ \\
\hline $\mathrm{k}_{1}{ }^{\prime}$ & $3.32\left(\mathrm{~s}^{-1}\right)$ \\
\hline $\mathrm{k}_{2}$ & $1.11 \times 10^{-1}\left(\mathrm{Lg}^{-1} \mathrm{~s}^{-1}\right)$ \\
\hline $\mathrm{k}_{2}{ }^{\prime}$ & $7.85 \times 10^{-5}\left(\mathrm{~s}^{-1}\right)$ \\
\hline $\mathrm{k} 3$ & $83.43\left(\mathrm{Lg}^{-1} \mathrm{~s}^{-1}\right)$ \\
\hline \multirow[t]{2}{*}{ k3', } & $6.35 \times 10^{-1}\left(\mathrm{~s}^{-1}\right)$ \\
\hline & $1.66 \times 10^{-}$ \\
\hline $\mathrm{k} 4$ & $\left(\mathrm{Lg}^{-1} \mathrm{~s}^{-1}\right)$ \\
\hline k4' & $1.79 \times 10^{-4} \quad\left(\mathrm{~s}^{-1}\right)$ \\
\hline $\mathrm{K}_{5}{ }^{\prime}$ ( $\left.\mathrm{k}_{\text {cat }}\right)$ & $56.66\left(\mathrm{~s}^{-1}\right)$ \\
\hline$F$ & 2200 \\
\hline $\mathrm{F}_{\mathrm{tab}}=3.98$ & or $1-\alpha=0.95$ \\
\hline
\end{tabular}


Table 5 shows the affinity and inhibition constants of the substrate and oxygen obtained from the kinetic parameters of the model (Table 4), expressed in $\mu \mathrm{M}$ for comparison with those reported experimentally by other authors for monooxygenases enzymes. Affinity and inhibition constants (Equation 4) were defined as the inverse of the equilibrium constants of the individual reactions:

$$
K=\frac{k_{j}{ }^{\prime}}{k_{j}}
$$

where $\mathrm{K}$ is the constant of affinity or inhibition, and $\mathrm{kj}^{\prime}$ and $\mathrm{kj}_{\mathrm{j}}$ are the dissociation and association kinetic parameters of the enzyme-substrate complex.

Table 5. Affinity and inhibition constants obtained in this work and reported in the literature

\begin{tabular}{lcccc}
\hline \multicolumn{1}{c}{ References } & $\begin{array}{c}\text { KMO2 } \\
(\mu \mathrm{M})\end{array}$ & $\begin{array}{c}\text { KMS } \\
(\mu \mathrm{M})\end{array}$ & $\begin{array}{c}\text { KIO2 } \\
(\mu \mathrm{M})\end{array}$ & $\begin{array}{c}\text { KIs } \\
(\mu \mathrm{M})\end{array}$ \\
\hline Trower et al. [22] $^{\mathrm{a}}$ & -- & 0.5 & -- & -- \\
Branchaudl and Walsh [23] $^{\mathrm{b}}$ & -- & 6 & -- & -- \\
Sheng et al. [11] $^{\mathrm{c}}$ & -- & 6.8 & -- & -- \\
Torres-Pazmiño et al. [15] $^{\mathrm{e}}$ & 10 & 80 & -- & -- \\
Buckko et al. [8] $^{\mathrm{d}}$ & -- & 1.4 & -- & 20.5 \\
Shannon et al. [24] $^{\mathrm{f}}$ & $15-30$ & -- & -- & -- \\
This work & 62.72 & 70.47 & 22.30 & 9.98 \\
\hline
\end{tabular}

In the case study without substrate inhibition or oxygen inactivation, the operating conditions were $1350 \mathrm{rpm}$ and $1.0 \mathrm{vvm}\left(\mathrm{kLa}=180 \mathrm{~h}^{-1}\right)$, with $0.35 \mathrm{~g}$ substrate $\mathrm{L}^{-1}$. The comparison between the experimental and calculated data obtained from the fit of the model versus bioconversion time is shown in Figure 3a. It was observed that the kinetic model adequately described the experimental data. The substrate was completely consumed in 70 minutes; assuming a substrate-product yield $\left(\mathrm{Y}_{\mathrm{S} / \mathrm{P}}\right)$ of 0.871 and $3.0 \mathrm{~g}$ biomass $\mathrm{L}^{-1}$, a specific rate of $0.11 \mathrm{~g}$ lactone $\mathrm{g}$ biomass ${ }^{-1} \mathrm{~h}^{-1}$ was obtained. This value is lower but on the same order of magnitude than values previously reported for the same strain; Melgarejo-Torres et al. [9] observed a specific rate of

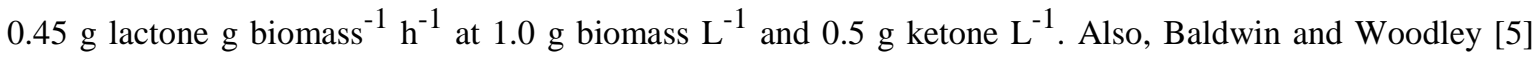
observed a specific rate of $0.65 \mathrm{~g}$ lactone g biomass ${ }^{-1} \mathrm{~h}^{-1}$ at $2.0 \mathrm{~g}$ biomass $\mathrm{L}^{-1}$ and $0.5 \mathrm{~g}$ ketone $\mathrm{L}^{-1}$. The concentration profiles of the estimated intermediates present inside the cell during the bioconversion versus bioconversion time are shown in Figure 3b. CHMO oxidation occurs in the first few minutes, generating the $\left[\mathrm{EO}_{2}\right]$ complex that is 
essential in the formation of the $\left[\mathrm{EO}_{2} \mathrm{~S}\right]$ complex which generates the product $[\mathrm{P}]$. Analyzing the affinity and kinetic parameters estimated for this case study, in the first reversible reaction, it was observed that $\mathrm{k}_{1}$ ' was smaller than $\mathrm{k}_{1}$, favoring the reaction equilibrium toward the formation of the $\left[\mathrm{EO}_{2}\right]$ complex. With these kinetic parameters, an oxygen affinity constant (KMO2) value of $62.72 \mu \mathrm{M}$ was obtained (Table 5), which is on the same order of magnitude as the values reported by Shannon et al. [24] and Torres-Pazmiño et al. [15], i.e. 15-30 and $10 \mu \mathrm{M}$, respectively. In the second reversible reaction, $\mathrm{k}_{3}$ ' was smaller than $\mathrm{k}_{3}$, favoring the reaction equilibrium toward the formation of the $\left[\mathrm{EO}_{2} \mathrm{~S}\right]$ complex. With these kinetic parameters, an oxygen affinity constant (KMs) value of $70.47 \mu \mathrm{M}$ was obtained (Table 5), which is reasonably similar to that reported by Torres-Pazmiño et al. [15] (Table 5). In the last reaction, the $\mathrm{k}_{5}$ parameter was $56.66 \mathrm{~s}^{-1}$ (Table 4), which is the reaction rate constant $\left(\mathrm{k}_{\mathrm{cat}}\right)$

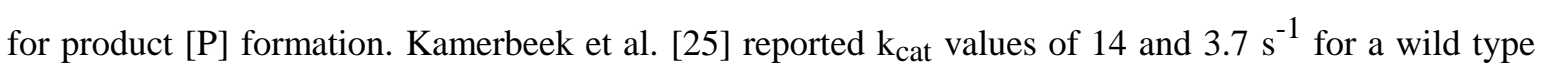
CHMO (E. coli TOP10 pQR230) and its mutant, respectively.

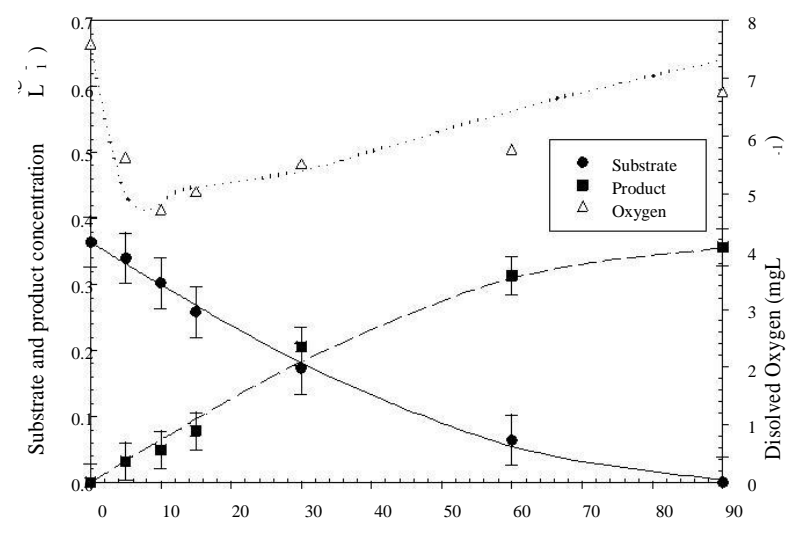

a

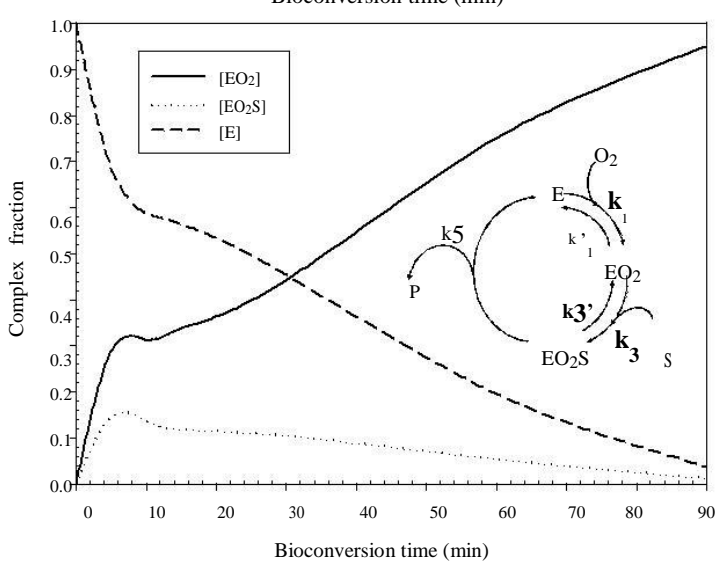

Figure 3. Case study without substrate inhibition or oxygen inactivation. The operating conditions were $1350 \mathrm{rpm}$, $1 \mathrm{vvm}\left(\mathrm{kLa}=180 \mathrm{~h}^{-1}\right)$ and $0.35 \mathrm{~g}$ substrate $\mathrm{L}^{-1}$. 3a. Substrate, product and dissolved oxygen concentrations of the experimental data and calculated values versus bioconversion time. $3 \mathrm{~b}$. Reaction mechanism and estimated intermediary complex fractions during the bioconversion. 
In the case study where oxygen inactivation was present since oxygen mass transfer in the reaction medium was increased, the operation conditions were $1950 \mathrm{rpm}$ and $1.4 \mathrm{vvm}\left(\mathrm{k}_{\mathrm{La}}=290 \mathrm{~h}^{-1}\right)$, and $0.35 \mathrm{~g}$ substrate $\mathrm{L}^{-1}$. The comparison between the experimental and calculated data versus bioconversion time is shown in Figure 4a. It was observed that the model was able to predict the decrease in lactone production due to CHMO oxidation. The relevant kinetic parameters estimated for this case study were $\mathrm{k}_{2}$ and $\mathrm{k}_{2}$. It was observed that $\mathrm{k}_{2} \gg>>$

k2' by four orders of magnitude; this high $\mathrm{k} 2$ value indicates that the CHMO oxidation reaction was virtually irreversible and coincides with that reported by Bennet [6], who mentioned that oxidation causes permanent enzyme inactivation. With these kinetic parameters, an oxygen inactivation constant (KIO2) value of $22.3 \mu \mathrm{M}$ was obtained (Table 5). There are no reports of the oxygen inactivation constant in the literature. Under these operational conditions, the percentage of experimental bioconversion was $42 \%$. The concentration profiles of the estimated intermediates present inside the cell during the bioconversion versus bioconversion time are presented in Figure $4 \mathrm{~b}$. It was observed that the formation of the first [EO2] complex was decreased, rapidly forming the $\left[\mathrm{O}_{2} \mathrm{EO}_{2}\right]$ and $\left[\mathrm{EO}_{2} \mathrm{~S}\right]$ complexes, oxygen inactivation complex and a complex essential for the formation of the product $[\mathrm{P}]$, respectively. The linear trend in $\left[\mathrm{O}_{2} \mathrm{EO}_{2}\right]$ complex formation in relation to $\mathrm{CHMO}$ oxidation shows that exposure to these conditions will cause total enzyme inactivation. 


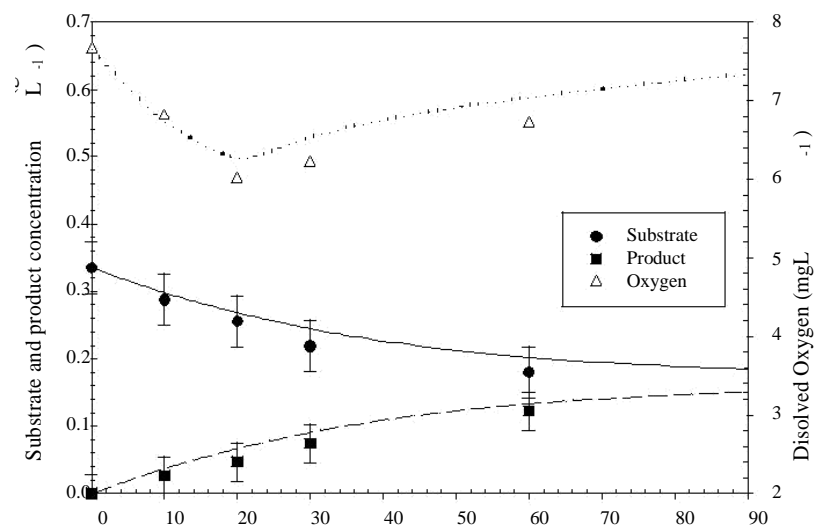

$\mathrm{a}$

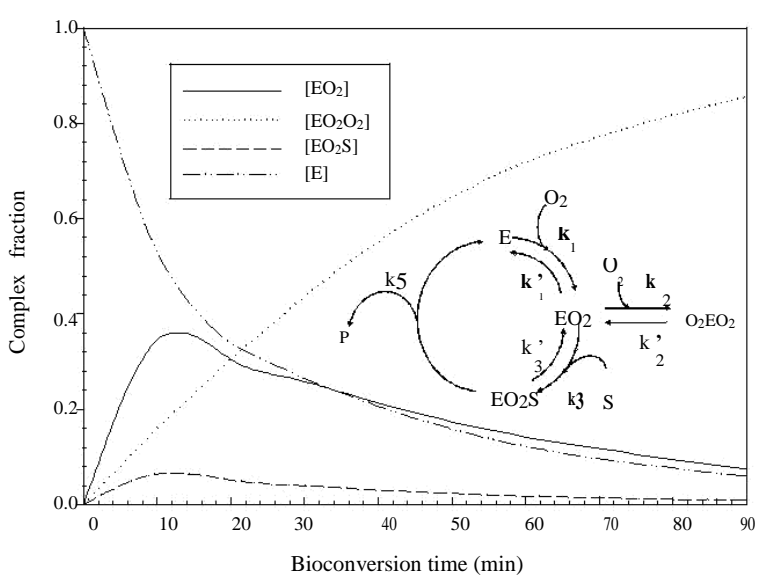

Figure 4. Case study with oxygen inactivation. The operating conditions were $1950 \mathrm{rpm}$ and $1.4 \mathrm{vvm}\left(\mathrm{k}_{\mathrm{La}}=\right.$

$290 \mathrm{~h}^{-1}$ ) and $0.35 \mathrm{~g}$ substrate $\mathrm{L}^{-1}$. 4a. Substrate, product and dissolved oxygen concentrations of the experimental data and calculated values versus bioconversion time. 4b. Reaction mechanism and estimated intermediary complex fractions during the bioconversion.

For the case study where substrate inhibition was present due to a greater substrate concentration in the reaction medium, the operation conditions were $1350 \mathrm{rpm}$ and $1.0 \mathrm{vvm}\left(\mathrm{kLa}=180 \mathrm{~h}^{-1}\right)$, and $0.70 \mathrm{~g}$ of substrate $\mathrm{L}^{-1}$. The comparison between the experimental and calculated data obtained from the fit of the model versus bioconversion time is shown in Figure 5a. Under these operational conditions, the experimental bioconversion was $20 \%$. It was observed that the model was also able to predict the decrease in lactone production due to substrate inhibition. The relevant kinetic parameters estimated for this case study were $\mathrm{k} 4$ and k4'. With these kinetic parameters, a substrate inhibition constant (KIS) value of $9.98 \mu \mathrm{M}$ was obtained (Table 5), which is half of that reported by Buckko et al. [8] (Table 5). It was found that k4 was three orders of magnitude greater than $\mathrm{k}^{\prime}$; this means that for substrate concentrations above $0.4 \mathrm{~g} \mathrm{~L}^{-1}$, the global reaction will tend to form more of the substrate inhibitory $\left[\mathrm{EO}_{2} \mathrm{SS}\right]$ complex than the product $[\mathrm{P}] . \mathrm{k} 4{ }^{\prime}$ is the kinetic dissociation constant of the reversible reaction of substrate inhibitory complex $\left[\mathrm{EO}_{2} \mathrm{SS}\right]$ formation. It is known that a reduction in the substrate concentration 
can reverse inhibition since the enzyme remains active, as most substrates do not bind to enzymes by covalent binding [20]. Figure $5 \mathrm{~b}$ shows the estimated concentrations of the [EO2] complex, which disappeared to form the $\left[\mathrm{EO}_{2} \mathrm{~S}\right]$ complex; this was transformed into the substrate inhibition $\left[\mathrm{EO}_{2} \mathrm{SS}\right]$ complex, leading to reduced product $[\mathrm{P}]$ formation.

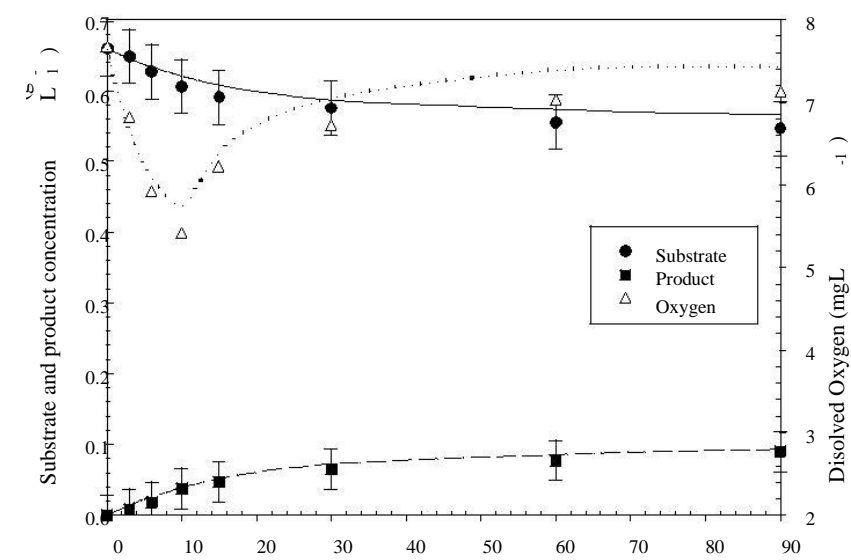

a

Bioconversion time (min)

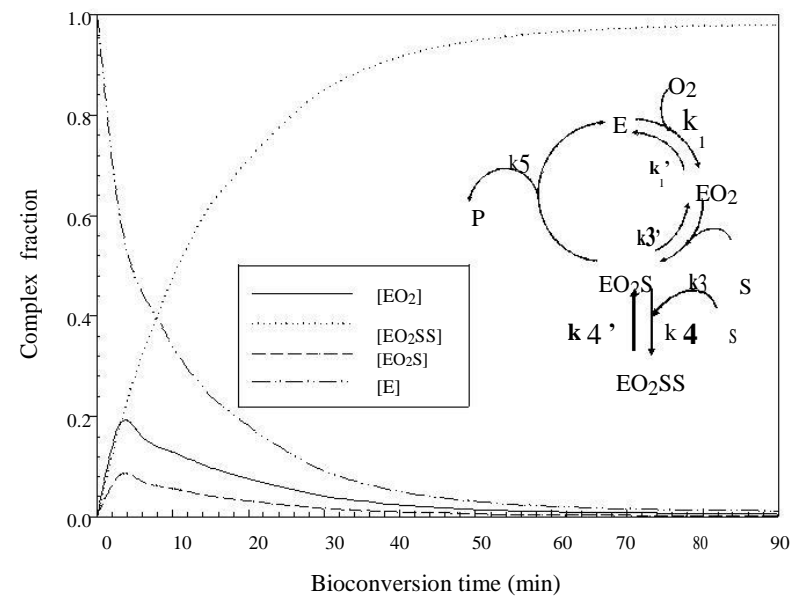

$\mathrm{b}$

Figure 5. Case study with substrate inhibition. The operating conditions were $1350 \mathrm{rpm}$ and $1.0 \mathrm{vvm}(\mathrm{kLa}=$ $180 \mathrm{~h}^{-1}$ ) and $0.70 \mathrm{~g}$ substrate $\mathrm{L}^{-1}$. 5a. Substrate, product and dissolved oxygen concentrations of the experimental data and calculated values versus bioconversion time. 5b. Reaction mechanism and estimated intermediary complex concentrations during the bioconversion.

Finally, the model was validated for the case study with both substrate inhibition and oxygen inactivation; the operating conditions were $1950 \mathrm{rpm}$ and $1.4 \mathrm{vvm}\left(\mathrm{k}_{\mathrm{La}}=290 \mathrm{~h}^{-1}\right)$, and $0.7 \mathrm{~g} \mathrm{~L}^{-1}$ of substrate. The comparison between the experimental and calculated data versus bioconversion time is shown in Figure 6a. Bioconversion performance under substrate inhibition and oxygen inactivation operational conditions was calculated by the model using the estimated kinetic constant obtained for the other case studies. Under these operational conditions, the percentage of experimental bioconversion was $17 \%$. The low bioconversion percentage may be explained analyzing the estimated kinetic parameters values of complex 
formation. The estimated intermediary complexes are shown in Figure 6b; k4 was two orders of magnitude greater than $\mathrm{k}_{2}$, which indicates that the formation rate of the [EO $\mathrm{EO}_{2} \mathrm{SS}$ ] complex by substrate inhibition was higher than that of the $\left[\mathrm{O}_{2} \mathrm{EO}_{2}\right]$ complex by oxygen inactivation. It was observed that the $\left[\mathrm{EO}_{2}\right]$ complex disappeared to form the inhibition $\left[\mathrm{EO}_{2} \mathrm{SS}\right]$ and inactivation $\left[\mathrm{O}_{2} \mathrm{EO}_{2}\right]$ complexes, while the rest was transformed into the product [P].
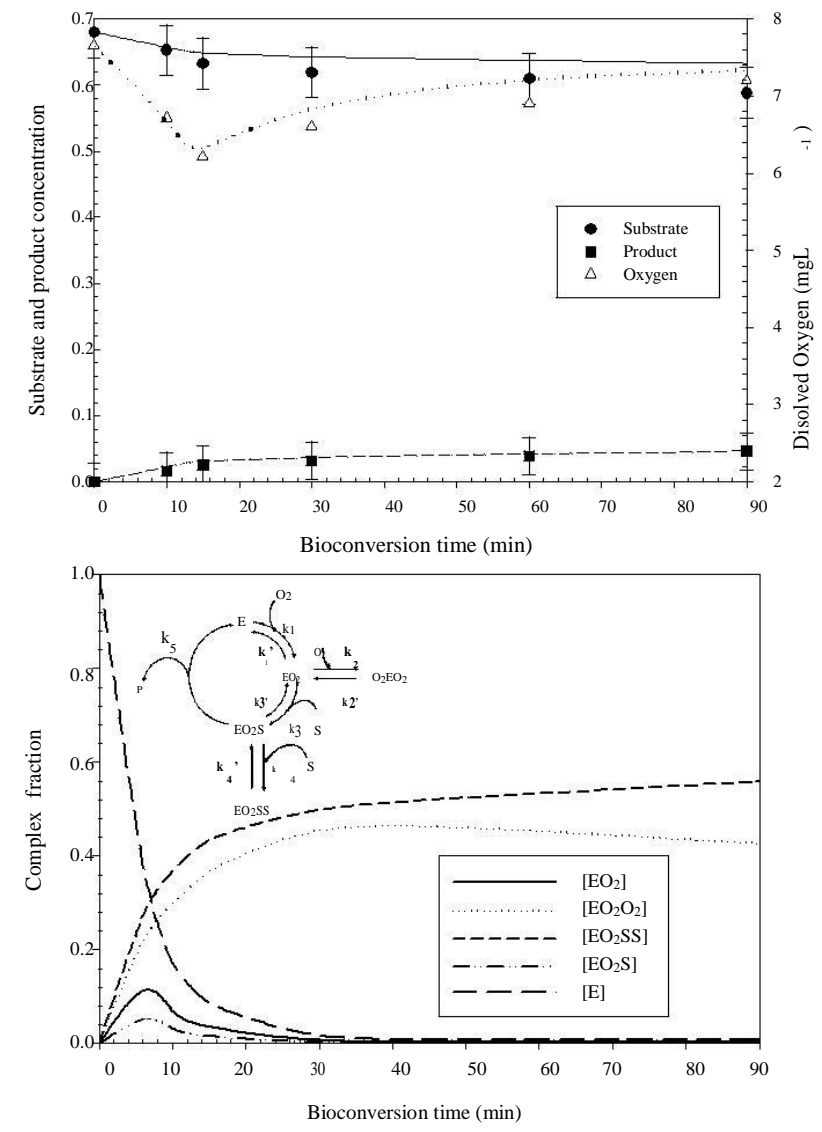

Figure 6. Case study with both substrate inhibition and oxygen inactivation. The operating conditions were 1950 $\mathrm{rpm}$ and $1.4 \mathrm{vvm}\left(\mathrm{kLa}=290 \mathrm{~h}^{-1}\right.$ ) and $0.70 \mathrm{~g}$ substrate $\mathrm{L}^{-1}$. 6a. Substrate, product and dissolved oxygen concentrations of the experimental data and calculated values versus bioconversion time. $6 \mathrm{~b}$. Reaction mechanism and estimated intermediary complex fractions during the bioconversion.

\section{CONCLUSIONS}

A non-reported pseudo intrinsic kinetic model based on elementary reactions accounting for substrate inhibition and oxygen inactivation for bicyclic ketone bioconversion was developed. The kinetic model, coupled to the reactor model taking into account interfacial oxygen mass transport, adequately fitted observations and was validated in predictive mode describing observations that were not used in the parameter estimation. The regression and these estimated parameters were statistically 
significant, making their analysis reliable regarding the kinetic behavior of CHMO, particularly allowing identify/understand the kinetic role of each substrate, intermediate and reaction product on the CHMO enzyme. Oxygen and substrate presented similar affinity to form the CHMO enzyme complex. Nevertheless, the CHMO enzyme was twice more sensitive to inhibition by an excess of substrate than oxygen. There are no reports of the oxygen inactivation constant in the literature. In further studies, this kinetic model will be essential to a successful design and scale-up of a partitioning bioreactor using this CHMO enzyme expressed in whole cells of Escherichia coli TOP10 pQR239.

\section{NOMENCLATURE}

$\begin{array}{ll}\text { CHMO } & \text { Cyclohexanone monooxygenase } \\ \mathrm{N}_{\mathrm{T}} & \text { Enzyme total concentration }\left(\mu \mathrm{g} \mathrm{g}^{-1} \text { of biomass }\right) \\ \theta_{\mathrm{E}} & \text { Free enzyme fraction } \\ \theta_{\mathrm{EO} 2} & \text { Enzyme-oxygen complex fraction } \\ \theta_{\mathrm{EO} 2 \mathrm{~S}} & \text { Enzyme-oxygen-substrate complex fraction } \\ \theta_{\mathrm{EO} 2 \mathrm{SS}} & \text { Substrate inhibition complex fraction } \\ \theta_{\mathrm{O} 2 \mathrm{EO} 2} & \text { Oxygen inactivation complex fraction } \\ {[\mathrm{P}]} & \text { Product concentration }\left(\mathrm{g} \mathrm{L}^{-1}\right) \\ {\left[\mathrm{O}_{2}\right]} & \text { Oxygen concentration }\left(\mathrm{g} \mathrm{L}^{-1}\right) \\ {[\mathrm{S}]} & \text { Substrate concentration }\left(\mathrm{g} \mathrm{L}^{-1}\right) \\ \mathrm{r}_{\mathrm{n}} & \text { Reaction rate of each enzymatic complex }\left(\mathrm{g} \mathrm{L}^{-1} \mathrm{~h}^{-1}\right) \\ \mathrm{k}_{\mathrm{j}} & \text { Kinetic constant of the reaction }\left(\mathrm{s}^{-1}\right) \\ \mathrm{kL}_{\mathrm{La}} & \text { Oxygen mass transfer coefficient }\left(\mathrm{h}^{-1}\right) \\ \mathrm{K} & \text { Affinity or inhibition constant of substrate and/or } \\ & \text { oxygen }\left(\mathrm{g} \mathrm{L} \mathrm{L}^{-1}\right)\end{array}$

\section{REFERENCES}

[1] M.J. Fink, F. Rudroff, M.D. Mihovilovic, Baeyer-Villiger monooxygenases in aroma compound synthesis, Bioorg. Med. Chem. Lett. 21 (2011) 6135-6138.

[2] S.D. Doig, P.J. Avenell, P.A. Bird, P. Gallati, K.S. Lander, G.J. Lye, R. Wohlgemuth, M.J. Woodley, Reactor operation and scale-up of whole cell BaeyerVilliger catalyzed lactone synthesis, Biotechnol. Prog. 18 (2002) 1039-1046. 
[3] H. Pfruender, R. Jones, V. Weuster-Botz, Water immiscible ionic liquids as solvents for whole cell biocatalysis, J. Biotechnol. 124 (2006)182-190.

[4] S.D. Doig, L.M. O’Sullivan, S. Patel, J.M. Ward, J.M. Woodley, Large scale production of cyclohexanone monooxygenase from Escherichia coli TOP10 pQR239, Enzyme Microb. Technol. 28 (2001) 265-274.

[5] C. Baldwin, M.J. Woodley, On oxygen limitation in a whole cell biocatalytic Baeyer-Villiger oxidation process, Biotechnol. Bioeng. 95 (2006) 362-369.

[6] A. Bennett, Mechanism of oxidative inactivation of Acinetobacter sp. NCIMB 9871. cyclohexanone monooxygenase, J. Undergrad. Res., 6(1) (2004) 1-9.

[7] K. Geitner, J. Rehdorf, R. Snajdrova, U.T. Bornscheuer, Scale-up of Baeyer-Villiger monooxygenase-catalyzed synthesis of enantiopure compounds, Appl. Microbiol. Biot. 88(5) (2010) 1087-1093.

[8] M. Buĉko, A. Schenkmayerová, P. Gemeinera, A. Vikartovská, M. Mihovilovibĉ, I. Lacíkc, Continuous testing system for Baeyer-Villiger biooxidation using recombinant Escherichia coli expressing cyclohexanone monooxygenase encapsulated in polyelectrolyte complex capsules, Enzyme Microb. Technol. 49 (2011) 284- 288.

[9] R. Melgarejo-Torres, D. Torres-Martínez, M. Gutiérrez-Rojas, A. Gómez de Jesús, G.J. Lye, S. Huerta-Ochoa, Regime analysis of a Baeyer-Villiger bioconversion in a three-phase (air-water-ionic liquid) stirred tank bioreactor, Biochem. Eng. J. 58-59 (2011) 87-95.

[10] D.J. Opperman and M.T. Reetz, Towards practical Baeyer-Villigermonooxygenases: Design of cyclohexanone monooxygenase mutants with enhanced oxidative stability. Chem. Bio. Chem. 11(18) (2010) 2589-2596.

[11] D. Sheng, D.P. Ballou, V. Massey, Mechanistic studies of cyclohexanone monooxygenase: chemical properties of intermediates involved in catalysis. Biochemistry-US. 40 (2001) 11156-11167.

[12] E. Malito, A. Alfieri, M.W. Fraaije, A. Mattevi, Crystal structure of a Baeyer- Villiger monooxygenase, P. Natl. Acad. Sci. USA. 101 (36) (2004) 13157-13162.

[13] D.E. Torres Pazmiño, H.M. Dudek, M.W. Fraaije, Baeyer-Villiger monooxygenases: recent advances and future challenges, Curr. Opin. Chem. Biol. 14(2) (2010) 138-144.

[14] C.M. Hogan and J.M. Woodley, Modelling of two enzyme reactions in a linked cofactor recycle system for chiral lactone synthesis, Chem. Eng. Sci. 55 (2000) 2001-2008. 
[15] D.E. Torres Pazmiño, B.J. Baas, D.B. Janssen, M.W. Fraaije, Kinetic mechanism of phenylacetone monooxygenase from Thermobifida fusca, Biochemistry-US, 47 (2008) 4082-4093.

[16] J. Marugán, R. van Grieken, A.E. Cassano, O.M. Alfano, Kinetic modelling of the photocatalytic inactivation of bacteria, Water Sci. Technol. 61(6) (2010)1547-1553.

[17] R. Fuchs, D. Dewey, A. Humphrey, Effect of surface aeration on scale-up producers for fermentation processes, Ind. Eng. Chem. Proc. D. D. 10(2) (1971) 1990-1996.

[18] G. Ascanio, B. Castro, E. Galindo, Measurement of power consumption in stirred vessels - A review. Trans IChemE, Part A. Chem. Eng. Res. Des. 82 (2004) 1282-1290.

[19] N. Staelens, M.F. Reyniers, G.B. Marin, Langmuir-Hinshelwood-Hougen-Watson rate equations for the transalkylation of methylamines, Chem. Eng. J. 90 (2002) 185-193.

[20] D. Voet and J.G. Voet. Biochemistry. 2011. John Wiley \& Sons Ltd; Edition: 4th Revised Edition.

[21] S.D. Doig, H. Simpson, V. Alphand, R. Furstoss, J.M. Woodley, Characterization of a recombinant Escherichia coli TOP10 [pQR239] whole-cell biocatalyst for stereoselective Baeyer-Villiger oxidations, Enzyme Microb. Technol. 32 (2003) $347-355$.

[22] M.K. Trower, M.R. Buckland, M. Griffin, Characterization of an FMN-containing cyclohexanone monooxygenase-grown Xanthobacter sp. Eur. J. Biochem. 181 (1989) 199-206.

[23] B.P. Branchaud, C.T. Walsh, Functional group diversity in enzymatic oxygenation reactions catalyzed by bacterial flavin-containing cyclohexanone oxygenase, J. Am. Chem. Soc. 10 (1985) 2153-2161.

[24] S.S. Shannon, A.F. Wilson, M. Maarten, J.P. Klinman, S.P. Lippard, Oxygen kinetic isotope effects in soluble methane monooxygenase, J. Biol. Chem. 276(7) (2001) 4549-4553.

[25] N.M. Kamerbeek, M.W. Fraaije, D.B. Janssen, Identifying determinants of NADPH specificity in Baeyer-Villiger monooxygenases. Eur. J. Biochem. 271 (2004) 2107-2116. 


\section{CHAPTER V}

REGIME ANALYSIS OF A BAEYER-VILLIGER BIOCONVERSION IN A THREE-PHASE (AIR-WATER-IONIC LIQUID) STIRRED TANK BIOREACTOR

TAKEN FROM Biochem. Eng. J. 58-59 (2011) 87- 95. 


\title{
REGIME ANALYSIS OF A BAEYER-VILLIGER BIOCONVERSION IN A THREE-PHASE (AIR-WATER-IONIC LIQUID) STIRRED TANK BIOREACTOR
}

\author{
Melgarejo-Torres, R. ${ }^{1}$, Castillo Araiza C. O. ${ }^{2}$ Huerta-Ochoa S..$^{*}$
}

\footnotetext{
${ }^{1}$ Departamento de Biotecnología, Universidad Autónoma Metropolitana-Iztapalapa, Av. San Rafael Atlixco 186, Col. Vicentina, 09340, México D.F. MEXICO.

${ }^{2}$ Grupo de Procesos de Transporte y Reacción en Sistemas Multifásicos. Dpto. De IPH, Universidad Autónoma Metropolitana, México D.F., México.
}

\begin{abstract}
The aim of this work was to carry out a regime analysis on a three-phase (air-water-ionic liquid) stirred tank bioreactor of the Baeyer-Villiger bioconversion process, using [OMA][BTA] ionic liquid as the dispersed phase. The regime analysis based on characteristic times of the different mechanisms involved ( mass transfer, kinetic and deactivation of the cell mechanisms) can yield a quantitative estimate of bioreactor performance. The characteristic time obtained for oxygen uptake rate $\left(54 \mathrm{~s}^{-1}\right)$ was among the characteristic times determined for oxygen transfer (13-327 $\left.\mathrm{s}^{-1}\right)$ to different operating conditions, suggesting that the oxygen transfer rate to higher or lower operating conditions there are mass transfer problems due to excess or deficency of substrates, respectively and on the other hand the cells suffer a loss of cell viability by the toxicity properties of the ionic liquid. The best performance of the bioconversion was $70 \%$ reached maybe due the CHMO enzyme had a natural dtoactivation by the oxygen and the loss of cell viability.
\end{abstract}

Keywords: Regime Analysis, Multiphase bioreactor, ionic liquid, bioconversion, mass transfer, oxygen transfer, deactivation of the cell. 


\section{AIM}

The aim of this chapter is to identify the limiting step in the ketone bioconversion in a three phase partitioning bioreactor process using a regime analysis through the use of characteristic times of the main transport, kinetic and deactivation mechanisms ocurring in the aforementioned bioreactor.

\section{INTRODUCTION}

Regime analysis, combined with small-scale experiments, is a powerful tool to identify the limiting step of a process and for the development of scale-down or scale-up strategies. Regime analysis can also be based on the characteristic times of the different mechanisms involved (mixing, mass transfer, reaction), which can provide a quantitative estimate of bioreactor performance [1,2]. Characteristic times have been defined as the ratio of capacity to flow. In other words, a low characteristic time implies a faster mechanism; while a high value indicates a slower mechanism. Thus, characteristic times can also be used to determine if there is a single rate-limiting mechanism (pure regime), or whether more than one mechanism (mixed regime) are limiting the studied process [3].

\subsection{Characteristic time definition}

The characteristic time, $\tau$, expresses the ratio beetwen the system capacity for transport (mass, energy, momentum) to the exchange rate or the system capacitance (1):

$\tau=\frac{\text { Capacity }}{\text { Capacitance }}$

\section{METHOLOGY}

The regime analysis was conducted accounting for six mechanisms: loss of cell viability due to ionic liquid fraction; substrate and oxygen specific rates; substrate, product and oxygen mass transfer. Then, their characteristic times were calculated to identify the limiting step of the bioconversion.

\subsection{Loss of cell viability}

The loss of cell viability is considered as an important mechanism ocurring in the bioconversion process (Chapter I). The characteristic time of the loss of cell viability rate can be expressed according to eq. (1) as follows: 
$\tau_{\mathrm{lcv}}=-\frac{1}{\mathrm{k}}$

3.2. Substrate and oxygen consumption specific rate

The substrate consumption specific rate, $\mathrm{k}_{\mathrm{cat}} \mathrm{S}$, was calculated during the first 15 minutes of the bioconversion using $3 \mathrm{~g} \mathrm{~L}^{-1}$ of biomass assuming a substrate-product yield (YS/P) of 0.871 . The operating conditions were $1350 \mathrm{rpm}, 1.0 \mathrm{vvm}, 0.7 \mathrm{~g} \mathrm{~L}^{-1}$ of initial substrate concentration in the bioreactor, and $5 \%$ of ionic fraction. The oxygen consumption specific rate, $\mathrm{kcatO} 2$, was obtained according to Melgarejo-Torres et al., [3]. The caracteristic times for substrate and oxygen consumption specific rate were obtained according to eq. (1) and defined as, respectively:

$$
\begin{aligned}
& \tau_{\text {cats }}=\frac{\left[\mathrm{S}_{0}\right]}{\mathrm{XK}_{\text {cats }} \mathrm{Y}_{\mathrm{s} / \mathrm{P}}} \\
& \tau_{\text {cat02 }}=\frac{\left[\mathrm{O}_{2}\right]}{\mathrm{Xk}_{\text {cat02 }}}
\end{aligned}
$$

3.3. Susbtrate, product and oxygen mass transfer mechanisms

For the determination of characteristics times for susbtrate, product and oxygen mass transfer mechanisms, the same methology reported by Melgarejo-Torres et al., [3] was used. The characteristic times for susbtrate, product and oxygen mass transfer mechanisms are given, in that order, as follows:

$$
\begin{aligned}
\tau_{\mathrm{S}} & =\frac{1}{\mathrm{ks} \mathrm{A}} \\
\tau_{\mathrm{P}} & =\frac{1}{\mathrm{kPA}} \\
\tau_{\mathrm{O}_{2}} & =\frac{1}{\mathrm{kLa}}
\end{aligned}
$$

\section{RESULTS}

\subsection{Loss of cell viability}

Figure 1 shows the dimensionless cell viability as a function of time at $5 \%$ of ionic liquid fraction. The cell viability decreases from the first minutes until the experiment ends. The fitting of the experimental data allowed to estimate an inihibiton constant $\mathrm{k}_{\text {in }}$, whose value was of $0.24 \mathrm{~h}^{-1}$. Thus, kin was used for determining the corresponding charateristic time. 


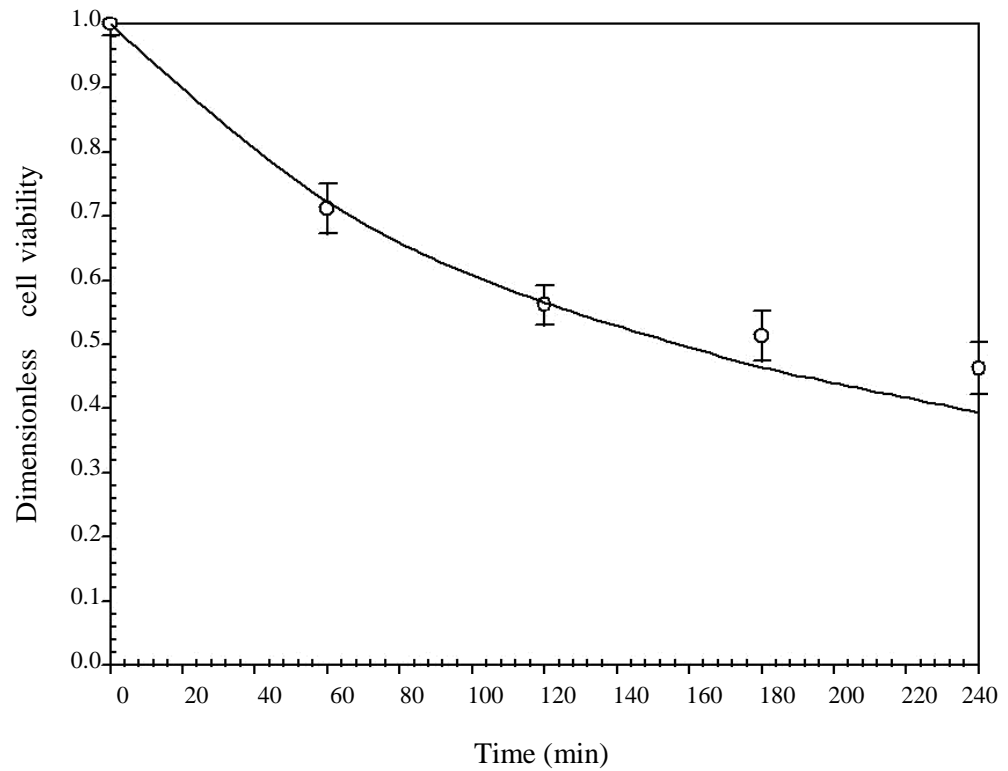

Figure 1. Fitted values (

) against experimental data (०) of dimensionless cell viability using 5\% of ionic liquid fraction.

\subsection{Substrate and oxygen consumption specific rates}

The maximum productivity for the bioconversion of ketones was obtained at $1350 \mathrm{rpm}, 1.0 \mathrm{vvm}, 0.7 \mathrm{~g}$ $\mathrm{L}^{-1}$ of initial substrate concentration and $5 \%$ of ionic liquid fraction in the bioreactor. At these operation conditions, a substrate consumption specific rate, $\mathrm{k}_{\text {cats, }}$, of $0.43 \mathrm{~g}$ lactone.g biomass ${ }^{-1} \mathrm{~h}^{-} 1$ was determined. The $\mathrm{k}_{\text {catS }}$ obtained was similar to that reported by Melgarejo-Torres et al., [3], i.e. $0.45 \mathrm{~g}$ lactone.g biomass ${ }^{-1} \mathrm{~h}^{-1}$. For oxygen consumption specific rate, the value of $\mathrm{k}_{\mathrm{catO} 2}$ was $0.166 \mathrm{~g} \mathrm{O}_{2} . \mathrm{g}$ biomass ${ }^{-1} \mathrm{~h}^{-1}$. Figure 2 shows the bioconversion as a function of time, at the end of the experiments the total bioconversion reached ca. $70 \%$.

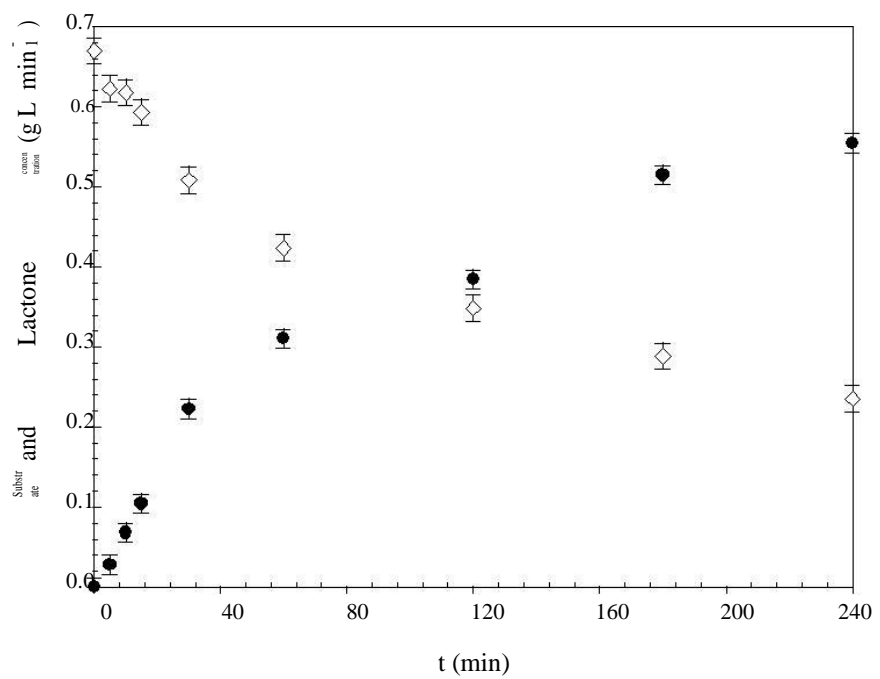

Figure 2. Kinetics of the bioconversion of ketones $(\diamond)$ to lactones $(\bullet)$ in a three phase system using OMA[BTA]. Operation conditions were $1350 \mathrm{rpm}, 1.0 \mathrm{vvm}, 0.7 \mathrm{~g} \mathrm{~L}^{-1}$ of initial substrate concentration in the bioreactor and $5 \%$ of ionic liquid fraction. 


\subsection{Susbtrate, product and oxygen mass transfer coefficients}

The ranges obtained for substrate and product mass transfer coefficients, ksA and kPA were 7.5-36 and 2.8-12 $\mathrm{h}^{-1}$, respectively. Whereas the maximum $\mathrm{k}_{\mathrm{L} a}$ value obtained in the three-phase system was $260 \pm 15 \mathrm{~h}^{-1}$, while the minimum value was $11 \mathrm{~h}^{-1}$. For more details see Chapter VII.

\subsection{Regime Analysis}

Characteristic times determined using information related to substrate, product and oxygen mass transfer mechanisms were reported at two levels. The highest values of characteristic times for mass transfer mechanisms were obtained at low agitation $(750 \mathrm{rpm})$ and aeration $(0.7 \mathrm{vvm})$ rates with $20 \%$ dispersed phase, while the lowest values were determined at high agitation $(1950 \mathrm{rpm})$ and aeration (1.4 vvm) rates with 5\% dispersed phase. Characteristic time for oxygen consumption specific rate $(54 \mathrm{~s})$ was found to be inside of the characteristic times for oxygen mass transfer (12-327 s), suggesting that the oxygen transfer rate under certain operating conditions could be a limiting step in this bioconversion process. Nevertheless, Bennett [5] mentioned that the excess of dissolved oxygen in the bioreactor produced enzyme inactivation due to the oxidation of two serines modifying permanently the enzyme structure. Law et al. [6] demonstrated that the limiting factors for Baeyer-Villiger monooxygenase catalysed synthesis of optically pure lactones in a single phase (aqueous phase) were product inhibition and natural deactivation of the biocatalysts. On the other hand, it has been reported that the addition of a second liquid phase in a partitioning bioreactor can be a useful tool to reduce product inhibition due to the presence of a partition coefficient favourable to the second liquid phase [7]. Product inhibition was not considered in this study, due to product inhibition concentration $\left(4 \mathrm{~g}_{\text {product }} \mathrm{L}^{-1}\right)$ was not reached. Characteristics time interval for substrate mass transfer was $163-480 \mathrm{~s}$, while the characteristic time for substrate consumption specific rate was 4,597 s, that means that the substrate mass transfer from dispersed phase to aqueous phase is faster than the substrate consumption rate. Melgarejo et al [3] reported a regime analysis in a TPPB using the IL [MeBuPyr][BTA] and they mentioned that the limiting step was oxygen mass transfer rate. The same research group [8] established the bioreactor operational conditions obtaining optimal oxygen transfer rates to avoid oxygen inactivation of the enzyme. These operational conditions were used in this regime analysis and the characteristic times of the mechanisms studied shown that in the first minutes of the bioconversion the main mechanisms that could be a limiting step was oxygen mass transfer rate (depending of the operating conditions). At these conditions a bioconversion of ca. $70 \%$ 
was reached. Probably all substrate was not consumed by the cell due to the CHMO had a natural deactivation by both oxygen and the cells suffers a loss of cell viability by the toxicity properties of the ionic liquid. Table 1 shows the values of the characteristic times of all mechanisms studied and how they were defined.

Table 1. Characteristic times in a three-phase stirred tank bioreactor

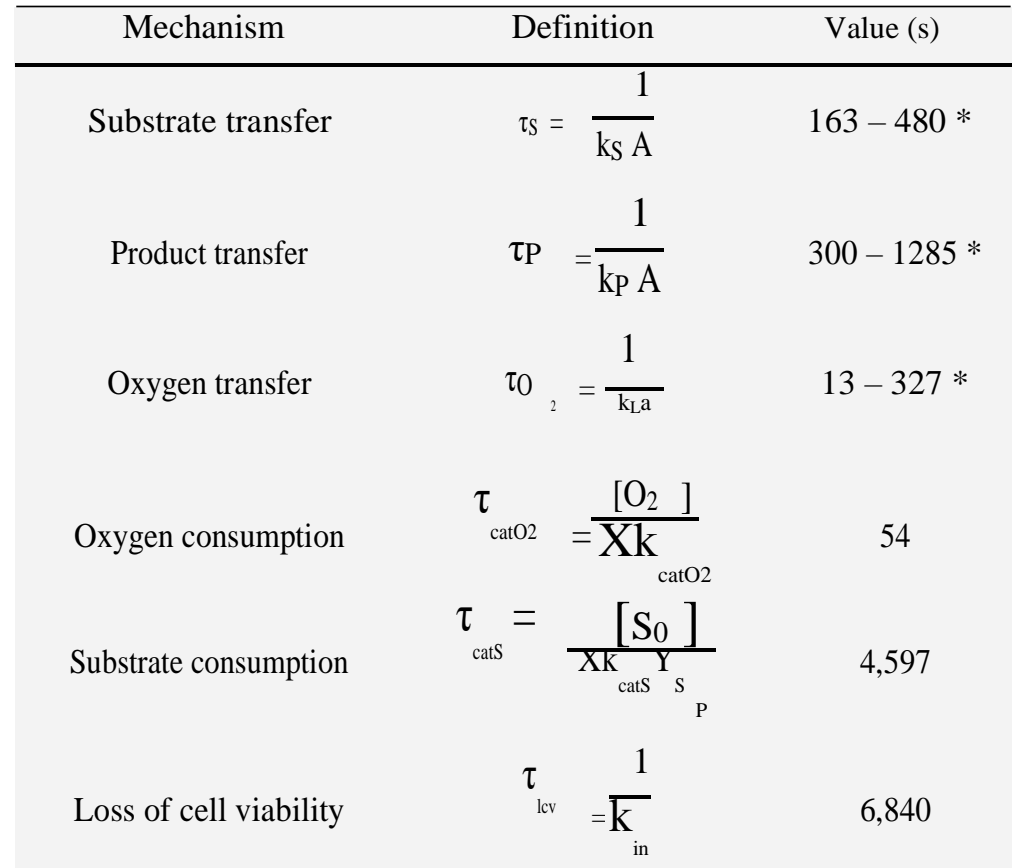

The higher values were determined at low agitation $(750 \mathrm{rpm})$ and aeration $(0.7 \mathrm{vvm})$ rates using $20 \%$ of dispersed phase, while the lower values were determined at high agitation $(1,950 \mathrm{rpm})$ and aeration $(1.4$ vvm) rates using $5 \%$ dispersed phase.

\section{CONCLUSIONS}

The regime analysis of a three-phase (air-water-ionic liquid) stirred tank bioreactor developed in this work for a Baeyer-Villiger monooxygenase catalysed synthesis allowed through characteristic times the determination of the main mechanism limiting the bioconversion. The results obtained suggest that in higher or lower operating conditions there are mass transfer problems due to excess or deficency of substrates, respectively, and to a lesser extent to the loss of cell viability; but in specific conditions the best bioconversion was ca. $70 \%$. Regime analysis promises to be an important tool to identify the operating conditions where there are limiting transport or kinetic steps in the design, scale up and operation of a TPPB.

\section{NOMENCLATURE}

$\left[\mathrm{S}_{0}\right]$ Initial substrate concentration in the bioreactor $\left(\mathrm{g} \mathrm{L}^{-1}\right)$ 
$\left[\mathrm{O}_{2}\right]$ Dissolved oxygen in the bioreactor $\left(\mathrm{g} \mathrm{L}^{-1}\right)$

kin Inhibition constant due to ionic liquid phase $\left(\mathrm{h}^{-1}\right)$

kcats Substrate consumption specific rate $\left(\mathrm{h}^{-1}\right)$

kcatO2 Oxygen consumption specific rate $\left(\mathrm{h}^{-1}\right)$

$\mathrm{N} \quad$ Colony-forming unit at anytime (CFU)

No Initial colony-forming unit (CFU)

$\mathrm{k}_{\mathrm{La}}$ Volumetric oxygen transfer coefficient in the bioreactor $\left(\mathrm{h}^{-1}\right)$

kPA Product volumetric mass transfer coefficient in the bioreactor $\left(\mathrm{h}^{-1}\right)$

kSA Substrate volumetric mass transfer coefficient in the bioreactor $\left(\mathrm{h}^{-1}\right)$

t Time

$\tau_{\mathrm{S}} \quad$ Substrate mass transfer characteristic time (s)

$\tau_{\mathrm{P}} \quad$ Product mass transfer characteristic time (s)

$\tau_{\mathrm{O} 2}$ Oxygen mass transfer characteristic time (s)

$\tau$ kcatO 2 Oxygen consumption specific rate characteristic time (s)

$\tau_{\text {catS }} \quad$ Substrate consumption specific rate characteristic time (s)

$\tau_{\mathrm{lcv}} \quad$ Loss of cell viability characterist time (s)

$\mathrm{X} \quad$ Biomass concentration $\left(\mathrm{g} \mathrm{L}^{-1}\right)$

$\mathrm{Y}_{\mathrm{S} / \mathrm{P}} \quad$ Substrate-product yield $\left(\mathrm{g} \mathrm{g}^{-1}\right)$

\section{REREFENCES}

[1] V. Alphand, R. Furstoss, Microbiological transformations 44. Optimisation of a new Baeyer-Villigerase activity: application to the stereospecific oxidation of 3phenylcyclobutanone, J. Mol. Catal. B-Enzym. 9 (2000) 209-217.

[2] E. Malito, A. Alfieri, M.W. Fraaije, A. Mattevi, Crystal structure of a Baeyer-Villiger monooxygenase, Biochemistry-US. 101 (2004) 131576-13162.

[3] R. Melgarejo-Torres, D. Torres-Martínez, M. Gutiérrez-Rojas, A. Gómez de Jesús, G.J. Lye, S. HuertaOchoa, Regime analysis of a Baeyer-Villiger bioconversion in a three-phase (air-water-ionic liquid) stirred tank bioreactor, Biochem. Eng. J. 58-59 (2011) 87-95.

[4] D. G. Zill 1997. Differential equations with Modelling Aplications. Ed. Brooks/Cole. ISBN: 0-534-95574-6.

[5] A. Bennett, Mechanism of oxidative inactivation of acinetobacter sp. NCIMB 9871. Cyclohexanone monooxygenase, J. Undergrad. Res. 6(1) (2004) pp. 1-9. 
[6] H.E.M. Law, C.V.F. Baldwin, B.H. Chen, J.M. Woodley, Process limitations in a whole-cell catalysed oxidation: sensitivity analysis, Chem. Eng. Sci. 61 (2006) 6646-6652.

[7] D. Torres-Martínez, R. Melgarejo-Torres, M. Gutiérrez-Rojas, L. Aguilera- Vázquez, M. Micheletti, G.J. Lye, S. Huerta-Ochoa, Hydrodynamic and oxygen mass transfer studies in a three-phase (air-water-ionic liquid) stirred tank bioreactor, Biochem. Eng. J. 45 (2009) $209-217$.

[8] R. Melgarejo-Torres, O. Castillo-Araiza, P. López-Ordaz, D. Torres-Martínez, M. Gutiérrez-Rojas, G.J. Lye, S. Huerta-Ochoa. Kinetic mathematical model for ketone bioconversion using Escherichia coli TOP10 pQR239. Chemical Engineering Journal 240 (2014) 1-9. 


\section{CHAPTER VI}

MATHEMATICAL MODEL OF A THREE PHASE PARTITIONING

BIOREACTOR FOR CONVERSION OF KETONES USING WHOLE CELLS

CHEMICAL ENGINEERING JOURNAL 260. 765-775 (2015) 


\title{
MATHEMATICAL MODEL OF A THREE PHASE PARTITIONING BIOREACTOR FOR CONVERSION OF KETONES USING WHOLE CELLS
}

\author{
Rodrigo Melgarejo-Torres ${ }^{1}$, Carlos O. Castillo-Araiza ${ }^{2}$, Abhishek Dutta ${ }^{3,4}$, Guido Bény ${ }^{3}$, Daniel Torres- \\ Martinez ${ }^{5}$, Mariano Gutiérrez-Rojas ${ }^{1}$, Gary J. Lye ${ }^{6}$, Sergio Huerta-Ochoa ${ }^{1 *}$ \\ ${ }^{1}$ Departamento de Biotecnología, Universidad Autónoma Metropolitana-Iztapalapa, Av. San Rafael Atlixco \\ 186, Col. Vicentina, 09340, México D.F., México \\ ${ }^{2}$ Grupo de Procesos de Transporte y Reacción en Sistemas Multifásicos. Dpto. de IPH, Universidad \\ Autónoma Metropolitana- Iztapalapa, México D.F., México. coca@xanum.uam.mx. \\ ${ }^{3}$ Faculteit Industriële Ingenieurswetenschappen, KU Leuven, Campus Leuven (@Groep T), Andreas \\ Vesaliusstraat 13, B-3000 Leuven, Belgium. \\ ${ }^{4}$ Departement Metaalkunde en Toegepaste Materiaalkunde (MTM), KU Leuven, Kasteelpark Arenberg 44, B- \\ 3001 Heverlee-Leuven, Belgium. \\ ${ }^{5}$ Universidad Politécnica de Tlaxcala, San Pedro Xalcaltzinco Tepeyanco, Tlaxcala, México \\ ${ }^{6}$ Department of Biochemical Engineering, University College London, London WC1E 7JE, United Kingdom.
}

*Corresponding author

E-mail address: sho@xanum.uam.mx (S. Huerta-Ochoa).

\begin{abstract}
In this study we developed a pseudo heterogeneous mathematical model for the oxidation of Bicyclic ketone bicyclo[3.2.0]hept-2-to-6-one to bicyclic lactone (1S,5R)-(-)-2-oxabiciclo[3.3.0]oct-6-en-3-ona using whole cells of E. coli strain TOP10 pQR239 in a three-phase partitioning bioreactor (TPPB). The pseudo heterogeneous TPPB model accounted for mass transfer mechanisms occurring in the air-water and water-ionic liquid phases along with bioconversion and loss of cell viability caused by ionic liquid - trioctylmethylammonium bis(trifluoromethylsulfonyl)imide ([OMA][BTA]). The development of the model was based on reactor engineering principles and, hence, experiments with and without bioconversion were carried out in order to characterize thermodynamic $\left(\mathrm{K}_{\mathrm{ps}}\right.$ and $\left.\mathrm{K}_{\mathrm{pp}}\right)$, transport $\left(\mathrm{k}_{\mathrm{s}}, \mathrm{k}_{\mathrm{p}}\right.$ and $\left.\mathrm{A}\right)$ and kinetic $\left(\mathrm{k}_{\mathrm{i}}\right.$ and $\left.\mathrm{k}_{\mathrm{i}}{ }^{\prime}\right)$ parameters along with the loss of cell viability $\left(\mathrm{k}_{\mathrm{in}}\right)$ parameter for the mechanisms involved. The model described adequately the bioconversion of experimental data with two different ionic liquid fractions, namely $5 \%(\mathrm{v} / \mathrm{v})$ and $12.5 \%(\mathrm{v} / \mathrm{v})$. A parametric sensitivity analysis of the model was conducted to obtain information on the effect of oxygen transport rate on bioconversion. The development of the TPPB model led to the following findings: (i) 5\% (v/v) ionic liquid fraction caused less cell deactivation; (ii) presence of ionic liquid decreased the oxygen transport rate; and (3) a higher oxygen transport rate lead to a higher bioconversion but also cell inactivation.
\end{abstract}

Key words: ketone conversion; partitioning bioreactor; mass transfer; cell viability; mathematical modeling. 


\section{INTRODUCTION}

The Baeyer-Villiger (BV) oxidation reaction, including the conversion of cyclic ketones into their corresponding lactones, was observed more than 100 years ago [1]. Enzymatic BV oxidation has been efficiently applied to synthetic organic chemistry since there are many enzymes that are being exploited in the last decade [2]. Particularly, in the BV oxidation reaction, cyclohexanone monooxygenase (CHMO) from Acinetobacter calcoaceticus NCIMB 9871 is one of the best-known enzymes [3]. In the last decade, an increase of the rate of oxidation of cyclic ketones has been obtained when the CHMO gene is cloned into an expression vector to give the biocatalyst strain E. coli TOP10 (pQR239)

[4]. Nevertheless, substrate/product inhibition was identified for this conversion with the whole cell-mediated conversion using bicyclo[3.2.0]hept-2-en-6-one [5]; particularly, the reaction is inhibited by ketone concentrations above $0.4 \mathrm{~g} / \mathrm{L}$ and by combined regioisomeric lactones with concentrations above $3.5 \mathrm{~g} / \mathrm{L}$.

A number of solutions have been recommended to decrease the substrate/product inhibition; for instance: the proposal of adsorbent resins [6]; in situ supply of the substrate and removal of lactone product, maintaining both substrate and product at sub-inhibitory levels in the environment of the biocatalyst [7]; and encapsulaion of biocatalyst to prevent CHMO oxidation [8]. However, one of the main limitations of these strategies is the difficulty in controlling mass transfer of substrate, product and oxygen that directly impacts on the productivity and the cost-benefit ratio.

The conversion of ketones using whole cells using a pseudo three-phase (air-water-ionic liquid) partitioning bioreactor (TPPB) seems a promising proposal since this technology leads to an increment on consumption rates [9] avoiding substrate/product inhibition and, mainly, giving a better control of the mass transfer phenomena [10].

In a previous work from our research group, the use of a TPPB maintaining the biocatalyst in the aqueous phase and using ionic liquid (IL) as immiscible phase for substrate reservoir and in situ product removal was attempted [11]. Specifically, a regime analysis for the oxidation of bicyclic ketone bicyclo[3.2.0]hept-2-to-6-one to bicyclic lactone (1S,5R)-(-)-2-oxabiciclo[3.3.0]oct-6-en-3-ona using whole cells based on E. coli strain TOP10

pQR239, using trioctylmethylammonium bis(trifluoromethylsulfonyl)imide ([OMA][BTA]) as IL, allowed to observe an increment on consumption rates avoiding substrate/product inhibition. From this end, since the establishment of design, scale up or 
scale down, optimization and operational guidelines ensuring optimal conversions require the understanding of process performance [12], modeling of this TPPB accounting for the interaction between mass transport phenomena and kinetics along with loss of cell viability is mandatory. To date there are few studies [13] explaining through mathematical modeling the complex interaction between mass transport phenomena along with kinetics and loss of cell viability in a TPPB considering the inclusion of a heavy organic solvent in the system. For example, Mahanty et al. [14] proposed a kinetic model for degradation of pyrene in a partitioning bioreactor; however, they did not account for the mass transfer mechanisms involved in. Bordel et al. [12] modeled gas-liquid VOC transport in a partitioning bioreactor and described adequately the mass transport mechanisms but kinetic modeling was not considered. For treating polluted air streams in a continuous stirred tank bioreactor, Mohammad [15] described the simulation trends of the model but failed to compare with experimental data.

The aim of this study was to develop a pseudo heterogeneous mathematical model for bioconversion of bicyclic ketone bicyclo[3.2.0]hept-2-to-6-one to bicyclic lactone (1S,5R)-(-)2-oxabiciclo[3.3.0]oct-6-en-3-ona using whole cells based on E. coli strain TOP10 pQR239 in a TPPB using $5 \%$ and $12.5 \%$ (v/v) of IL fraction ([OMA][BTA]). The model was based on independent studies in abiotic bioconversion and loss of cell viability conditions, which in turn were used to determine the mass transport, kinetic and deactivation parameters respectively, that characterize the corresponding phenomenon involved in the TPPB. Finally, the developed pseudo heterogeneous TPPB model was used to carry out a parametric sensitivity study with a goal to observe the effect of oxygen transport rate on bioconversion.

\section{MATERIALS AND METHODS}

\subsection{Chemicals}

The ionic liquid used as a dispersed phase in this study was OMA[BTA] purchased from Solvent Innovation GmbH (Köln, Germany). Bicyclic ketone bicyclo[3.2.0]hept-2-to-6one ( $\geq 98 \%)$ and bicyclic lactone (1S,5R)-(-)-2-oxabiciclo[3.3.0]oct-6-en-3-ona ( $\geq 99 \%)$ (Fluka, Switzerland) were used as substrate and product standards, respectively. For the culture medium tryptone, yeast extract, $\mathrm{NaCl}$ and glycerol were purchased from Sigma Aldrich (EUA). 


\subsection{Microorganism}

The E. coli strain TOP10 pQR239 was kindly provided by Professor John M. Ward (UCL, UK) for research and academic purposes, and is referred to hereafter simply as E. coli. To prepare inoculum for conversion experiments, E. coli cells were cultured in Erlenmeyer flasks of $250 \mathrm{~mL}$ containing $70 \mathrm{~mL}$ of a complex media (in $\mathrm{g} \mathrm{L}^{-1}$ ): tryptone 10.0 , yeast extract $10, \mathrm{NaCl} 10.0$, in phosphate buffer $50 \mathrm{mM}$ pH 7.0, supplemented with $10 \mathrm{gL}^{-1}$ glycerol. Culture media was sterilized in an autoclave at $120{ }^{\circ} \mathrm{C}$ for $15 \mathrm{~min}$ and supplemented with $100 \mathrm{mg} \mathrm{L}^{-1}$ ampicillin (previously filter sterilized using a $0.25 \mu \mathrm{m}$ filter). Erlenmeyer flasks were incubated at $150 \mathrm{rpm}$ for $16 \mathrm{~h}$ at $37^{\circ} \mathrm{C}$. After a $16 \mathrm{~h}$ growth period, cyclohexanone monooxygenase (CHMO) expression was induced by adding the necessary amount of arabinose solution $\left(100 \mathrm{gL}^{-1}\right)$ to reach a final concentration of 2 $\mathrm{gL}^{-1}$. After $3 \mathrm{~h}$ of induction, cells were harvested by centrifugation at $5000 \mathrm{rpm}$ for $10 \mathrm{~min}$.

\subsection{Stirred tank bioreactor}

A module with two glass $100 \mathrm{~mL}$ stirred tank min-bioreactors (MMBR100, UAM-I, Mexico) was used as TPPB. The jacketed mini-bioreactors were provided with an internal diameter of $4.75 \mathrm{~cm}$ and an operating volume of $70 \mathrm{~mL}\left(\mathrm{HL}_{\mathrm{L}} \mathrm{D}\right.$ T $\left.=0.87\right)$. The bioreactors were fitted with a single, six flat blade Rushton turbine, $\mathrm{D}_{\mathrm{i}}=1.9 \mathrm{~cm}\left(\mathrm{Di}_{\mathrm{i}} / \mathrm{D}_{\mathrm{T}}=0.40\right)$, located $1.9 \mathrm{~cm}$ from the flat base of the vessel, and were equipped with four equidistant baffles, $0.5 \mathrm{~cm}$ width.

\subsection{Overall volumetric oxygen mass transfer coefficient $\mathrm{k}_{\mathrm{La}}$}

Optical fiber for Dissolved Oxygen (DO), mini sensors (PreSens, GmbH Germany) were used for kLa determination. The DO sensors were coupled to a 4-Channel Oxygen Meter OXY- 4 mini (PreSens, GmbH Germany). A central composite experimental design with three independent factors (aeration, agitation and ionic fraction) each with three levels of operating

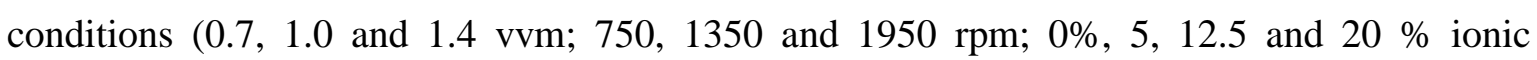
fraction) was used in the study. Overall oxygen mass transfer coefficients, kLa, were calculated according to dynamic method and the correlation proposed by Fuchs et al. [16] which takes into account the electrode response time and the dimensionless DO concentration in the bioreactor:

$$
\mathrm{YP}_{\mathrm{P}}=\frac{\mathrm{K}_{\mathrm{P}} \cdot \mathrm{e}^{-\mathrm{k}_{\mathrm{L}} \text { at }}-\mathrm{k}_{\mathrm{L}} \mathrm{a} \cdot \mathrm{e}^{-\mathrm{K}_{\mathrm{P}} \mathrm{t}}}{\mathrm{K}_{\mathrm{P}}-\mathrm{k}_{\mathrm{L}} \mathrm{a}}
$$

where $\mathrm{YP}_{\mathrm{P}}$ is the dimensionless DO concentration in the bioreactor defined as:

YP

$$
\left[\overline{\left.\mathrm{O}_{2} *\right]-\left[\mathrm{O}_{20}\right]}\right.
$$

$$
=\left[\begin{array}{l}
\mathrm{O}_{2} \\
*
\end{array}\right]-\left[\begin{array}{l}
\left.\mathrm{O}_{2}\right) \\
]
\end{array}\right]
$$


where $\left[\mathrm{O}_{2}^{*}\right]$ is the saturated oxygen concentration $\left(7.2 \mathrm{mg} \mathrm{L}^{-1}\right.$, which was determined with the OXY-4 module software using the atmospheric pressure of Mexico City, 1016.9

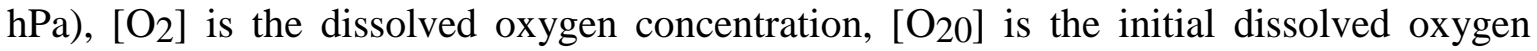
concentration the bioreactor. $\mathrm{KP}_{\mathrm{P}}$ is the electrode constant defined as the inverse of the response time, $\mathrm{kLa}_{\mathrm{La}}$ is the overall volumetric oxygen mass transfer coefficient, and $\mathrm{t}$ is the time required for the sensor to reach the saturated oxygen concentration. Curve fitting is performed using a non-linear regression Levenberg-Marquardt algorithm in Polymath ${ }^{\mathrm{TM}}$.

\subsection{Bioconversion of ketones}

Two sets of experiments were carried out during bioconversion of ketones in TPPB. Both set of experiments considered the following conditions in the bioreactor: $50 \mathrm{~mL}$ aqueous phase (50 $\mathrm{mM}$ of phosphate buffers, $\mathrm{pH} 7$ ); before starting the bioconversion, the bioreactor was saturated with substrate and oxygen; $3 \mathrm{gL}^{-1}$ of biomass was then resuspended in $20 \mathrm{~mL}$ of $50 \mathrm{mM}$ of phosphate buffers for starting the conversion; the bioconversions took place at $30{ }^{\circ} \mathrm{C}$ and $\mathrm{pH} 7$; and the initial substrate concentration in the bioreactor was $0.7 \mathrm{gL}^{-1}$, being $0.35 \mathrm{gL}^{-1}$ in aqueous phase because of the partitioning coefficients of OMA[BTA] (see section 2.7). In the first set, $5 \%(\mathrm{v} / \mathrm{v})$ of IL fraction was added at $1350 \mathrm{rpm}$ and $1.4 \mathrm{vvm}$, while in the second set, $12.5 \%(\mathrm{v} / \mathrm{v})$ of IL fraction was added at $1950 \mathrm{rpm}$ and $1 \mathrm{vvm}$. During experiments, samples of $500 \mu \mathrm{L}$ were taken every 3 minutes during the first 15 minutes and then every hour for 4 hours. The samples were then quickly frozen to stop the reaction. The substrate and product were quantified by gas chromatography.

\subsection{Analysis}

Gas Chromatography (GC) was used to quantify the concentrations of bicycle[3.2.0]hept2-en-6-one and the corresponding regioisomeric lactones. Samples $(1 \mu \mathrm{L})$ were injected into an X|L gas chromatograph (Perkin Elmer, Norwalk, CT) fitted with a CYCLOSILB 113-6632 capillary column (30 m x $530 \mu \mathrm{m})(\mathrm{J} \& \mathrm{~W}$ Scientific), and concentrations were determined using an external calibration curve. The GC injector temperature was set at 250 ${ }^{\circ} \mathrm{C}$. The $\mathrm{GC}$ temperature program used was as follows: the initial oven temperature was $100{ }^{\circ} \mathrm{C}$, held for $1 \mathrm{~min}$ and followed by a temperature increase at $10{ }^{\circ} \mathrm{C}\left(\mathrm{min}^{-1}\right)$ up to 150 ${ }^{\circ} \mathrm{C}$, which was then held for $3 \mathrm{~min}$. Retention times were $3.7 \mathrm{~min}$ and $3.95 \mathrm{~min}$ for the substrate (mixture of ketone isomers) and $8.5 \mathrm{~min}$ for the product.

\subsection{Parameter related to loss of cell viability}

The loss of E. coli viability due to IL was evaluated in an Erlenmeyer flask. E. coli was inoculated in 20 $\mathrm{mL}$ of $50 \mathrm{mM}$ phosphate solution at $7 \mathrm{pH}, 3 \mathrm{gL}^{-1}$ biomass and the IL 
fraction evaluated were 5 and $12.5 \%$. Samples of $500 \mu \mathrm{L}$ were taken each hour $(0-4 \mathrm{~h})$ before the incubation. These samples were diluted $\left(10^{-1}\right.$ to $\left.10^{-6}\right)$, and $0.1 \mathrm{~mL}$ of each dilution was used to inoculate Petri dishes containing $10 \mathrm{~mL}$ of nutritive agar, which was incubated for $24 \mathrm{~h}$ at $30{ }^{\circ} \mathrm{C}$. E. coli viability was calculated on the basis of viable cell counts by considering colony-forming units $\left(\mathrm{CFU} \mathrm{mL}{ }^{-1}\right)$ (Coult-counter, Quebec, Canada). The experiments were carried out in triplicate and were used to determine the parameter $\mathrm{k}_{\text {in }}$ in Eq. 21 accounting for the loss of cell viability due to the presence of IL.

\subsection{Substrate and product partitioning coefficients}

The partitioning coefficients were determined using known concentrations of substrate and product with a total volume of $7 \mathrm{~mL}$ in a Corning tube of $15 \mathrm{~mL}$ capacity (with same volumes of the aqueous phase and ionic liquid) at temperature and pressure used during bioconversion experiments. The tubes were agitated every 6 hours for $5 \mathrm{~min}$ and $300 \mu \mathrm{L}$ samples of the aqueous phase were taken for a period of 24 hours. The samples were centrifuged at $5000 \mathrm{rpm}$ for $10 \mathrm{~min}$ and the aqueous phase was analyzed by GC.

\subsection{Sauter mean diameter $\left(\mathrm{d}_{32}\right)$}

Optical Reflectance Measurement (ORM) techniques are able to show the change in drop size distribution for various power inputs, although they are not able to measure the exact size of the drops. Nevertheless, they are successfully used in control of processes $[17,18]$. In this study, the Sauter mean drop diameter $\left(\mathrm{d}_{32}\right)$ was measured using a 3D ORM particle size analyser (Messtechnik Schwartz, Germany). 2000 drop diameter ( $\left.\mathrm{d}_{1}\right)$ determinations were performed automatically for each measurement, enabling calculation of the Sauter mean diameter $\left(\mathrm{d}_{32}\right)$ according to:

$$
\mathrm{d}_{32}=\frac{\sum_{\mathrm{d}_{1}{ }^{3} \mathrm{n}_{1}}}{\sum^{\mathrm{d}^{2}{ }^{2} \mathrm{n}_{1}}}
$$

IL drop diameter distribution was obtained in situ and on-line during all the experiments. Because the ORM measures drop sizes using laser beam reflectance, and the fact that gas bubbles do not have reflective properties, it was assumed that gas bubbles do not interfere with liquid drop size measurements. No evidence of such interference was observed in any of the initial size distributions and therefore ORM drop diameter measurements were recorded directly from TPPB. Measurements were recorded at least 15 min after mixing was initiated in order to ensure that equilibrium in drop diameter distribution was established. The interfacial area available for substrate and product mass transfer (A) is given by: 


$$
A=\frac{6 \phi}{d_{32}}
$$

where $\varphi$ is the volume fraction of the dispersed phase. The interfacial area is obtained using a Lewis cell [19] to estimate the mass transfer coefficients (ks and kP) and, hence, their overall mass transfer coefficients (kSA and kPA) for substrate and product respectively. Even though interfacial mass transfer coefficients for substrate and product, ks and kP, respectively, are not reliable because of the hydrodynamic differences between a Lewis cell and the studied partitioning bioreactor, the obtained values from the former will be used as initial guesses to estimate suitable coefficients in the latter.

\section{MATHEMATICAL MODEL}

\subsection{Kinetic model}

The kinetic model used in this study was obtained from our previous search [20]. So far, the model development was based on experiments in TPPB without the presence of IL and, hence, loss of cell viability. For sake of brevity, the mechanism based on Langmuir-Hinshelwood-Hougen-Watson formalism and developed model are summarized as follows:

a) Glycerol enters in the pentose phosphate pathway and citric acid cycle, generating a sufficient concentration of $\mathrm{NADPH}^{2+}$ to regenerate and hold constant the active site of the CHMO in the reduced form, $\mathrm{FADPH}^{2+}$.

b) The substrate is not consumed as an energy or carbon sources

c) All the steps with the exception of product formation are considered reversible.

d) It is considered the oxidation of the active site $(\mathrm{E})$ to form the complex enzyme-oxygen $\left(\mathrm{EO}_{2}\right)$ :

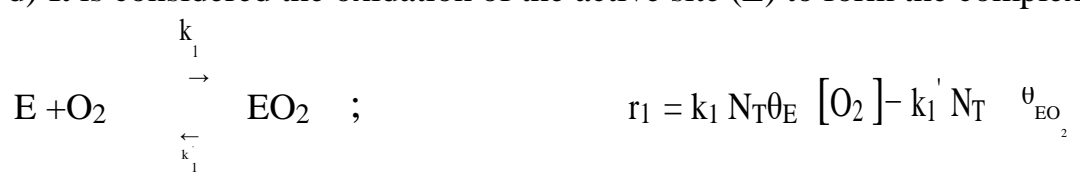

e) The complex enzyme-oxygen leads to the formation of one inactive complex involving the over-oxidation of the active site $\left(\mathrm{O}_{2} \mathrm{EO}_{2}\right)$ :

$$
\mathrm{EO}_{2}+\mathrm{O}_{2} \stackrel{\mathrm{r}_{2}}{\stackrel{\mathrm{k}_{2}}{\rightarrow}} \mathrm{O}_{2} \mathrm{EO}_{2} \quad ; \quad \mathrm{r}_{2}=\mathrm{k}_{2} \mathrm{~N}_{\mathrm{T}} \quad \underset{\mathrm{EO}_{2}}{\mathrm{EO}_{2}}\left[\mathrm{O}_{2}\right]-\mathrm{k}_{2}^{\prime} \mathrm{N}_{\mathrm{T}} \underset{2}{\dot{\mathrm{O}}_{2}}
$$

f) Besides, $\mathrm{EO}_{2}$ interacts with the substrate (S) to form the complex enzyme-oxygensubstrate $\left(\mathrm{EO}_{2} \mathrm{~S}\right)$ :

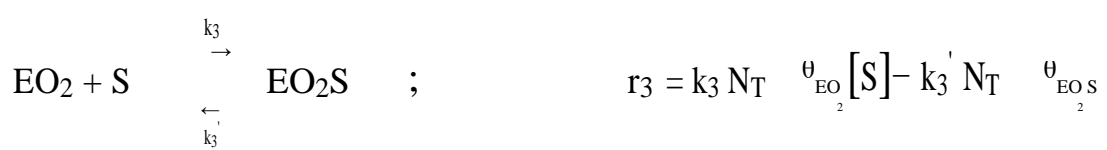

g) $\mathrm{EO}_{2} \mathrm{~S}$ is a complex intermediate promoting the formation of one inactive complex that 
represents substrate inhibition $\left(\mathrm{EO}_{2} \mathrm{SS}\right)$ :

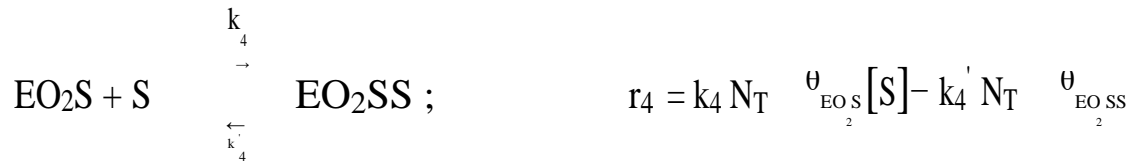

h) Furthermore, $\mathrm{EO}_{2} \mathrm{~S}$ is the intermediate to form the product of interest $(\mathrm{P})$ and finally the regeneration of the active site $(\mathrm{E})$ to start again the catalytic cycle:

$\mathrm{EO}_{2} \mathrm{~S} \rightarrow \mathrm{E}+\mathrm{P} ; \quad \mathrm{K}_{5}$

i) Fractions of the enzyme intermediary complex are described by the

following differential equations:

$$
\begin{aligned}
& \mathrm{N}_{\mathrm{T}} \frac{\mathrm{d} \theta_{\mathrm{E}}}{\mathrm{dt}}=\mathrm{r}_{5}-\mathrm{r}_{1} \\
& \mathrm{~N}_{\mathrm{T}} \frac{\mathrm{d} \theta_{\mathrm{EO}}}{\mathrm{dt}}=\mathrm{r}_{1}-\mathrm{r}_{2}-\mathrm{r}_{3} \\
& \mathrm{~N}_{\mathrm{T}} \frac{\mathrm{d} \theta}{\mathrm{O} \text { EO }} \\
& \mathrm{N}_{\mathrm{T}} \frac{\mathrm{dt}}{\mathrm{dt}} \\
& \mathrm{N}_{\mathrm{T}} \frac{\mathrm{dt}}{\mathrm{dt}}=\mathrm{r}_{3}-\mathrm{r}_{4}-\mathrm{r}_{5}
\end{aligned}
$$

j) Balance of enzyme intermediary complex is:

$$
\theta_{\mathrm{E}}+\theta_{\mathrm{EO}_{2}}+\theta_{\mathrm{O}_{2} \mathrm{EO}_{2}}+\theta_{\mathrm{EO}_{2} \mathrm{SS}}+\theta_{\mathrm{EO}_{2} \mathrm{~S}}=1
$$

Table 1 presents the kinetic parameters used in this study. It is worthwhile to recall that the kinetic parameters $\mathrm{k}_{2}$ and $\mathrm{k}_{2}$ ' were estimated from the experimental data when oxygen inactivation was present, kinetic parameters $\mathrm{k} 4$ and $\mathrm{k} 4$ ' were estimated from the experimental data when substrate inhibition was present and the other kinetic parameters ( $\mathrm{k}_{1}, \mathrm{k}_{1}$ ', $\mathrm{k}_{3}, \mathrm{k}_{3}$ ' and $\mathrm{k}_{5}$ ) were estimated in absence of any type of deactivation or inhibition. Details on the kinetic model and corresponding parameters can be reviewed elsewhere [20]. 
Table 1. Kinetic parameters

\begin{tabular}{ccc}
\hline Kinetic parameters & Value & Units \\
\hline $\mathrm{k}_{1}$ & 1653.33 & $\mathrm{Lg}^{1} \mathrm{~S}^{-1}$ \\
$\mathrm{k} 1{ }^{\prime}$ & 3.32 & $\mathrm{~S}^{-1}$ \\
$\mathrm{k} 2$ & $1.11 \times 10^{-1}$ & $\mathrm{Lg}^{-1} \mathrm{~S}^{-1}$ \\
$\mathrm{k} 2$ & $7.85 \times 10^{-5}$ & $\mathrm{~S}^{-1}$ \\
$\mathrm{k} 3$ & 83.43 & $\mathrm{Lg}^{-1} \mathrm{~S}^{-1}$ \\
$\mathrm{k} 3{ }^{\prime}$ & $6.35 \times 10^{-1}$ & $\mathrm{~S}^{-1}$ \\
$\mathrm{k} 4$ & $1.66 \times 10^{-1}$ & $\mathrm{Lg}^{-1} \mathrm{~S}^{-1}$ \\
$\mathrm{k} 4{ }^{\prime}$ & $1.79 \times 10^{-4}$ & $\mathrm{~S}^{-1}$ \\
$\mathrm{k}^{\prime}{ }^{\prime}\left(\mathrm{k}_{\mathrm{cat}}\right)$ & 56.66 & $\mathrm{~S}^{-1}$ \\
\hline
\end{tabular}

\subsection{TPPB Reactor model}

The reactor model coupling transport phenomena and kinetics along with loss of cell viability was based on reaction engineering principles. The main model assumptions were as follows:

a) The reaction system was operated isothermally.

b) There was no substrate or product evaporation.

c) There was no cell shear damage due to stirring, as observed previously for the same conversion system [20].

d) A pseudo homogenous phase between cell and aqueous phase was considered since interface mass transfer resistance between these phases were negligible because of insignificant shear stress provoked by cells and high cell superficial areas, and mass transfer resistances into the cell were negligible because of the small cell size $(\approx 6 \mu \mathrm{m})$.

e) The reactor model accounted for the gas phase, gp, dispersed phase, dp and the pseudo homogeneous aqueous phase, ap, wherein microorganism was contained.

f) Kinetics was obtained from independent experiments in the TPPB but without the presence of IL and hence without loss of cell viability, vide section 3.1.

g) Overall volumetric oxygen mass transfer $\left(\mathrm{k}_{\mathrm{L}} \mathrm{a}\right)$ from gp to ap was accounted for and determined from independent experiments in an abiotic system with and without the presence of IL, vide section 2.4. 
h) Partition coefficients for substrate and product between aqueous and IL phases, $\mathrm{K}_{\mathrm{ps}}$ and $\mathrm{K}_{\mathrm{pp}}$, respectively, were determined from independent experiments at temperature and pressure used during bioconversion experiments in TPPB, vide section 2.8 .

Based on the aforementioned assumptions, the model is described as follows: the substrate concentration in dp related to its mass transport rate from $\mathrm{dp}$ to ap depends of interfacial mass transfer, ks, interfacial area of the ionic liquid drops $\mathrm{A}$, thermodynamics, $\mathrm{K}_{\mathrm{ps}}$, and concentration gradient that in turns is indirectly a function of metabolic demand of the cell in ap:

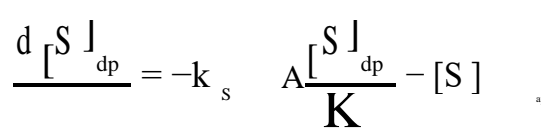

dt

The variation in time of substrate consumption in ap is due to the conversion by E.coli described by $\mathrm{r}_{3}$ ' and $\mathrm{r}_{4}$ ' and the rate of substrate supply from the dp:

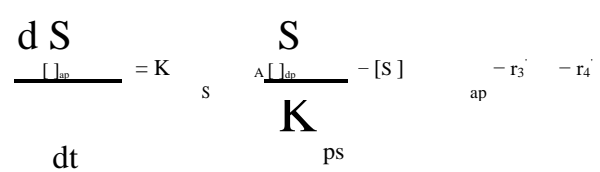

The variation in time of oxygen accumulation in ap is a function of the metabolic demand of the cell in ap described by $\mathrm{r}_{1}$ ' and $\mathrm{r}_{2}$ ' and rate of transport of oxygen from gp to ap which is a function of the interfacial mass transfer $\left(\mathrm{k}_{\mathrm{La}}\right)$ :

$$
\frac{\mathrm{d}\left[\mathrm{O}_{2}\right]_{\mathrm{ap}}}{\mathrm{dt}}=\mathrm{k}_{\mathrm{L}} \mathrm{a}\left(\left[\mathrm{O}_{2}{ }^{*}\right]-\left[\mathrm{O}_{2}\right]_{\mathrm{ap}}\right)-\mathrm{r}_{1}{ }^{\prime}-\mathrm{r}_{2}{ }^{\prime}
$$

The variation in time of product formation in ap is associated to its rate of production $\mathrm{r}_{5}$ ' and the rate of recovery in situ by the dp which is a function of thermodynamics $K_{p p}$, interfacial mass transfer $\mathrm{kp}$ and interfacial area of the IL drops, A:

$$
\frac{\mathrm{d}[\mathrm{P}]_{\mathrm{ap}}}{\mathrm{dt}}=\mathrm{r}_{5}{ }^{\prime}-\mathrm{K}_{\mathrm{P}}\left(\mathrm{K}_{\mathrm{pp}}[\mathrm{P}]_{\mathrm{ap}}-[\mathrm{P}]_{\mathrm{dp}}\right)
$$

Furthermore, the variation in time of product in dp depends on the rate of product extraction from ap to $\mathrm{dp}$, which is a function of thermodynamics, $\mathrm{K}_{\mathrm{p}}$, interfacial mass transfer $\mathrm{k}_{\mathrm{p}}$, and interfacial area of the ionic liquid drops $\mathrm{A}$.

$$
\frac{\mathrm{d}[\mathrm{P}]_{\mathrm{dp}}}{\mathrm{dt}}=\mathrm{kp}_{\mathrm{p}} \mathrm{A}\left([\mathrm{P}]_{\mathrm{ap}} \quad \mathrm{K}_{\mathrm{pp}}-[\mathrm{P}]_{\mathrm{dp}}\right)
$$

Finally, the model includes a term for describing the rate of loss of cell viability owing to the IL in dp, vide section 2.7.

$\mathrm{r}_{\mathrm{i}}^{\prime}=\mathrm{r}_{\mathrm{i}}[\mathrm{E}] \quad$ and $\quad \frac{\mathrm{d}[\mathrm{E}]}{\mathrm{dt}}=\mathrm{k}_{\text {in }}([\mathrm{E}])^{2}$ 
response variables. The kinetic parameters were estimated by a software program (ODRPACK 2.01) using multi-response non-linear regression using Levenberg-Marquardt algorithm with $95 \%$ confidence interval. The mathematical model was supplied with the experimental data consisting of three response variables namely, dissolved oxygen, substrate and product concentration and was solved by integrating a set of ordinary differential equations (ODEs) with the Runge-Kutta-Fehlberg method. To determine the statistical significance of these parameters the t-test was used, while the F-test was used to obtain the regression significance.

\section{RESULTS AND DISCUSSION}

Section 4.1 discusses the loss of cell viability experiments and the corresponding estimated deactivation parameters through Eq. (21). Section 4.2 presents the results from mass transfer of oxygen from gp to ap following a discussion of the estimated overall oxygen mass transfer coefficients under abiotic conditions. Section 4.3 presents the experimentally obtained values of Sauter mean drop diameter i.e. d32, of the IL used as dispersed phase in order to calculate the interfacial area available for substrate and product mass transfer. Section 4.4 elucidates the capability of the reactor model in describing observations at different IL fractions. The analysis gives information on the interaction among mass transport mechanisms with kinetics along with loss of cell viability. Finally, in the section 4.5 the TPPB model developed is used to carry out a parametric sensitivity analysis varying the oxygen transpor rate from the gp to the ap for its importance on bioconversion. 4.1 Parameter related to loss of cell viability

An adequate choice of the IL for the dispersed phase is necessary because of its influence on loss of cell viability. Kumar and Malhotra [21] studied therapeutic applications of ILs and for the first time demonstrated anti-carcinogenic activities and cytotoxicity of three different classes of ILs (imidazolium, phosphonium and ammonium) for 60 human tumor cell lines. These authors mentioned that the imidazolium and pyrrolidinium compounds confer more toxicity than ammonium. From this perspective, the evaluation of different IL was carried out to obtain the one leading to the least loss of cell viability. In these experiments $5 \%(\mathrm{v} / \mathrm{v})$ of IL fraction was used. The IL OMA[BTA] presented the lowest effect on loss of cell viability (56\%) compared to others ILs $(\approx 77 \%)$, i.e., 1-butyl-3-metyl-imidazolium hexafluorophosphate BMIM[PF6], 1-hexyl-3methylimidazolium bis (trifluoromethylsulfonyl)imide HMT[BTA] and butylmethyl pyrrolidinium bis (trifluoromethylsulfonyl)imide MBP[BTA]. Notice the cation of the OMA[BTA] has 
ammonium, while for the other ILs the cations have imidazolium and pyrrolidinium, explaining obtained results. Therefore, OMA[BTA] was used as disperse phase in experiments with and without bioconversion.

The model accounting for the loss of cell viability, vide Eq. (21), considered two ionic liquid fractions. One of them maintained at $5 \%(\mathrm{v} / \mathrm{v})$ and the other at $12.5 \%(\mathrm{v} / \mathrm{v})$. Figure 2 presents a comparison among observed and fitted cell viability as a function of time. The loss of cell viability was $56 \%$ and $88 \%$ at $5 \%(\mathrm{v} / \mathrm{v})$ and $12.5 \%(\mathrm{v} / \mathrm{v})$ of IL fraction, respectively. In fact, as the fraction of IL increased, the cell viability decreased. Besides, the deactivation model fitted adequately the experimental observations, both regression and estimated parameter being statistically significant. The experimental deactivation parameter i.e. kin, obtained was $0.24 \mathrm{~h}^{-1}$ and $0.55 \mathrm{~h}^{-1}$ for $5 \%$ and $12.5 \%(\mathrm{v} / \mathrm{v})$ of IL fraction respectively, being in agreement with the observations related to loss of cell viability. These findings were similar to those observed by Quijano et al. [22] who studied cell toxicity for a microbial consortium with two ILs. They mentioned that IL fractions larger than 5\% $(\mathrm{v} / \mathrm{v})$ resulted in a deteriorated metabolic activity. Baumannn et al. [23] studied six ILs for biocompatibility with three xenobiotic-degrading bacteria namely, P. putida, A. xylosoxidans and S. aromaticivorans and concluded that IL fractions around $6 \%(\mathrm{v} / \mathrm{v})$ were optimal for bioconversion. From this end, it can be observed that in the design of a TPPB, the type and fraction of IL are essential parameters to develop such a complex technology.

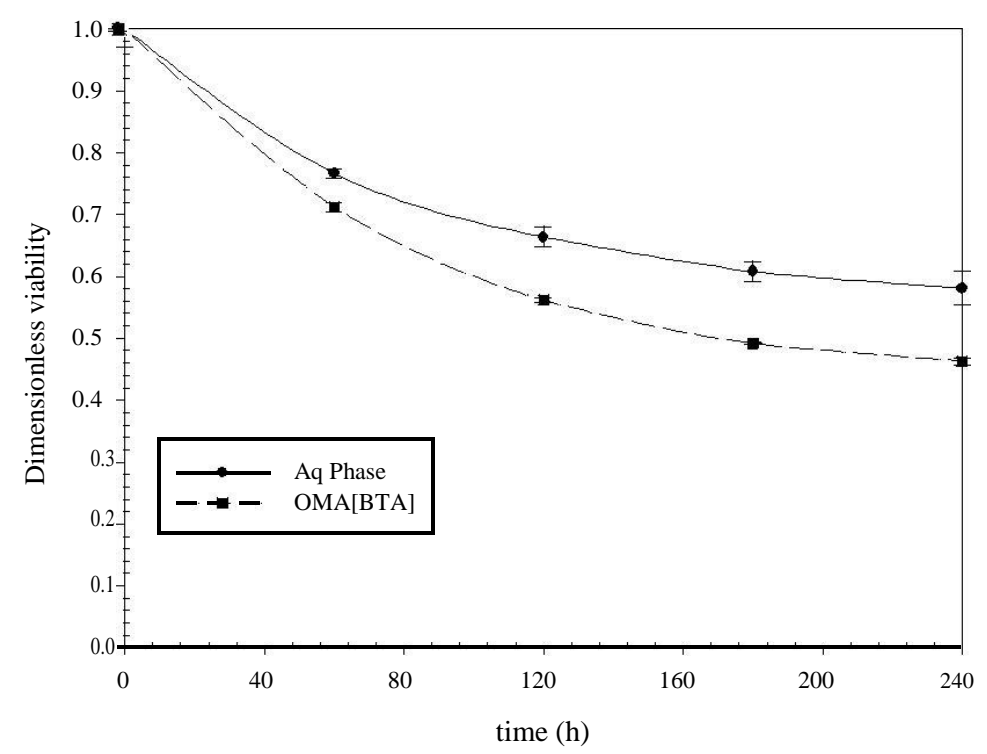

Figure 2. Fit of an empirical model ( ) to experimental data of the dimensionless loss of cell viability at 5 (०) and $12.5(\bullet) \%$ ionic liquid fraction. 


\subsection{Overall volumetric oxygen mass transfer coefficient}

The mass transfer of oxygen from gp to ap is characterized through the estimation of $\mathrm{k}_{\mathrm{La}}$ from experiments in absence of bioconversion with and without the presence of the dispersed phase (IL). Therefore, kLa was determined from experiments in a bi-phasic system (air-water) and in a tri-phasic system (air-water-ionic liquid) with the aim of understanding whether or not the dispersed phase had an influence on the oxygen mass transfer between gp and ap.

Determination of $\mathrm{k}_{\mathrm{La}}$ with and without the presence of the disperse phase was obtained at different operating conditions [20]. In fact, the $\mathrm{k}_{\mathrm{L}}$ a obtained in the bi-phasic system was used to develop the kinetic model, and the $\mathrm{k}_{\mathrm{L}}$ a obtained in the tri-phasic system was used to model the TPPB wherein the IL might influence hydrodynamics and, hence, mass transfer of oxygen from gp to ap. For the air-water liquid system, the maximum $\mathrm{k}_{\mathrm{L}}$ a value obtained was $310 \pm 15 \mathrm{~h}^{-1}$ at $1950 \mathrm{rpm}$ and $1 \mathrm{vvm}$. An analysis on the determination of $\mathrm{k}_{\mathrm{L}} \mathrm{a}$ in absence of IL fraction can be seen elsewhere [20]. Besides, Figure 3(a-c) shows the variation in $\mathrm{k}_{\mathrm{L}}$ a obtained for the air-water-ionic liquid system under different operating conditions. The maximum $\mathrm{k}_{\mathrm{L}}$ a value obtained in the pseudo tri-phasic system was $260 \pm 15 \mathrm{~h}^{-1}$. It is evident from these figures that an increase in ionic fraction caused a decrease in hydrodynamic behavior that led to limitation in mass transfer of oxygen from gp to ap, contrary to the results observed by Nielsen et al. [24] who examined the effect of increasing volume fraction of disperse phase nhexadecane on $\mathrm{k}_{\mathrm{L} a}$, probably due to the physicochemical properties of the ionic liquid OMA[BTA]. Torres-Martínez et al. [25] observed a similar trend for $\mathrm{k}_{\mathrm{L}}$ a values in a stirred tank reactor of $1 \mathrm{~L}$ with the same ionic liquid. 

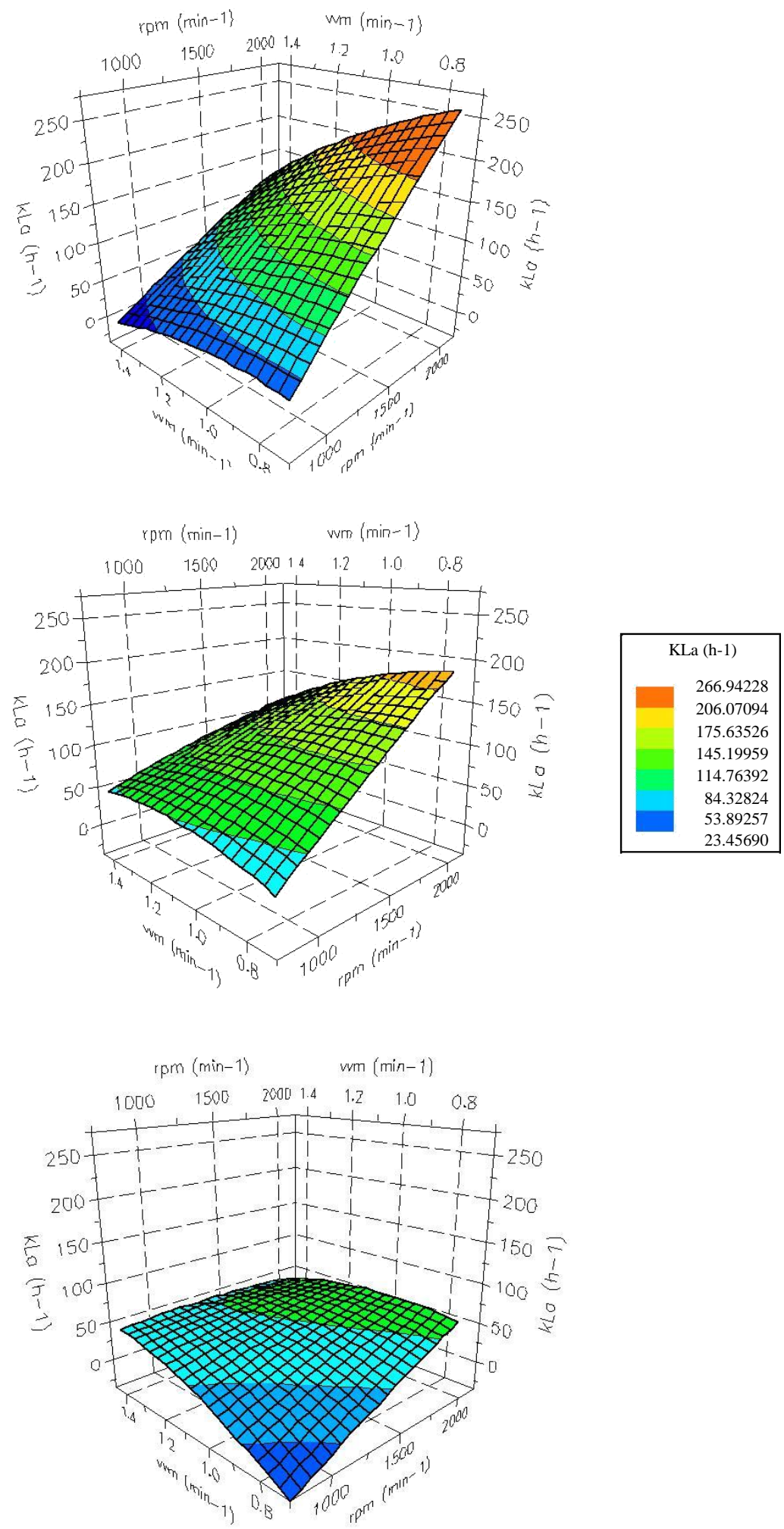

Figure 3. Variation of the overall volumetric oxygen mass transfer coefficient kLa in a TPPB using three different operating conditions (agitation, aeration and ionic fraction) with different ionic fraction namely, a) $5 \%$, b) $12.5 \%$ and c) $20 \%$.

\subsection{Sauter mean drop diameter $\mathrm{d}_{32}$}

The mass transfer of substrate and product from dp to ap is a function of interfacial mass transfer coefficients and interfacial area from drops of IL formed at specific operating 
conditions. This interfacial area was determined from the experimentally determined Sauter mean drop diameter of the dispersed phase $\mathrm{d}_{32}$, vide Eq. 4 . The range of values obtained in all these experiments were between 10 and $20 \mu \mathrm{m}$. Figure 4a shows that the highest value of $\mathrm{d}_{32}(20 \mu \mathrm{m})$ was obtained in all the experiments involving 5\% IL fraction. From Figures $4 \mathrm{~b}$ and $4 \mathrm{c}$, it is evident that $\mathrm{d} 32$ decreased when the volume fraction of the dispersed phase increased. In fact, a Pareto chart indicated that dispersed phase fraction and agitation were the most influential factors $(p>0.95)$ while aeration was the least influential operating parameter $(\mathrm{p}<0.05)$ on the variation in drop size distribution (DSD) inside a TPPB. Besides, an increase in impeller speed led to smaller drops due to an increase in the drop breakage frequency. Boye et al. [26] carried out experiments to determine the effect of dispersed phase concentration on $\mathrm{d}_{32}$ of xylene in water in a mechanically agitated vessel, and observed that the disperse phase fraction ( $\sim 50 \%$ by volume) exhibited strong influence on TPPB hydrodynamic conditions. Zaheri et al. [27] studied the influence of dispersed phase fraction on drop size and showed that a higher fraction leaded to a higher collision frequency between the drops, promoting the coalescence of drops. Kumar et al. [28] using a batch turbulent stirred vessels showed that as the fraction of the dispersed phase increased, the $\mathrm{d} 32$ increased and decreased depending on the used fraction. Torres-Martinez et al. [25] observed that an increase in ionic fraction decreased the $\mathrm{d}_{32}$ values which ranged between $14-21 \mu \mathrm{m}$ using $1 \mathrm{~L}$ stirred tank reactor and OMA[BTA] as the dispersed phase.

The obtained $\mathrm{d}_{32}$ allowed the determination of interfacial area according to Eq. (4), and was correlated with the mass transfer coefficients determined by Melgarejo-Torres et al.

[11]. The initial range of the model parameters mass transfer coefficients for substrate and product ksA and kPA was between 7.5-36 and 2.8-12 $\mathrm{h}^{-1}$ respectively. 

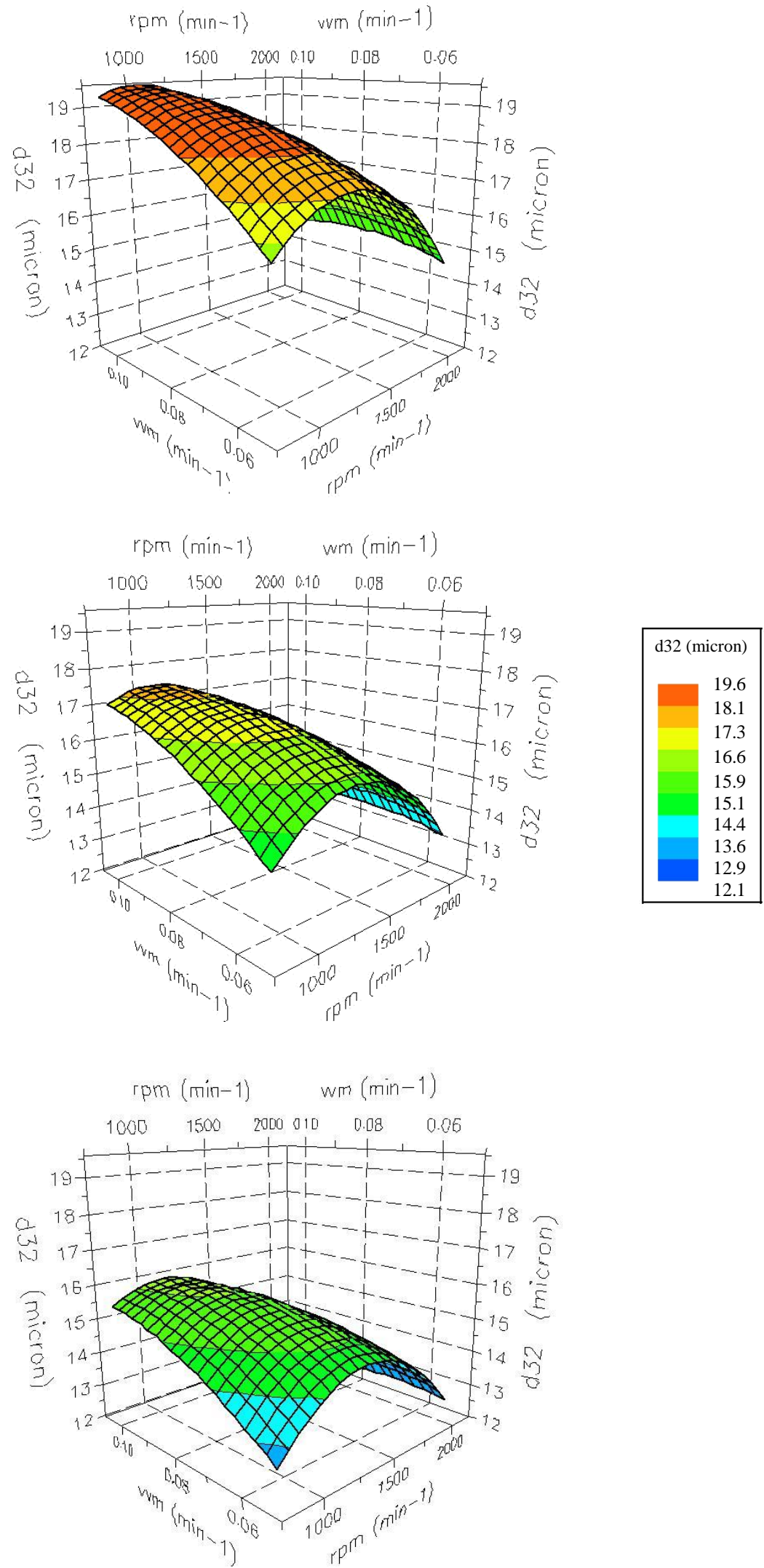

Figure 4. Variation of Sauter mean drop diameter $\mathrm{d}_{32}$ in a TPPB using three different operating conditions (agitation, aeration and ionic fraction) with different ionic fraction namely, a) $5 \%$, b) $12.5 \%$ and c) $20 \%$. 


\subsection{Reactor model}

The pseudo heterogeneous model for the TPPB, vide Eqs. (5)-(21), contains 9 kinetic parameters ( $\mathrm{ki}_{\mathrm{i}}$ and $\mathrm{ki}_{\mathrm{i}}$ ), 1 deactivation parameters $\left(\mathrm{k}_{\mathrm{in}}\right), 3$ transport parameters related to oxygen ( $\mathrm{kLa}$ ), to substrate (kSA) and to product ( $\mathrm{kPA})$ and 2 thermodynamic parameters related to the partitioning coefficients of substrate, $K_{p s}$, and product, $K_{p p}$. The 9 kinetic parameters were estimated from similar bioconversion experiments without the presence of IL as presented elsewhere [20], vide section 3.1. The partitioning coefficients, $\mathrm{K}_{\mathrm{ps}}$ and $\mathrm{K}_{\mathrm{pp}}$, were determined according section 2.7 and the values were $13.5 \pm 0.9$ and $4.13 \pm 0.5$ respectively. The overall mass transfer coefficient (kLa) and the inhibition constant ( $\mathrm{kin}$ ) were estimated using different IL fractions as presented in sections 4.1 and 4.2, respectively. The interfacial area of IL drops in TPPB was determined from Sauter mean drop diameter of the dispersed phase, $\mathrm{d}_{32}$. Even though a Lewis cell is usually used to estimate interfacial mass transfer coefficients of substrate, ks, and of product, kP, the hydrodynamics in this system was completely different to that observed in a TPPB, and therefore those estimated values of ks and kP were not reliable for modeling a TPPB. Therefore, considering that ks and kP cannot be obtained from observations in the TPPB under abiotic conditions because of experimental constraints, a strategy to obtain them was proposed out. Specifically, ks and kP, were the only parameters to be estimated from TPPB observations with bioconversion by using the model given through Eqs. (5)-(21); wherein, to have certainty in their estimation, initial guesses were made from those results obtained in Lewis cell [19].

Figure 5a shows the model fit in aqueous phase for substrate consumption and product formation, while Figure $5 \mathrm{~b}$ shows the model fit for oxygen concentration in ap. The operating conditions were $1.4 \mathrm{vvm}$, $1350 \mathrm{rpm}$ and 5\% IL fraction. Figure 6a shows the model fit compared with experimental data for the rate consumption of substrate and product formation and Figure $6 \mathrm{~b}$ shows oxygen concentration in ap. The operating conditions were $1 \mathrm{vvm}, 1950 \mathrm{rpm}$ and $12.5 \% \mathrm{IL}$ fraction. The conversion is determined through a mass balance between the $\mathrm{dp}$ and ap and the initial substrate concentration $\left(\approx 0.7 \mathrm{gL}^{-1}\right)$. It is noteworthy to mention that this concentration is twice more than the substrate inhibition concentration for a similar conversion in a pseudo two-phase (air-water) system. Parameters used and estimated in TPPB model are presented in Table 2. Regression and parameters were statistically significant for two study cases. As expected, an increase in the IL fraction led to a lower conversion, i.e., maximum conversions of $70 \%$ and $25 \%$ were obtained when $5 \%(\mathrm{v} / \mathrm{v})$ and $12.5 \%(\mathrm{v} / \mathrm{v})$ of IL fraction were employed. These results were 
mainly related to the loss of cell viability caused by using $12.5 \% \mathrm{IL}$ fraction. Besides, the estimated values of $\mathrm{k}_{\mathrm{S}}$ and $\mathrm{k}_{\mathrm{P}}$ in this study were in the same magnitude order than other studies, e.g. Juang et al. [29] using kerosene for phenol removal from saline solutions coupled with degradation at $30^{\circ} \mathrm{C}$ in a TPPB, reported overall mass transfer coefficients from $6.40 \times 10^{-6}$ to $7.83 \times 10^{-6} \mathrm{~ms}^{-1}$ which matches with the values from $4.33 \times 10^{-7}$ to $6.00 \times 10^{-}$

$3 \mathrm{~ms}^{-1}$ obtained in this study. Working with partitioning bioreactors, Juang et al. [30] and Bordel et al. [12] reported values of $0.312-4.90 \mathrm{~h}^{-1}$ and $0.024 \mathrm{~h}^{-1}$ for kSA while in the present study the values of $\mathrm{kSA}$ and $\mathrm{kPA}$ were 1.38 to $0.13 \mathrm{~h}^{-1}$. For the case of $\mathrm{kLa}_{\mathrm{L}}$ used in the mathematical model, the value was between $110-140 \mathrm{~h}^{-1}$ for 5 and $12.5 \%(\mathrm{v} / \mathrm{v}) \mathrm{IL}$ fraction, respectively. It is noteworthy to mention that Torres-Martínez et al. [25] reported $\mathrm{kL}_{\mathrm{L}}$ values ranging between $20-220 \mathrm{~h}^{-1}$ under similar conditions using the same ionic liquid ([OMA][BTA]) but with a $1 \mathrm{~L}$ bioreactor.

Table 2. TPPB model parameters at $5 \%$ and $12.5 \%$ of IL fraction.

\begin{tabular}{ccc}
\hline \multirow{2}{*}{ Model parameters } & \multicolumn{2}{c}{ Ionic fraction } \\
\cline { 2 - 3 } & $5 \%$ & $12.5 \%$ \\
\hline $\mathrm{A}\left(\mathrm{m}^{-1}\right)$ & 3500 & 8566 \\
$\mathrm{kSA}$ for substrate consumption $\left(\mathrm{h}^{-1}\right)^{*}$ & 1.38 & 28.8 \\
$\mathrm{kPA}$ for product formation $\left(\mathrm{h}^{-1}\right)^{*}$ & 0.13 & 2.48 \\
$\mathrm{~kL}_{\mathrm{L} \text { a for oxygen }\left(\mathrm{h}^{-1}\right)}$ & 160 & 140 \\
$\mathrm{ki}_{\mathrm{n}}\left(\mathrm{h}^{-1}\right)$ & 0.24 & 0.55 \\
\hline \multirow{2}{*}{ Statistical analysis for $1-\alpha=0.95$} & $\mathrm{~F}=509, \mathrm{Ftab}=3.36$ \\
& $\mathrm{~F}=312, \mathrm{~F}_{\text {tab }}=5.28$ \\
\hline
\end{tabular}



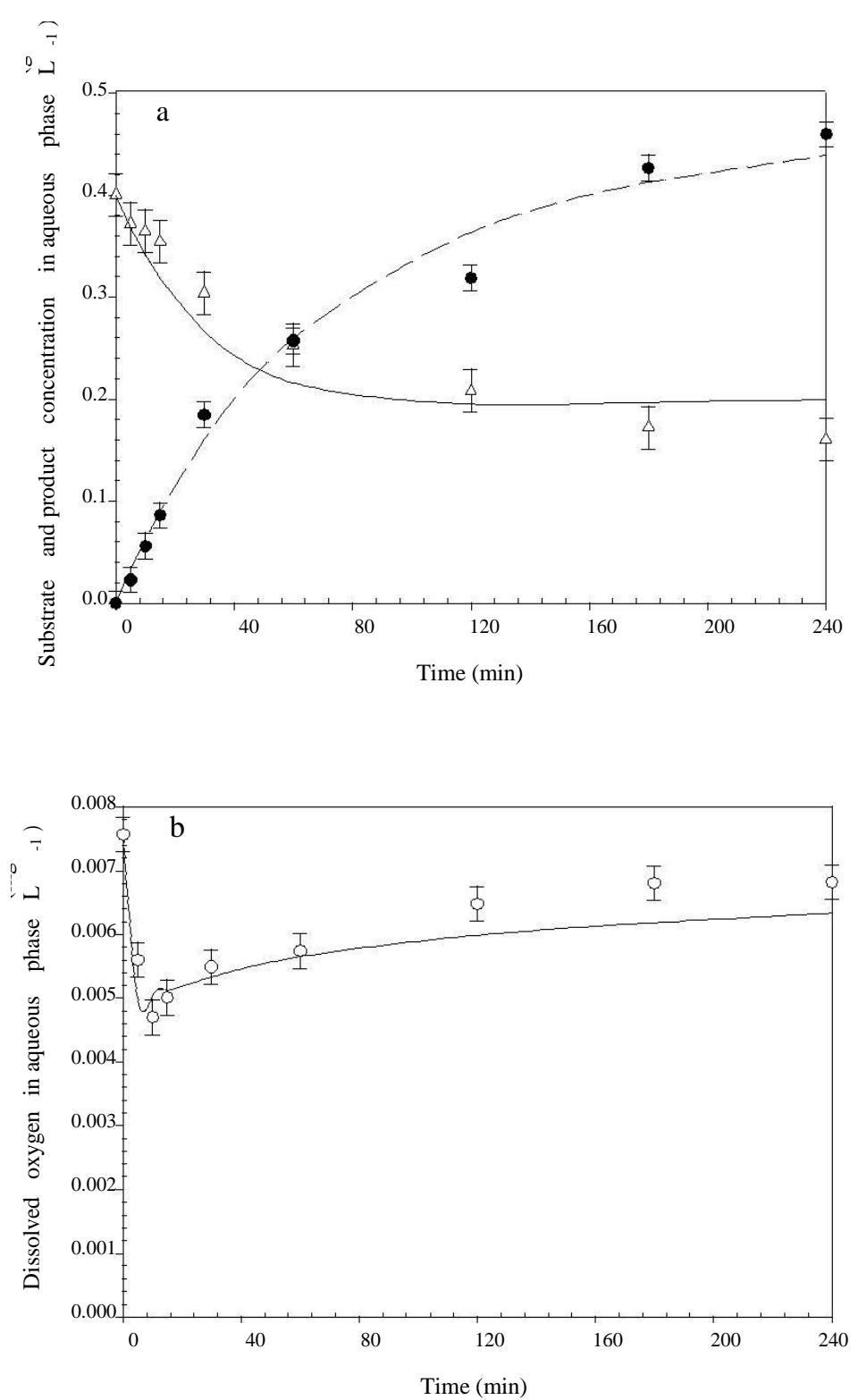

Figure 5. Model fit at $1.4 \mathrm{vvm}, 1350 \mathrm{rpm}$ and 5\% ionic liquid fraction $\left(\mathrm{k}_{\mathrm{La}}=160 \mathrm{~h}^{-1}\right)$. a) Consumption substrate $(\Delta)$ and product formation $(\bullet)$. b) Dissolved oxygen concentration $(\circ)$ in aqueous phase. 

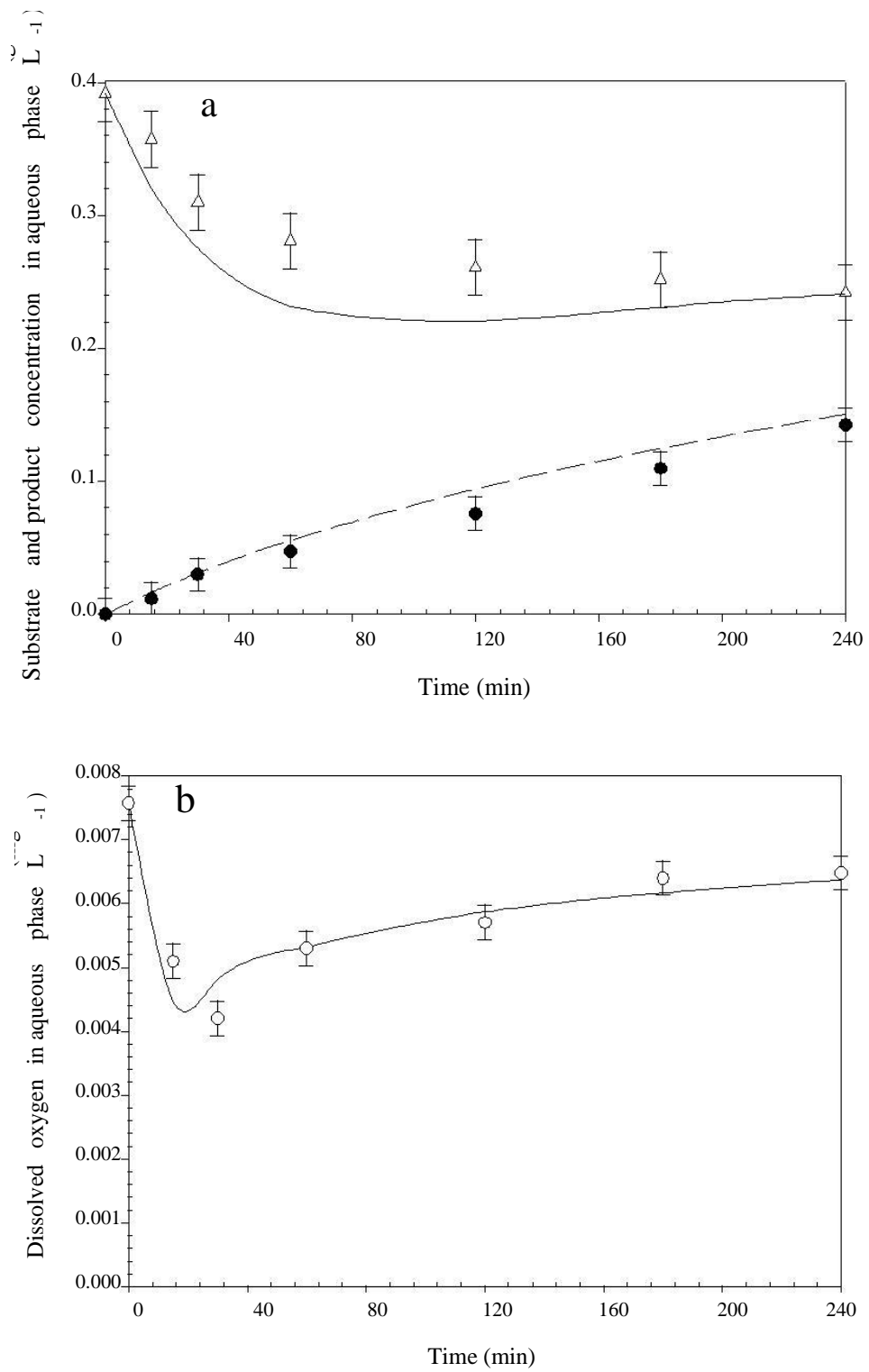

Figure 6. Model fit at $1 \mathrm{vvm}, 1950 \mathrm{rpm}$ and $12.5 \%$ ionic fraction $\left(\mathrm{k}_{\mathrm{La}} \approx 140 \mathrm{~h}^{-1}\right)$. a) Consumption substrate $(\Delta)$ and product formation $(\bullet)$. b) Dissolved oxygen $(\circ)$ in aqueous phase.

\subsection{Parametric sensitivity in TPPB}

The behavior of the studied TPPB was mainly affected by oxygen transport rates as observed elsewhere [20]. Therefore it is necessary to analyze the TPPB sensitivity behavior when different operating conditions affecting oxygen transport rate were employed. For this, two cases in particular were studied, vide Figure 7. In the first case, the model behavior is studied at high oxygen mass transfer rate $\left(\mathrm{k}_{\mathrm{L}} \mathrm{a}=260\right.$ $\mathrm{h}^{-1}$ ), obtained at $1.4 \mathrm{vvm}, 1950 \mathrm{rpm}$ and $5 \%$ IL fraction. Figure 7a presents the model prediction. As expected, higher rates of agitation favored the oxygen transport rate from gp to aq but so does the transport rate of substrate from dp to ap, being higher than the metabolic demand of the microbial cell 
and, hence, kinetically leading to substrate inhibition. For the product, it is not observed since its partitioning coefficient is much smaller than that of the substrate, vide Table 2. Besides the product rate concentration decreased as it is extracted by the ionic liquid since the product mass transfer rate was higher than the product formation in ap. The oxygen concentration in ap indicated that at higher rates of oxygen transport from gp to ap led to concentration of oxygen almost constant in the ap, and kinetically leading to permanent denaturation of CHMO due to oxidation of -SH groups in the active site $[31,20]$.
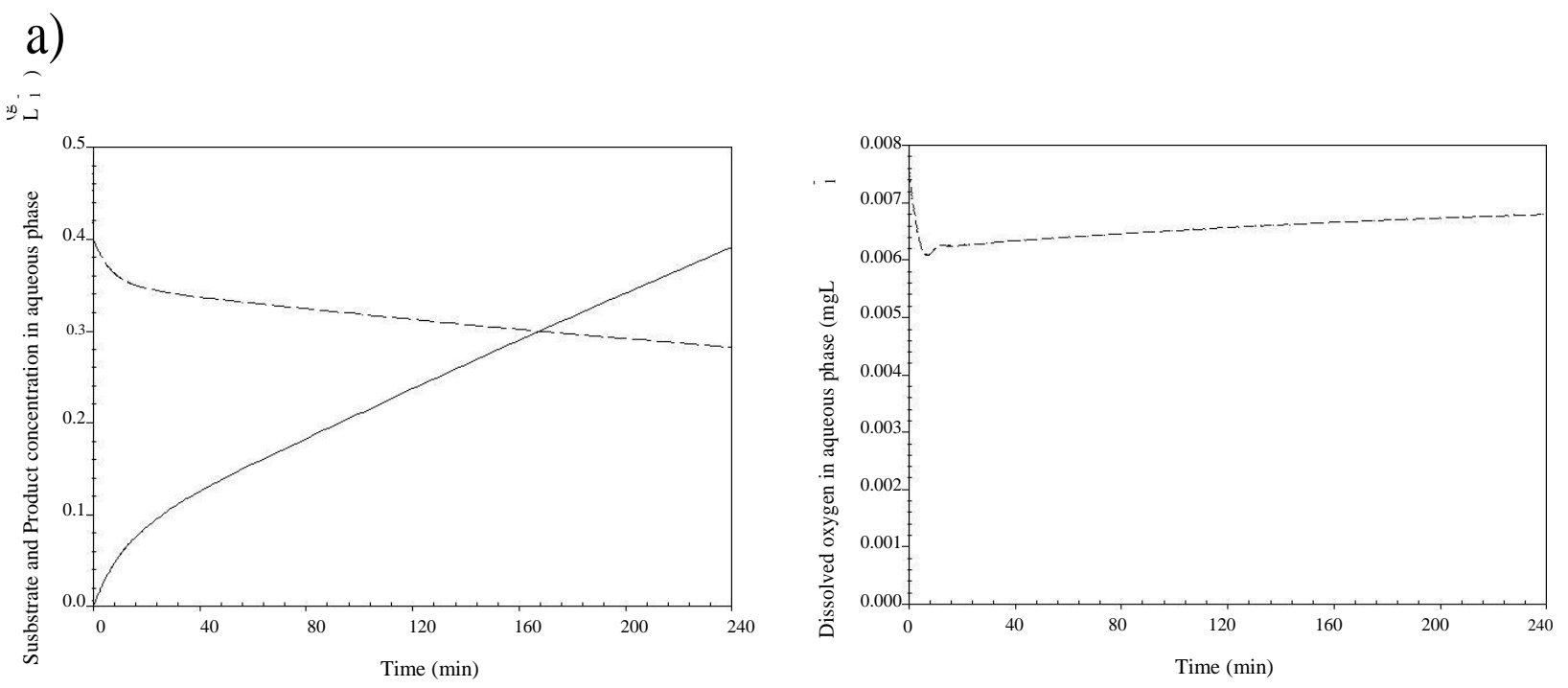

b)
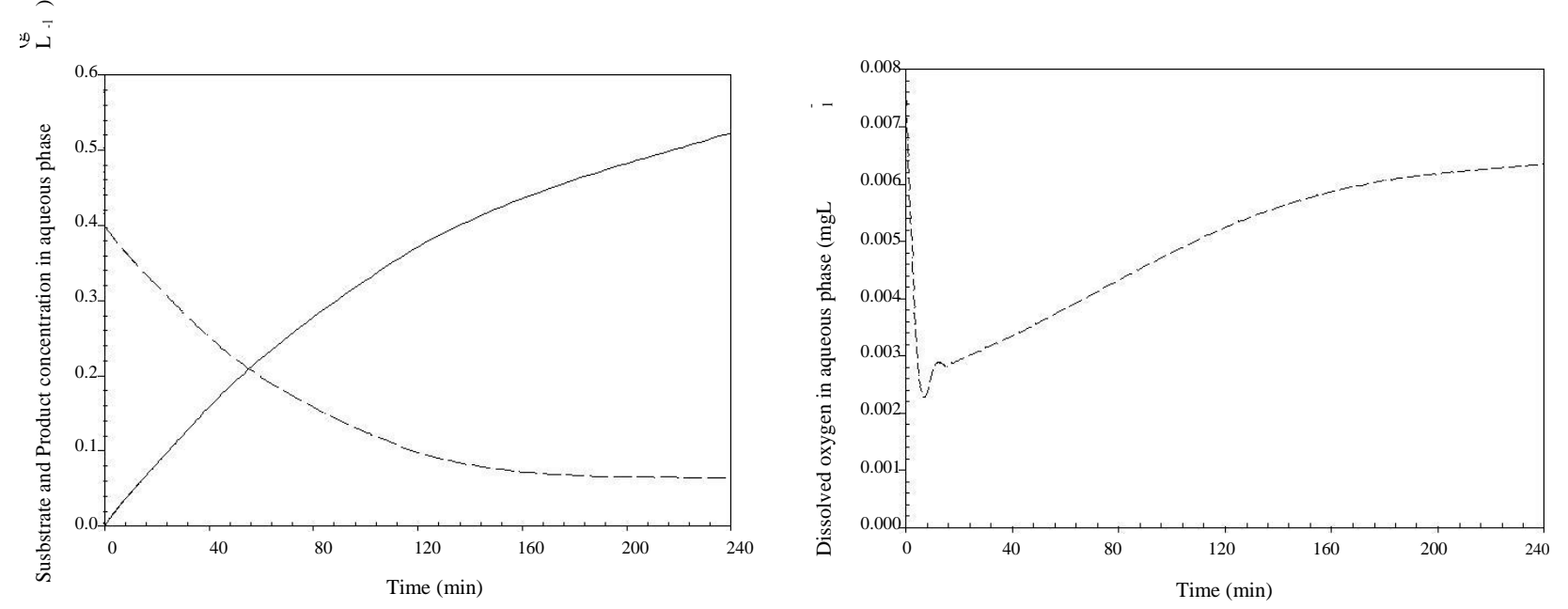

Figure 7. Model prediction and experimental data trends of Substrate consumption (---), product formation ( ), and dissolved oxygen (---) in aqueous phase at a) $1.4 \mathrm{vvm}, 1950 \mathrm{rpm}$ and 5\% ionic fraction, and b) 0.7 vvm, $750 \mathrm{rpm}$ and $5 \%$ of ionic fraction.

In the second case, the model behavior is studied with an aim to observe the role of a limited oxygen transport rate $\left(\mathrm{kLa}=90 \mathrm{~h}^{-1}\right)$ on bioconversion at $0.7 \mathrm{vvm}, 750 \mathrm{rpm}$ and $5 \%$ 
ionic fraction. Figure $7 \mathrm{~b}$ presents the model prediction. In this operating condition, the rate of substrate consumption is found to be higher than the rate of mass transfer of substrate from dp to ap. Hence the substrate concentration decreased in the ap and the rate of product formation in ap became higher than the rate of mass transfer of product from ap to dp. A lower oxygen transport rate led to a limited oxygen concentration in the ap, being not enough to supply oxygen for the metabolic demand of the microbial cell, thus leading to a deficiency in oxygen for the conversion and thereby to a lower productivity. These results were related to some reports mentioning the influence of oxygen and substrate consumption as a function of the operating conditions. For example, Déziel et al. [32] proposed three main mechanisms through which microorganisms utilized substrates in TPPB: uptake of dissolved substrate from the aqueous phase, aqueous-organic interfacial uptake and uptake of substrate by direct contact with the organic phase. However the predominant uptake mechanism was supposed to be the interfacial uptake [33] where the substrate was taken up by microorganism present in the interfacial area and therefore the degradation rate was mainly limited by agitation rate and phase volume ratio in a TPPB.

\section{CONCLUSIONS}

In accordance with the results, the developed mathematical pseudo heterogeneous model constitutes an important step in the analysis of process performance in bioconversions using a three-phase partitioning bioreactor system. The TPPB model is capable of estimating and describing mass transfer coefficients for substrate, product and DO coupled with the kinetic model, using IL as dispersed phase. The proposed model could describe the conversion at different operating conditions, including cell toxicity caused by the dispersed phase. The study also indicates that for a good conversion of ketones, it is better to employ an air-water-ionic liquid three-phase system rather than an air-water two-phase system. The proposed model promises to be a useful tool in the understanding and evaluation of design and optimization of bioconversions in a TPPB during further scale up or scale down operations. 


\section{NOMENCLATURE}

A interfacial area per unit volume $\left(\mathrm{m}^{2} \mathrm{~m}^{-3}\right)$

$\mathrm{d}_{32}$ Sauter mean diameter of the ionic phase $(\mu \mathrm{m})$

A Interfacial mass transfer area of the drop of ionic phase $\left(\mathrm{m}^{-1}\right)$

kL Oxygen mass transfer coefficient $\left(\mathrm{ms}^{-1}\right)$

ks Substrate mass transfer coefficient $\left(\mathrm{ms}^{-1}\right)$

kP Product mass transfer coefficient $\left(\mathrm{ms}^{-1}\right)$

kLa Overall oxygen mass transfer coefficient $\left(\mathrm{h}^{-1}\right)$

ksA Overall substrate mass transfer coefficient $\left(\mathrm{h}^{-1}\right)$

kPA Overall product mass transfer coefficient $\left(\mathrm{h}^{-1}\right)$

kin inhibition constant due to ionic liquid fraction $\left(\mathrm{h}^{-1}\right)$

$\mathrm{N}_{\mathrm{T}}$ Enzyme total concentration ( $\mu \mathrm{g} \mathrm{g}_{-1}$ of biomass)

$[\mathrm{P}]$ Product concentration $\left(\mathrm{g} \mathrm{L}^{-1}\right)$

[O 2 ] Oxygen concentration $\left(\mathrm{g} \mathrm{L}^{-1}\right)$

$\left[\mathrm{O}_{2}{ }^{*}\right]$ Saturated oxygen concentration in ap $\left(\mathrm{g} \mathrm{L}^{-1}\right)$

$\left[\mathrm{O}_{20}\right]$ Initial dissolved oxygen concentration in ap $\left(\mathrm{g} \mathrm{L}^{-1}\right)$

[S] Substrate concentration $\left(\mathrm{g} \mathrm{L}^{-1}\right)$

rn Reaction rate of each enzymatic complex $\left(\mathrm{g} \mathrm{L}^{-1} \mathrm{~h}^{-1}\right)$

kj Kinetic constant of the reaction $\left(\mathrm{s}^{-1}\right)$

$\mathrm{K}_{\mathrm{n}}$ Partitioning coefficient between aqueous and ionic phase (-)

\section{Notations}

ag gas phase

ap aqueous phase

dp dispersed or ionic phase

\section{CHMO Cyclohexanone monooxygenase}

IL ionic liquid

Greek symbols

$\varphi$ Ionic or dispersed fraction (-) $\theta_{\mathrm{E}}$

Free enzyme fraction (-)

ӨEO2 Enzyme-oxygen complex fraction (-)

$\theta$ EO2S Enzyme-oxygen-substrate complex fraction (-)

$\theta$ EO2SS Substrate inhibition complex fraction (-) $\theta \mathrm{O} 2 \mathrm{EO} 2$

Oxygen inactivation complex fraction (-) 


\section{REFERENCES}

[1] A. Baeyer, V. Villiger, Einwirkung des Caro'schen Reagens auf Ketone, Berichte der deutschen chemischen Gesellschaft. 32 (1899) 3625-3633.

[2] E.H. Doo, W.H. Lee, H.S. Seo, J.H. Seo, J.B. Park, Productivity of cyclohexanone oxidation of the recombinant Corynebacterium glutamicum expressing chnB of Acinetobacter calcoaceticus, J. Biotechnol. 142 (2009) 164-169.

[3] N.A. Donoghue, D.B. Norris, P.W. Trudgill, The purification and properties of cyclohexanone oxygenase from Nocardia globerula CL1 and Acinetobacter NCIB 9871, Eur. J. Biochem. 63 (1976) 175-192.

[4] S.D. Doig, L.M. O’Sullivan, S. Patel, J.M. Ward, J.M. Woodley, Large scale production of cyclohexanone monooxygenase from Escherichia coli TOP10 pQR239, Enzyme Microb. Technol. 28 (2001) 265-274.

[5] S.D. Doig, H. Simpson, V. Alphand, R. Furstoss, J.M. Woodley, Characterization of a recombinant Escherichia coli TOP10 [pQR239] whole-cell biocatalyst for stereoselective Baeyer-Villiger oxidations, Enzyme Microb. Technol. 32 (2003) 347-355.

[6] I. Hilker, V. Alphand, R. Wohlgemuth, R. Furstoss, Microbial transformations, 56. Preparative scale asymmetric Baeyer-Villiger oxidation using a highly productive "two-in-one" resinbased in situ SFPR concept, Adv. Synth. Catal. 346 (2004) 203-214.

[7] H.D. Simpson, V. Alphand, R. Furstoss, Microbiological biotransformations 49. Asymmetric biocatalysed Baeyer-Villiger oxidation: improvement using a recombinant E. coli whole cell biocatalyst in the presence of an adsorbent resin, J. Mol. Catal. B Enzym. 16 (2001) 101-108.

[8] M. Buĉko, A. Schenkmayerová, P. Gemeinera, A. Vikartovská, M. Mihovilovibĉ, I. Lacíkc, Continuous testing system for Baeyer-Villiger biooxidation using recombinant Escherichia coli expressing cyclohexanone monooxygenase encapsulated in polyelectrolyte complex capsules, Enzyme Microb. Technol. 49 (2011) 284-288.

[9] L.D. Collins, A.J. Daugulis, Biodegradation of phenol at high initial concentrations in two-phase partitioning batch and fed-batch bioreactors, Biotechnol. Bioeng. 55 (1997) 155-162.

[10] G. Eibes, G. McCann, A. Pedezert, M.A. Moreira, G. Feijoo, J.M. Lema, Study of mass transfer and biocatalyst stability for the enzymatic degradation of anthracene in a twophase partitioning bioreactor, Biochem. Eng. J. 51 (2010) 79-85. 
[11] R. Melgarejo-Torres, D. Torres-Martínez, M. Gutiérrez-Rojas, A. Gómez de Jesús, G.J. Lye, S. Huerta-Ochoa, Regime analysis of a Baeyer-Villiger conversion in a three-phase (airwater -ionic liquid) stirred tank bioreactor, Biochem. Eng. J. 59 (2011) 87-95.

[12] S. Bordel, M. Hernandez, S. Villaverde, R. Muñoz, Modelling gas-liquid VOCs transport in two-liquid phase partitioning bioreactors. International Journal of Heat and Mass Transfer 53 (2010) 1139-1145.

[13] J.S. Devinny, J. Ramesh, A phenomenological review of biofilter models, Chem. Eng. J. 113 (2005) 187-196.

[14] B. Mahanty, K. Pakshirajan, V. Dasu, Biodegradation of pyrene by Mycobacterium frederiksbergense in a two-phase partitioning bioreactor system, Bioresource Technology 99 (2008) 2694-2698.

[15] H.F. Mohammad, A model for treating polluted air streams in a continuous two liquid phase stirred tank bioreactor, Journal of Hazardous Materials 148 (2007) 453-458.

[16] R. Fuchs, D. Dewey, A. Humphrey, Effect of surface aeration on scale-up producers for fermentation processes, Ind. Eng. Chem. Proc. D. D. 10(2) (1971) 1990-1996.

[17] S.G. Cull, J.W. Lovick, G.J. Lye, P. Angeli, Scale-down studies on the hydrodynamic of twoliquid phase biocatalytic reactors, Bioproc. Biosyst. Eng. 25 (2002) 143-153.

[18] J. Lovick, A.A. Mouza, S.V. Paras, G.J. Lye, P. Angeli, Drop size distribution in highly concentrated liquid-liquid dispersions using a light back scattering method, J. Chem. Technol. Biotechnol. 80 (2005) 545-552.

[19] R. Melgarejo-Torres, D. Torres-Martínez, C.O. Castillo-Araiza, C. Arriaga-Juárez, M. Gutiérrez-Rojas, P. Esponda-Aguilar, G. Aroca, G.J. Lye, S. Huerta-Ochoa, Mass transfer coefficient determination in three biphasic systems (water-ionic liquid) using a modified Lewis cell. Chem. Eng. J. 182 (2012) 702-707.

[20] R. Melgarejo-Torres, C.O. Castillo-Araiza, P. López-Ordaz, D. Torres-Martínez, M. Gutiérrez-Rojas, G.J. Lye, S. Huerta-Ochoa, Kinetic mathematical model for ketone bioconversion using Escherichia coli TOP10 pQR239, Chem. Eng. J. 240 (2014) 1-9.

[21] V. Kumar, S.V. Malhotra, Antitumor activity of ionic liquids on human tumor cell lines, Chapter 8: Ionic Liquids Applications: Pharmaceuticals, Therapeutics and Biotechnology (2010) 91-102.

[22] G. Quijano, A. Couvert, A. Amrane, G. Darracq, C. Couriol, P. Le Cloirec, L. Paquin, D. Carrie, Potential of ionic liquids for VOC absorption and biodegradation in multiphase systems, Chem. Eng. Sci. 66 (2011) 2707-2712. 
[23] M.D. Baumann, A.J. Daugulis, P.G. Jessop, Phosphonium ionic liquids for degradation of phenol in a two-phase partitioning bioreactor, Appl. Microbiol. Biotechnol. 67 (2005) 131-137.

[24] D.R. Nielsen, A.J. Daugulis, P.J. McLellan, A novel method of simulating oxygen mass transfer in two-phase partitioning bioreactors, Biotechnol. Bioeng. 8 (2003) 735-742.

[25] D. Torres-Martínez, R. Melgarejo-Torres, M. Gutiérrez-Rojas, L. Aguilera-Vázquez, M. Micheletti, G.J. Lye, S. Huerta-Ochoa, Hydrodynamic and oxygen mass transfer studies in a three-phase (air-water-ionic liquid) stirred tank bioreactor, Biochem. Eng. J. 45 (2009) 209-217.

[26] A.M. Boye, M.Y.A. Lo, P.A. Shamlou, The effect of two-liquid phase rheology on drop breakage in mechanically stirred vessels. Chemical Engineering Communications. 143 (1996) 149-167.

[27] M. Zaheri, H. Aboalghasemi, M.G. Maragheh, P. Zaheri, A. Ahmad, 2011. The Experimental Study of Effective Parameters on Mean Drop Size in a Mixer-Settler, Iranian Journal of Chemical Engineering. 8 (2011) 38-45.

[28] S. Kumar, V. Ganvir, C. Satyanand, R. Kumar, K.S. Gandhi , Alternative Mechanisms of drop breakup in stirred vessels. Chemical Engineering Science. 53 (1998) 32693280 .

[29] R.S. Juang, H.C. Kao, K. Tseng, Kinetics of phenol removal from saline solutions by solvent extraction coupled with degradation in a two-phase partitioning bioreactor,

Separation and Purification Technology 71 (2010) 285-292.

[30] R.S. Juang, K.H.C. Kao, Z. Zhang, A simplified dynamic model for the removal of toxic organics in a two-phase partitioning bioreactor, Separation and Purification Technology. 90 (2012) 213-220.

[31] C.T. Walsh, J. Latham, Mechanism based inactivation of the flavoprotein cyclohexanone monooxygenase by S-oxygenation, J. Protein Chem. 5 (1986) 79-87.

[32] E. Déziel, Y. Comeau, R. Villemur, Two-phase bioreactors for enhanced degradation of hydrophobic/toxic compounds. Biodegradation 10 (1999) 219-233.

[33] C.T. MacLeod, A.J. Daugulis, Interfacial effects in a two-phase partitioning bioreactor: degradation of polycyclic aromatic hydrocarbons (PAHs) by a hydrophobic Mycobacterium. Process Biochem. 40 (2005) 1799-1805. 


\section{GENERAL CONCLUSIONS}

The use of a three phase partitioning bioreactor as a strategy and the selection of an adequate dispersed phase allowed to increase two folds the substrate concentration $\left(0.7 \mathrm{~g} \mathrm{~L}^{-1}\right)$ and showed a better performance rather than an air-water system in the bioconversion of ketones by CHMO. The study of the mass transfer coefficients of subtrate, product and oxygen enabled to know the magnitud order of the their values ocurring in this type of bioreactors. The development of a extrinsec kinetic mathematical model allowed to estimate, understand and identify the main kinetic parameters that affect the bioconversion. The regime analysis allowed to identify that at certain operating conditions there are an equilibrium between the mass transfer and kinetic mechanisms avoiding the substrate inhibition and the inactivation or deficency by oxygen preventing a limiting step by mass transfer. The bioconversion only reached $70 \%$ probably due to the loss of cell viability since it started from the begining. Coupling mass transfer, kinetic and deactivation mechanisms in a mathematical model for a TPPB permited to estimate the substrate, oxygen and product mass transfer coefficients, describe and understand the bioconversion of ketones at different operating conditions in the TPPB. This thesis promises to be an important step in the analysis of process performance in bioconversions using a TPPB and useful tool in the understanding and evaluation of the design of bioconversions in this type of bioreactors to scale-up or scale-down operations.

\section{PERSEPECTIVES}

Future work involves carrying out scale-up and scale-down studies compared to the one used in this work in order to define scaling critera for multiphasic bioprocesses. This work could be a starting point to establish the window of operation for commercial exploitation involving bioconversion of ketones in a three phase partitioning bioreactor. 
ANNEXES 
These annexes shows the publish papers until now in this tesis and corresponing to the mass transfer and kinetic mechanisms studied in a TPPB.

\section{ANNEXE I}

Chemical Engineering Journal 181-182 (2012) 702-707

\section{Mass transfer coefficient determination in three biphasic systems (water-ionic liquid) using a modified Lewis cell}

R. Melgarejo-Torres ${ }^{a}$, D. Torres-Martínez ${ }^{\mathrm{a}}$, C.O. Castillo-Araiza ${ }^{\mathrm{b}}$, C. Arriaga-Juáreza ${ }^{\text {, }}$ M. Gutiérrez-Rojas ${ }^{\text {a }}$, P. Esponda-Aguilar ${ }^{\mathrm{a}}$, G. Aroca ${ }^{\text {, G. G. Lye }}{ }^{\mathrm{d}}$, S. Huerta-Ochoa ${ }^{\mathrm{a}, *}$

a Departamento de Blotecnologia, Untversidad Autónoma Metropolatana, PA. 55-535, 09340 Iztapalapa, Méxtco, D.F., Mexico

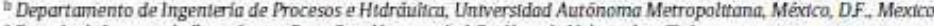

Escuela de Ingenter í Bloquimica. Pontificla Untversidad Catölica de Valparaiso, Chlie

${ }^{4}$ The Advanced Centre for Btachemical Engtneering, Department of Biochentical Engtneering, Untverstry College London, London WCIE JE, United Ktngulomi

A R T ICLE INFO

\section{Article histary:}

Received 16 September 2011

Received in revised form

25 November 2011

Accepted 14 December 2011

\section{Keymards:}

Partitioning bioreactors

Mass transfer coefficients

lonic liquids

Lewis cell

\section{A B STRACT}

Baeyer-Villiger bioconversion productivity of the cyclic ketone ( \pm --cis-bicyclo [3.2.0] hept-2-en-6ona by the biocatalyst Escherichia coll TOP10 DOR239 in a multiphase system can be limited by mass transport. Mass transfer rates through the liquid-liquid interface depend on the volumetric mass transfer coefficient $(k A)$ and the substrate and product partition coefficients. In situ experimental determination of the volumetric mass transfer coefficient in a partitioning bioreactor is complex. In this work, the substrate $\left(k_{s}\right)$ and product $\left(k_{p}\right)$ global mass transfer coefficients were determined in a modified Lewis cell in three water-ionic liquids systems. The ionic liquids used were butylmethylpyrrolidinium bis(trifluoromethylsulfonyl imide [MeBuPyrr][BTA], trioctylmethylammonium bis trifluoromethylsulfonyl)imide [OMAIIBTA] and 1-butyl-3-metyl-imidazolium hexafluorophosphate $[\mathrm{BMIM}]\left[\mathrm{PF}_{6}\right]$. The maximum $k_{5}$ and $k_{\mathrm{p}}$ values obtained were $4.35 \times 10^{-5}$ and $1.21 \times 10^{-5} \mathrm{~m} \mathrm{~s}^{-1}$ for water[BMIM][PF 6 ]. The maximum $k_{5}$ and $k_{p}$ values obtained were $4.35 \times 10^{-5}$ and $1.21 \times 10^{-5} \mathrm{~m} \mathrm{~s}^{-1}$ for water-
[MeBuPyrr][BTA] system: $1.53 \times 10^{-5}$ and $7.84 \times 10^{-5} \mathrm{~m} \mathrm{~s}^{-1}$ for water-[OMA][BTA] system, respectively: and $k_{5}$ values up to $1.01 \times 10^{-5} \mathrm{~ms}^{-1}$ were found for the water-[BMIM][PF $]$ system. The association among the mass transfer coefficients and the physicochemical properties (interfacial tension, viscosity and density) and the thermodynamics (partition coefficients) are analysed and discussed, Finally, the volumetric mass transfer coefficients $\left(k, A\right.$ and $\left.k_{-}-A\right)$ were calculated using interfacial areas $(A)$ of the dispersed ionic liquid phase estimated from the "Sauter" mean drop diameter $\left(d_{32}\right)$ in a one litre stirred tank partitioning bioreactor.

o 2011 Elsevier B.V. All rights reserved. 
ANNEXE II

Chemical Enginearing journal 240 (2017) 1 -9

Contents lists available at ScienceDirect

Chemical Engineering Journal

Chemical

Engineering

Journal

\section{Kinetic mathematical model for ketone bioconversion using Escherichia coli TOP10 pQR239}

R. Melgarejo-Torres ${ }^{a}$, O. Castillo-Araiza ${ }^{\text {, }}$, P. López-Ordaz ${ }^{a}$, D. Torres-Martínez ${ }^{d}$, M. Gutiérrez-Rojas ${ }^{a}$, G.J. Lye ${ }^{c}$, S, Huerta-Ochoa ${ }^{3,+}$

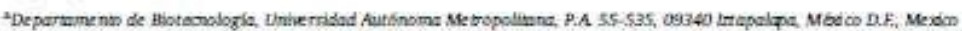

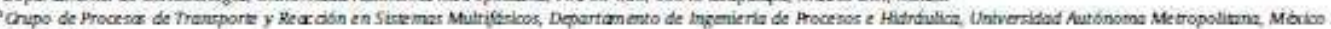

D.F, Madios

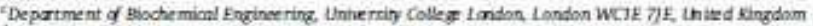

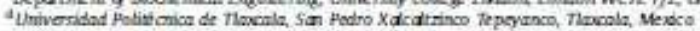

H I GHLIGHS

- A non-reported pseudo intrinsic kinetic model was develaped on bask reactions.

- The reaction mechanism proposed followed the firmalism of Langmuir-Hinshelwood.

- Complexes format ion af substrate inhilition and oxygen inactivat ion are accounted.

- Affinity and intitition constants were abthined fram the kinetic model.

- This is the first report for axygen inactivation canstant $(223 \mu \mathrm{M})$.

ARTLCLE INFO

Artide history:

kextived 201 September 201

keceived in revised form. 18 Novemher 2013

Accepted 23 Nowember 2013

Avallable on line 1 Deoember 201

\section{Karwont:}

Hiocomesisian

Cydohexanone monoorygenses

Modeling

Kinetic purameter

Oxygen inacavatio

Eocherichia $c$ d
A BSTRACT

The aim of the current war $k$ was to dkvel ap a pse ixfo intrinsic kinet $i c$ motel, bused an elementary reac. tiors, to describe the behwiot of the binconversion of ketanes using fscheridria coll TOP10 pQR239. Simce there are no reports af the axygen inactivation canstant in the literature, this study gave new insights ta flind aptimal canditions of a suitable oxysen supply dis ing the biocarversion. In this madel the feaction

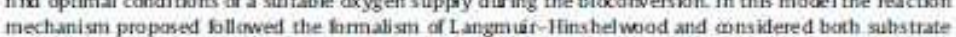
inhibition and axysen inactivarion by the formation of intermediary complexes Therefore, approxima: tions of the preudo equifibrium of reaction rates or steaty state irternediary pecies were not considtions of the preudo equilibrium of reaction fates or steady state intermediary species were not consid-
ered, which allowed for identifying the role of each reaction step involved in the biocanversion. This efed, which allowed for identifyitg the role of each rastion step involved in the biocanversion. This
kinetic model adequately described the observations with and without substrate inhibition and/or axy-
gen inactivation. And the regression a nd the estimated paramelers were statistically significant, making gen inactivation. And the regression and the estimated parameters were statistically significant, making these analyses reliable regarding the biretic behavior of armo. Then, sulstrate and axygen afintity and gen and subscrate presented similar affinity onst ant values. The sulstrate inhibition $\left(K_{i}\right.$ ) and oxygen inactivation $\left(K_{-0}\right)$ corstants were determined to be $9.98 \mu \mathrm{M}$ and $223 \mu \mathrm{M}$, respectively, showing that the CroMO enzyme was twice more sensitive to inhitition by an exess of substrate that oxyger 
ESTUDIO DE LOS MECANISMOS DE TRANSEERENCIA DE MASA,

CINETICOS Y DE DESACTIVACION EN UN BIORREACTOR DE

PARTICION DE TRES FASES USANDO CELULAS COMPLETAS

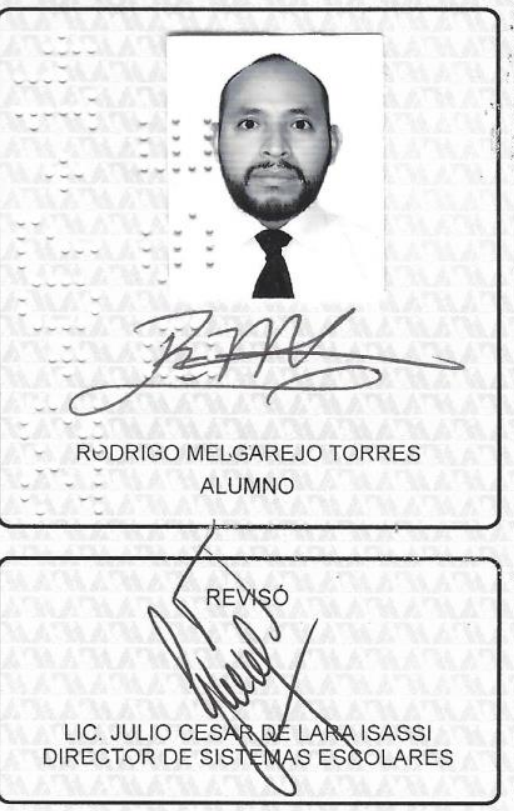

En México, D.F., se presentaron a las 12:00 horas del día 11 del mes de julio del año 2014 en la Unidad Iztapalapa de la Universidad Autónoma Metropolitana, los suscritos miembros del jurado:
DR. FREDERIC THALASSO SIRET
DR. MANUEL ALEJANDRO LIZARDI JIMENEZ
DR. DUTTA ABHISHEK
DR. CARLOS OMAR CASTILLO ARAIZA

Bajo la presidencia del primero y con carácter de Secretário el último, se reunieron a la presentación de la Disertación pública cuya denominación aparece al margen, para la obtención del grado de:

DOCTOR EN BIOTECNOLOGIA

DE : RODRIGO MELGAREJO TORRES

y de acuerdo con el artículo 78 fracción IV del Reglamento de Estudios Superiores de la Universidad Autónoma Metropolitana, los miembros del jurado resolvieron:

\section{APROBAR}

Acto continuo, el presidente del jurado comunicó al interesado el resultado de la evaluación y, en caso aprobatorio, le fue tomada la protesta.
DIRECTORA DE LA DIVISIÓN DE CBS

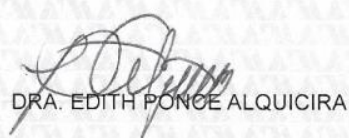

PRESIDENTE

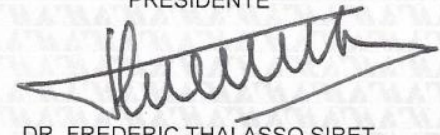

DR. FREDERIC THALASSO SIRET

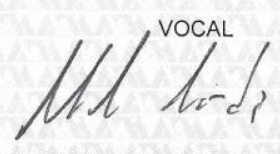

DR. MANUEL ALEJANDRO LIZARDI JIMENEZ

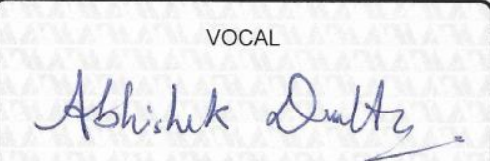

DR. DUTTAABHISHEK

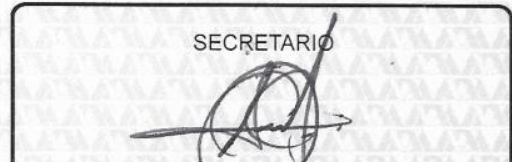

DR. CARLOS QMAR CASTILLO ARAIZA 